Please cite this paper as:

Derrick, J. and K. Ecclestone, (2008), "English-language Literature Review", in Teaching, Learning and Assessment for Adults: Improving Foundation Skills, OECD Publishing. http://dx.doi.org/10.1787/172251338713
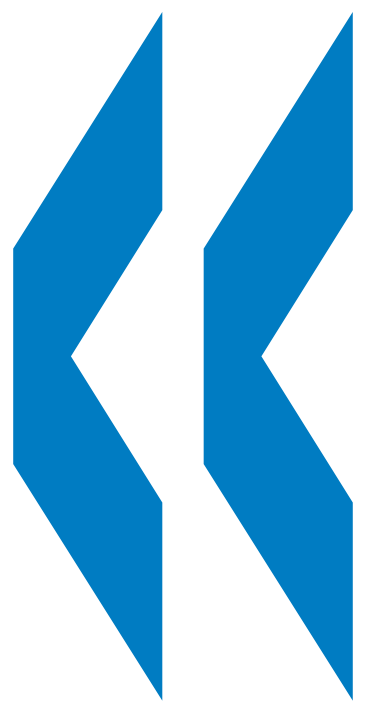

\title{
Teaching, Learning and Assessment for Adults
}

\author{
Improving Foundation Skills
}

\section{English-language Literature Review}

Jay Derrick and Kathryn Ecclestone

Centre for Educational Research and Innovation

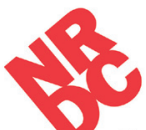


Please cite this paper as:

Derrick, J. and K. Ecclestone (2008), "Englishlanguage Literature Review", in Teaching, Learning and Assessment for Adults: Improving Foundation Skills, OECD Publishing. http://dx.doi.org/10.1787/172251338713

\title{
TEACHING, LEARNING AND ASSESSMENT FOR ADULTS IMPROVING FOUNDATION SKILLS
}

\author{
English-language Literature Review \\ Jay Derrick and Kathryn Ecclestone
}





\section{Table of Contents}

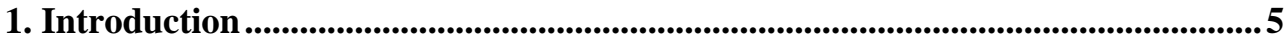

2. The review's methodology and structure ........................................................6

3. Defining formative assessment in adult learning...........................................................9

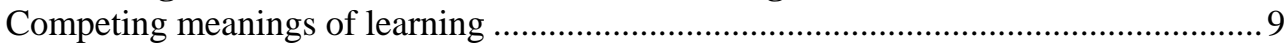

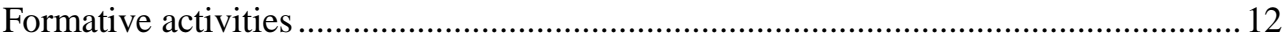

4. Formative assessment and adult learning: discussion of themes emerging from the literature ................................................................................14

Developing an atmosphere and culture conducive to learning ....................................15

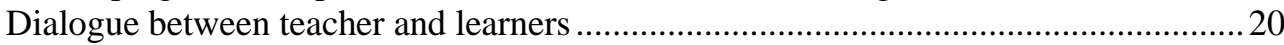

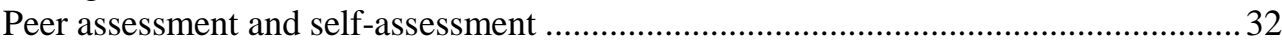

Learners' understanding of assessment and the language of assessment .......................38

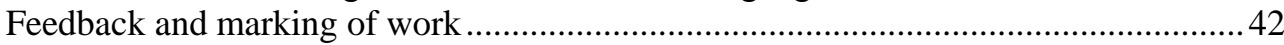

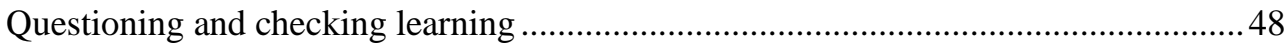

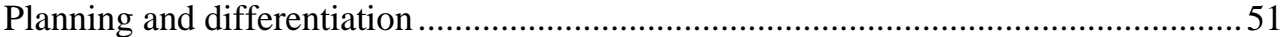

Improving motivation and confidence, autonomy, and citizenship...............................53

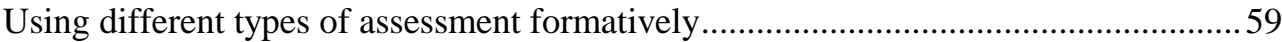

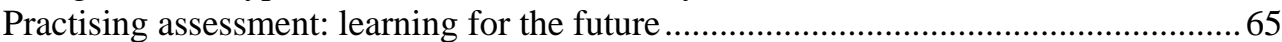

5. Conclusions and messages for teachers .....................................................................68

Formative assessment and learners of adult literacy, numeracy and language ..............68

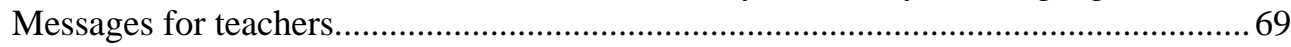

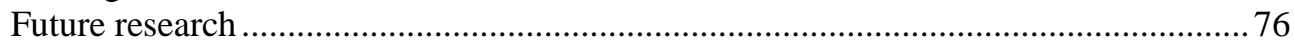

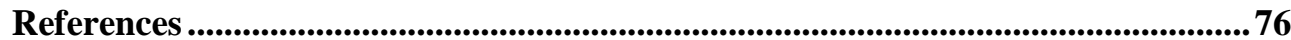

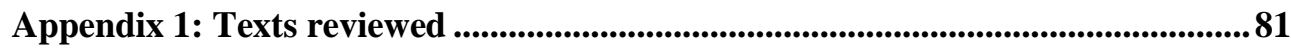

Appendix 2: Analysis of review texts..........................................................................123 



\section{Introduction}

(Note: where references are made to the material surveyed in the literature review, they are printed in bold text. These references are given in appendix 1 of the review. Other references, printed in ordinary text, are given in the references section.)

This review has been produced as a jointly-funded element of two research projects. The first is 'Improving Formative Assessment' (IFA), a three year study of formative assessment practices in post-compulsory learning settings in the UK, which will be completed in December 2007. This study has been funded by the Nuffield Foundation and the National Research and Development Centre for adult literacy and numeracy (NRDC). The second is the Organisation for Economic Co-operation and Development's (OECD) study Teaching, Learning and Assessment for Adults: Improving Foundation Skills. This is a study of national policy contexts and formative assessment practices in relation to adult literacy, numeracy and language learning in seven countries. The OECD study also commissioned literature reviews in French, German, Spanish, and English: the last of these is the present paper.

Much of the influential work in the UK on ideas about formative assessment and assessment for learning has been developed either in the compulsory sector in the context of a highly prescriptive summative testing system at five stages of children's schooling (Black and Wiliam, 1998; Black et al., 2005), or in relation to higher education (see for example Gibbs and Simpson, 2003, Brookhart, 2001, Crooks, 1988). While the theoretical and empirical work has generated a sound evidence base for identifying generic techniques and activities that teachers can use with students, there has not yet been an attempt to either a) relate these ideas to their potential use with adult learners in contexts for learning that are very different from schools and universities; or b) review the literature that might illuminate how formative assessment works with adults in the learning and skills sector and in informal learning situations.

It is especially important to establish a clear understanding based on sound theories and practices of formative assessment in the context of England and Wales, where the learning and skills sector (which includes adult education) has strong implicit theories of learning embedded in its systems for funding, quality assurance and performance measurement. The basic measurement tool for all these systems is the counting of qualification outcomes, which through benchmarking and comparison at all levels in the system, puts pressure directly onto teachers to adapt their teaching to the narrow requirements of the system rather than the needs of learners. The use 
of summative outcomes for accountability thus directly affects ideas and practices in relation to formative assessment (see Derrick et al., in press; Ecclestone et al., in progress).

The gap in research on formative assessment for adult learning and growing evidence about the impact of strongly target-driven summative systems make it important to differentiate between activities that look like formative assessment but which may be little more than coaching or continuous summative assessment, and to examine the political, social and cultural factors that affect how teachers and students practise formative assessment in different learning and assessment contexts (Ecclestone, 2002, 2004, Torrance et al., 2005, Ecclestone et al., in progress). We hope that this literature review will make a contribution to the illumination of these important issues, and ultimately make a positive material difference to the work of teachers and learners in adult education services.

\section{The review's methodology and structure}

The material surveyed directly in this review was gathered and selected between June 2005 and February 2007, through a combination of means, including Internet searches on key words, suggestions from colleagues, bibliographical trails, and personal knowledge and experience. We started with a number of overview studies of adult learning, including Edwards et al. (1998), Cullen et al. (2002), and in particular found Tusting and Barton (2003) and Zachry and Comings (2006) very useful. But finding relevant material has not been a systematic process, because attempts to search systematically for material on formative assessment and adult learning produced few results, except in relation to teaching and learning in higher education. These we decided to exclude in order to ensure this review had its main focus clearly in the learning and skills sector, (that is, in adult learning in post-compulsory education not provided in universities and in workplaces), in informal adult learning, and in adult basic education; we hope however, that this review will complement other research focusing directly on higher education. Of course, the fact that relevant material was not found through systematic searches does not mean that 'formative assessment' is a topic which is irrelevant to, or which has been ignored by writers on adult learning, but that the term 'formative assessment' has only rarely been used until recently in the context of adult or lifelong learning.

It appears in a UNESCO report as early as 1978, which, in examining conceptual approaches to the evaluation of schooling and assessing their relevance for lifelong learning, argues that: 


\section{'There should be a much greater emphasis on formative assessment} than is found in the school sector' (Skager, 1978).

Apart from this isolated recommendation, the earliest explicit reference found to formative assessment in relation to lifelong or adult learning was in Boud (2000), though relevant work published since then is much more likely to use the term. We have found only one book-length treatment of post-compulsory learning that uses the term 'formative assessment' in its title (Ecclestone, 2002), and this is based on a study of two groups of 16-19 year-old vocational students in a qualification where goals of formative assessment for autonomy and motivation were built into a radical, controversial assessment model. Only one short published paper on adult education uses 'formative assessment' in its title (Swain et al., 2006). However, many other studies focussing on a wide range of settings for adult learning deal with topics and concepts clearly related to formative assessment, though mostly not explicitly and almost never systematically. For example, many publications discuss 'feedback' as an important component of adult learning but few link this to the notion of formative assessment.

The term 'formative assessment' is not clearly defined and has not been current in the literature on adult learning until recently. However, other relevant terms and concepts have been widely studied as being central to effective adult learning. A relatively unsystematic approach is supported by Black and Wiliam (2003) who acknowledge the complexity of research reviews in social science and the difficulties of producing 'objective syntheses' of research findings, and the dangers of the accidental but systematic exclusion of relevant material, particularly in fields which are under-theorised and not well-defined. In particular, in the relative absence of systematic academic studies, this review has sought to access 'practitioner wisdom' wherever possible, and agrees with the definition of 'evidencebased practice' given by NCSALL in the USA as 'the integration of professional wisdom with the best available empirical evidence in making decisions about how to deliver instruction' (Comings, 2003). We therefore hope that our review contributes to the eventual development of a systematic conceptual framework for theorising formative assessment in adult learning. However, we are well aware that we have probably missed relevant material, particularly from English-speaking countries other than the UK, and that relevant new publications and reports are appearing with increasing rapidity.

We have organised discussion of the review material under relevant themes in discussions of formative assessment, even though these are not always wholly distinct headings and different terminology is apparently used for similar aspects of teaching and learning. A short summary of the 
main points arising from the discussion of the literature under each theme is given at the end of the relevant section.

It is important to stress that evidence discussed here does not firmly establish strong links between specific teaching approaches and improved achievement, though it may help in the design of future investigations aiming to explore this question. Indeed, some studies demonstrate the difficulty of isolating the clear effects of a single approach or technique in a system in which policy and assessment design, mechanisms to regulate and moderate teachers' assessment, and their impact on institutional providers and groups of learners are complex and intractably entangled (see for example Ecclestone, 2002).

While there have been no large-scale systematic studies of adult learning aiming to identify such links, the Improving Formative Assessment project is revealing the importance of understanding the links between policy, teachers' and students' beliefs about learning and the effects of assessment practices in adult literacy and numeracy programmes (see Ecclestone et al., in progress).

The review is therefore mainly descriptive and makes only cautious generalisations about effective practice. Nevertheless it highlights provisional messages about effective practice and suggests future research questions.

The 99 articles, papers, and chapters surveyed in this literature review are listed with abstracts or summaries at the end of the review. They are grouped into the following categories:

A. Academic papers published in peer-reviewed journals or books reporting on mostly small-scale studies on topics connected with formative assessment (37 studies). The sample size in each case is given with the abstract or summary.

B. High-level academic studies providing overviews of the research literature on topics associated with formative assessment and adult learning (32 studies).

C. Reports making 'arguments to policy', usually including references to academic literature and other policy documents, on topics related to formative assessment (7 studies).

D. Papers and handbooks written to support good practice and pedagogy in the teaching of adults, dealing explicitly or implicitly with formative assessment (18 studies).

E. Publications aimed at adult learners, dealing with self-assessment (1 study). 
F. Publications dealing with formative assessment, where the primary focus is the education of children, but which reference lifelong or adult learning either explicitly or implicitly (4 studies).

Sixty-five per cent $(67 \%)$ of the studies reviewed come from the UK. Fifty-eight $(59 \%)$ of the studies have a primary focus on adult literacy, numeracy or language teaching and learning.

\section{Defining formative assessment in adult learning}

\section{Competing meanings of learning}

Discussions of teaching, learning, and assessment in the context of the UK at the present time have to recognise that these are controversial and contested topics. Within the broad context of education as a whole, the increasing political attention paid to what teachers actually do in classrooms, as well as the charged debates about the increasingly selective processes by which learners in schools transfer between primary and secondary schooling, secondary and tertiary phases, and between tertiary and university or the world of work, have brought ideas about assessment onto the centre stage of political and media discussion. For adult learners, these debates are in some ways even more pointed: demonstrating the value to the taxpayer of continued state funding for provision of opportunities for adult learning has always been difficult in a system still dominated by and organised around the idea of education as something mainly for children and young people, undertaken full-time, and leading in an uncomplicated way to national qualifications. The range of purposes for learning and the meanings of success and achievement in learning are more complex and diverse in relation to adult learners, and one might expect this diversity to be reflected in political debates about and the regulation of assessment in this context, but this is not the case. Rather, adult learners have to fit into a system ever more narrowly-focussed on the goal of improving industrial and business productivity, and which utilises indicators of achievement, success and quality designed for that purpose alone.

Recent research on teaching and learning in schools has raised powerful objections to these narrowly-focussed political goals for education and the current methodologies for assuring the quality of provision in schools, on the grounds that they do not work as well as viable alternative approaches to both pedagogy and to performance measurement and accountability to the taxpayer (Black and Wiliam, 1998, Black et al., 2002). The key concept in this critique is Formative Assessment (FA), sometimes described as 'assessment for learning' as distinct from 'assessment of learning': 
Assessment for learning is any assessment for which the first priority in its design and practice is to serve the purpose of promoting students' learning. It thus differs from assessment designed primarily to serve the purposes of accountability, or of ranking, or of certifying competence. An assessment activity can help learning if it provides information to be used as feedback, by teachers, and by their students, in assessing themselves and each other, to modify the teaching and learning activities in which they are engaged. Such assessment becomes 'formative assessment' when the evidence is actually used to adapt the teaching work to meet learning needs. (Black et al., 2002).

According to the Assessment Reform Group, assessment for learning should:

1. be part of effective planning for teaching and learning so that learners and teachers should obtain and use information about progress towards learning goals; planning should include processes for feedback and engaging learners;

2. focus on how students learn; learners should become as aware of the 'how' of their learning as they are of the 'what';

3. be recognised as central to classroom practice, including demonstration, observation, feedback and questioning for diagnosis, reflection and dialogue;

4. be regarded as a key professional skill for teachers, requiring proper training and support in the diverse activities and processes that comprise assessment for learning;

5. should take account of the importance of learner motivation by emphasising progress and achievement rather than failure and by protecting learners' autonomy, offering some choice and feedback and the chance for self-direction;

6. promote commitment to learning goals and a shared understanding of the criteria by which they are being assessed, by enabling learners to have some part in deciding goals and identifying criteria for assessing progress;

7. enable learners to receive constructive feedback about how to improve, through information and guidance, constructive feedback on weaknesses and opportunities to practise improvements;

8. develop learners' capacity for self-assessment so that they become reflective and self-managing; 
9. recognise the full range of achievement of all learners (from ARG, 2002).

Activities that emerge from these principles can, simultaneously, reflect and influence the meanings of learning that are implicitly or overtly communicated to students. These can be characterised as:

- transmission of external knowledge and the teacher's expertise, knowledge and advice;

- transaction between teachers and students or between students about process or activity, the content of an activity or task or about its goals;

- transformation of students' and teacher's understanding and insight in concepts and processes associated with learning a subject.

Since the publication of Black and Wiliam's 1998 paper, attempts have been made to address their critique in relation to teaching, learning and assessment in schools. These have typically consisted of adding 'formative assessment' into the list of things effective teachers are expected to do during the learning process. However, many teachers, students and designers of qualifications and summative tests equate formative assessment with continuous or modular assessment which merely comprises summative tasks broken up into interim ones. Hargreaves points out that teachers can espouse a rhetoric about formative assessment that either promotes learning-asattaining-objectives or learning-as-the-construction-of-knowledge. Learning as attaining objectives depicts knowledge as fixed and externally-defined while learning as the construction of knowledge conveys knowledge as fluid, open to reconstruction to aid understanding and in need of 'reworking' by students so that it makes sense to them (Hargreaves, 2005).

Evaluating conceptions of learning embedded in formative assessment therefore requires attention to language and practices. Hargreaves shows how the well-known notion of 'closing the gap' between students' existing performance and the quality they are aiming for is often rooted in teacherled images of 'performance', 'delivery', adapting teaching in the light of assessment information, or as a 'gift' from teacher to pupil. This leads to a variety of ideas about what formative assessment is for:

- monitoring performance against targets or objectives (with the language of marking, tracking, checking, identifying a level, monitoring progress);

- giving feedback on next steps for improvement;

- learning about students' progress and adapting teaching accordingly; 
- enabling students to take charge of their own learning and to adapt their own habits and approaches;

- providing students with opportunities to practice skills individually and collectively as part of the learning process, and particularly to exercise, discuss and reflect on qualitative judgements about the success of their practice;

- promoting inquiry and reflection (with the language of discovering, reflecting, reviewing, finding out, engaging with, understanding, constructing knowledge, making sense of experience) (adapted from Hargreaves, ibid.).

\section{The 'spirit' and the 'letter' of formative assessment}

Further insights about the meaning of learning embedded in formative assessment practices emerged in a project in the Economic and Social Science Research Council's (ESRC) Teaching and Learning Research Programme (TLRP) on 'learning how to learn'. This showed that teachers in the same subject team can change techniques such as classroom questioning, but there is a marked difference in whether teachers present and understand this in the spirit or letter of assessment for learning (AfL) (see Marshall and Drummond, 2006).

This useful distinction illuminates how the spirit of AfL goes beyond extrinsic success in meeting targets and, instead, enables students to combine better performance with engagement and good learning habits in order to promote 'learning autonomy'. In contrast, the letter of AfL means that formative techniques promote a teacher-centred, transmission view of knowledge and learning, rather than transaction and transformation of understanding. However, as with all categories, these are not neatly separated from each other: teachers in this project often had a particular goal and focus of attention in mind, but shifted between these and others during a lesson (Marshall and Drummond, 2006). The same phenomenon is also apparent amongst vocational and adult education teachers (see Ecclestone et $a l .$, in progress).

\section{Formative activities}

Formative and diagnostic data and insights can come from a range of activities normally associated with 'teaching', such as classroom questioning and feedback, group work and peer assessment on a piece of previously assessed work, from summative assessment outcomes and from draft or interim assessments: 
- initial guidance interview;

- initial diagnostic assessment (tests, assignments, etc.);

- questions asked individually or in class to diagnose understanding and to build understanding with students;

- written feedback and advice from teachers, oneself, peers: it is important to note that self and peer assessment are commonly assumed to be 'formative' but they might be used entirely for summative purposes;

- oral feedback for answers to questions asked of students or to questions that students ask;

- drafting assignments or work for feedback from teachers, self or peers;

- using exemplars of good and poor quality work to assess the quality of one's and others' work in relation to the assessment criteria;

- individual and group exercises in evaluation of students' work against different success criteria;

- tutorials or reviews - group and individual, peer or teacher-led;

- questions at the end of sessions to find out what was easy or difficult, what still needs to be learned;

The focus of attention can be seen broadly as:

- getting a better grade or mark;

- improving skills and knowledge in a specific subject, topic or task;

- reflecting on 'learning to learn' processes (meta-cognition);

- making, discussing, and reflecting on qualitative judgements of performance;

- building a sense of positive identity, ego, confidence - personal development;

Competing meanings of learning in activities that are ostensibly 'formative' make it important to show where instrumental learning can be a springboard for deeper forms and where it remains merely instrumental (see Ecclestone et al., in progress). Narrow, prescriptive outcomes and criteria used for accountability and national measurement cannot easily serve the educational purposes of formative assessment. Validity is therefore crucial: if summative goals are narrow and lead to superficial learning, their validity 
for formative purposes is immediately compromised: a key criterion for validity is therefore one of deep engagement from students (see Stobart, 2005).

This discussion is a critical context for the literature review that follows, which is organised around key themes illuminating ideas about formative assessment approaches and practices in adult learning contexts that have been identified in the sources listed. The theoretical, political and practice issues discussed here strongly suggest that treating these themes simplistically as elements of a 'recipe' of good practice, ready to be ticked off on a list held by an inspector or observer, would be mistaken. Rather it suggests that formative assessment, while often characterised by particular activities and practices, is better understood as a strategic approach, not just to teaching and learning in the classroom, but to managing all aspects of the 'learning culture' (Hodkinson, Biesta and James, 2007 forthcoming).

\section{Formative assessment and adult learning: discussion of themes emerging from the literature}

The last chapter's discussion supports two arguments which have influenced the particular approach to selecting and discussing the literature we have taken in this review. The first is that to have adopted a definition of formative assessment at the outset, and to have selected and evaluated the literature systematically through its lens, would have unduly limited the scope and value of the review, particularly as the term has only been applied recently in the context of adult learning, and that no such formal definition has even been proposed for this context, let alone discussed. Secondly, the themes which structure the discussion in this chapter are seen as emerging from the sources, rather than as illustrating an already-agreed definition. Furthermore, we do not see them as straightforwardly 'adding up' to a definition of formative assessment, and still less as a list of elements of 'good practice'. Rather we hope they may be useful in contributing to clearer discussions of formative assessment and adult learning in the future. As is clear from the following discussions, the themes are not wholly distinct or well-defined, and the discussion is not a linear one leading to a series of logical conclusions. Our aim is that the discussion of each theme contributes to a gradually more developed and emerging picture of the complexity and sophistication of formative assessment as a pedagogical approach. Following this section, we provisionally outline some messages for teachers and providers that seem to follow from the thematic discussions. 


\section{Developing an atmosphere and culture conducive to learning}

An important aspect of effective formative assessment practice is referred to variously in the literature as the need for an appropriate 'atmosphere', 'classroom culture', or 'organisational environment', meaning a relaxed interpersonal climate in which learners are comfortable to interact, listen to others, even to disagree with or challenge others, including the teacher. Most commentators see the creation of such an atmosphere as one of the most important roles of the teacher, though one group also recognises that there are usually factors affecting the climate for interaction that are outside the teacher's control. Another group point out that an atmosphere conducive to learning is not simply a comfortable environment in which students can feel safe: on the contrary, learning implies a degree of challenge. Teachers concerned too much with 'caring for' their learners, they argue, may be inhibiting successful learning.

Very many commentators on adult learning stress the importance of ensuring that there is an appropriate 'atmosphere' in the class for effective learning. Among these are Absolum (2007), Hillier (2002), Knowles (1983), Barton et al. (2006), Ivanic et al. (2006), Beder (2005), and Brookfield (1990). They draw attention to the need to enable adult learners, particularly those new to formal learning, or who have had negative previous experiences of education, to be relaxed and comfortable, so that they are ready for effective learning, and to face any challenges involved. For adult educators this has always been one of the first rules for teachers, based on the assumption that for many adults, formal learning may be an unfamiliar and potentially threatening experience. The elements that contribute to the 'atmosphere' of the class include the physical environment, the layout of the room, the behaviour of other students, and, most importantly, the behaviour of the teacher. Teachers are encouraged to work on generating friendly relations, goodwill and trust between all the members of the group, so that individual students are more willing to take risks, to expose themselves, as part of the sometimes difficult process of learning. The main way in which teachers work to develop and maintain this atmosphere is through their own behaviour - the way they relate to students, their communicative style, what they say, and what they do. Some commentators see this fundamental role for teachers as potentially the first stage in the development of a 'community of practice' (Marr, 2000, Lave and Wenger, 1991), in which individual and collective learning is integrated with productive activity. However others argue that there is a danger in practice of over-emphasising the 'nurturing' and 'caring' aspects of teaching and learning, at the expense of learning for the real world. They point out that unconfident learners may enjoy coming to classes that are undemanding, sociable, and fun, and that teachers too, may find it easier to 
collude with such learners, so that little productive learning takes place. Windsor and Healey (2006), for example, in a discussion of tutorials as part of ESOL teaching and learning, argue for clarity about the limits of the role of the tutor in tutorials: 'they are there to support the learners' learning, not their personal needs'. Ecclestone (2004b) believes that there is now too much emphasis on the 'well-being' of students, with consequently less emphasis on the need for students to acquire truly useful knowledge and skills, through a process of learning that may indeed be difficult and challenging. She argues that an unhealthy pre-occupation with health specifically, the emotional well-being of the student - gets in the way of learning, with stultifying consequences for the learner and teacher alike, creating 'a new sensibility that resonates with broader cultural pessimism about people's fragility and vulnerability'.

An important group of studies highlight the importance of organisational culture in relation to learning in the workplace, including: Evans (2002), Fuller and Unwin (2002), and Belfiore and Folinsbee (2004). Each of these studies focuses on the 'managerial environment' or 'management style' of the workplace. Belfiore and Folinsbee discuss the degree of involvement of workers in the training itself, and the management style of the workplace in relation to quality input from the workers, both of these being indicators of dialogic practice. Training is seen as more effective in terms of management objectives and sustainability if it starts with the realities of the workplace and individual workers, rather than a formal curriculum transmitted to passive trainees. Examples of ways in which improvements suggested by the employees demonstrate that they are critical thinkers and system analysts suggest that training and quality improvement processes should be participatory rather than teacher or manager-led and top-down. Evans (2002) discusses the contribution of the organisational context to workplace learning and argues that systematically utilising all the skills and knowledge of workers, including the tacit, is more likely to be effective in 'democratic' as opposed to 'technocratic' models of the learning society. These models are differentiated primarily along the spectrum of participation, involvement, and ownership of decisions taken in workplaces and in society as a whole. For Evans, the key concept (and practical goal of training and education) is transferability of skills and knowledge between different contexts. She argues that the greater the tacit dimension of these skills and knowledge (all knowledge has both tacit and explicit dimensions), then the more transfer has to involve high levels of social interaction. She cites research which suggests that for the purposes of genuine transferability of skills and knowledge, demonstration, manuals and written accounts are of little help. 
Fuller and Unwin (2002) focus on how people learn from and teach others about work tasks. They argue that the act of learning to do one's job in the workplace is worthy of close attention, and that much of this learning takes place through explicit pockets of activity which make use of a range of pedagogical methods. It also argues that pedagogical skills can be found in all types of workplaces, at all levels in an organisation, and that they are not restricted by age. The paper thus challenges the traditional conceptions of 'novice' and 'expert' generally associated with models of skills formation, and in particular, apprenticeship. The paper focuses deliberately on the term 'pedagogies' to counter both the experiential learning tradition which sees workplace learning as almost entirely informal, and the HRD tradition which is concerned mostly with improving the effectiveness of 'off the job' training, often through the use of new technology. Both these traditions play down the role of pedagogy, which, research drawn on in this paper shows, continues to be a salient part of working life. This study too, therefore, highlights the significance for effective formal and informal learning, of the way training, development, and transfer of skills is seen by managers in organisations, whatever the intentions of teachers or trainers. Both factors make a difference to the degree to which social interactions can benefit learning.

Knowles (1996), Alexander (2004), and Swan (2006) also challenge simplistic notions of learning as the simple transmission of skills and knowledge. Alexander argues that the learning process can entail challenge and disagreement as well as consensus. Swan's view suggests that challenge and disagreement are in some sense essential to the most effective learning situations. This works only if classroom culture has moved beyond the onesided transmission relationship between teacher and learner. If it hasn't, then dialogic and challenging teaching may intimidate and inhibit some learners. Knowles' theory of andragogy implies a shift from teacher assessment of learning to a self-evaluative process, based on re-diagnosis. The teacher therefore needs to be skilful in establishing a supportive climate in which hard-to-accept information about one's performance can be looked at objectively. This perspective is very similar to that of Absolum (2006), who in a comprehensive discussion of effective relationships in classrooms emphasises the importance of developing 'learning-focussed relationships' between learners and between the teacher and the learners, that learning will not flourish if the teacher focuses primarily on controlling the student, and that classroom relationships characterised by power and control at best generate passivity and at worst non-engagement or cynicism. Like Alexander and Ecclestone (2004b), he also distinguishes between learningfocussed relationships and caring relationships, and argues that learning will not flourish if the primary focus of the teacher is caring for the student. 
The emphasis of many commentators (for example Young, 2000, Barton et al., 2004, 2006, Ivanic, 2006, and Marshall and Wiliam, 2006), is on the learning environment needing to be a 'safe space' in which learners under various kinds of pressure in their lives can face up to anxiety about past educational failure, allow their assumptions to be challenged, aspects of their identities to be developed and changed, and to 'play' (Absolum, 2006) with newly-acquired and developing skills.

James (1997) notes that some of the key barriers to learning may come from the culture of adult students themselves. She notes that processes of adult learning often evoke powerful emotional responses, when for example personal constructs are challenged, and that these responses may even be likely in some contexts of learning such as workplace training in the use of new technologies and more flexible work processes, or for more effective community participation and constructive citizenship. Her study of three groups of male 'mature-age' adults training to be teachers after experience of working in a range of different trades, argues that these responses must be addressed if sustainable learning is to take place:

'During their two years of teacher education, they were.... responsible for conducting classes in Victorian secondary schools.... Yet, instead of endeavouring to learn the new skills that could assist them, it was group solidarity, maintained through sexist and racist humour, on which they came to rely during their teacher education program. This solidarity apparently provided support through 'trying' lectures and enabled them to withstand any challenges to their beliefs. Their practices were themselves often stress-inducing, very authoritarian methods, for example, generating considerable resentment among their adolescent students. Negativism towards almost everyone, including students, parents and the educational institution, emerged as a favourite coping strategy, unfortunately resulting in the avoidance of professional change.... significant learning from their course, for most of them, appeared to be minimal' (James, 1997)

The study piloted an intervention specifically aiming to deal with this resistance to learning, which utilised a short narrative case-study describing a trainee teacher like the group members themselves, facing a major life transition. Small group discussions were set up to explore how the degree to which the trainees' own experiences and feelings were similar to those of the protagonist of the case study. The study found that this approach was highly successful:

'People began to speak of themselves, tentatively at first, and then with greater confidence, using the language of the narrative to 
describe their own experiences. The narrative thus led to unprecedented self-disclosure' (James, 1997),

and she concludes that:

If people are to continue learning when identities are challenged, they need to understand how their aspirations can be realised by their study, what learning or lack of it will mean for future prospects, and how the culture of the group can enable or inhibit progress....culturally-specific narrative can be used to initiate these changes, but non-directively, in addition to enabling reflection and empowerment. Direct questioning of deeply-ingrained beliefs may often arouse only defensiveness and resentment....this study may have greatest relevance in situations in which communication skills and personal learning, sometimes related to vocational requirements, are the focus of the class' (James, 1997).

In a similar vein, Nonesuch (2006) argues that students who feel resistant to aspects of the learning experience need the opportunity and perhaps encouragement to express this resistance, if it is to be addressed constructively. She quotes a small research study that actually found that such an approach can be associated with increased levels of learner 'persistence', noting that the more complex and open their resistance to the teacher and the teaching, the more likely the student was to attend regularly:

These results suggest a positive association between conscious, active resistance and regular attendance. It also suggests that the more that conscious resistance is encouraged, the more likely it is that regular attendance will result (Pare, 1994).

This paradoxical result illustrates again the complexity of the communicative skills required of teachers if they are to realise the potential for learning and persistence in what seem at first to be the unlikeliest of resources. An analogous point made by Swan (2006) concerning the value of highlighting disagreements between learners themselves, or even between learners and the teacher, about strategies for solving problems, or interpretations of situations requiring mathematical analysis, was referenced earlier in the section on dialogue.

\section{Summary}

This section has aimed to unpack some practical aspects of developing an atmosphere and culture conducive to learning. This is often the first element of guides to teaching in adult education, and highlights the importance of students feeling relaxed and secure for effective learning to take place, and of the common need to address fears based on negative 
previous experiences at school or elsewhere. However, there is a danger of encouraging a comfortable and undemanding social experience which may diminish the possibility of real learning. The literature also suggests that a key role is played by the management of the organisation in which the learning is taking place, in terms of the extent to which, and the manner in which, the culture of the organisation supports learning. Commentators suggest that learning is not a straightforward process of acquiring knowledge and skills, but involves learner identity and motivation: learners need to allow themselves to be challenged, and learning needs conflict and resistance to be expressed. Learning will not flourish if the primary focus of the teacher is caring for the student. Using case studies to help students to look at their own situations from the outside can help them address negative feelings about learning.

\section{Dialogue between teacher and learners}

Learning through dialogue is a major theme in the literature on adult learning, though it appears with a wide variety of nuances and emphases. For Knowles (1983), dialogue is both practical and political:

- it recognises the centrality of the status of the learners as adults and enables the exposition and utilisation of their accumulated experience and knowledge for the benefit of everyone in the group;

- it is through dialogue with the learners themselves that the teacher can best discover how to differentiate (or perhaps 'personalise') the learning programme so that the diversity of needs and purposes among any group of learners can be addressed;

- since adults are seen by Knowles to be less concerned with subjectknowledge than with the need to tackle specific tasks, dialogue enables teachers to orient the learning programme towards those particular tasks.

Politically, Hostler (1986) agrees that if we see adults as autonomous and self-directing, they have a right to participate in decisions that affect them. In relation to learning, participation cannot be achieved without discussion and dialogue between all the members of the group. A vision of groups as models for democratic practice through discussion and debate is one of the longest-established elements of a major, influential tradition in British adult education, originating in the corresponding societies and $19^{\text {th }}$ century socialist movements (see Williams, 1993, Fieldhouse and associates, 1996). 
Yet, a utilitarian shift is evident in recent writing, where similar modes and espoused values of learning and participation are recommended for effectiveness rather than democratic propriety (see for example Boud, 2000, Ivanic, 1996). The earlier focus on democratic discussion and debate was content-focussed, aiming to share experiences and accumulated knowledge of the topic in hand. In contrast, a recent focus is on discussion of learning itself, and of the ways in which it can be evaluated and developed. This emphasis is seen not just as a means of improving attainment but, variously, as capacity-building for the future (e.g. Boud, 2000), as a means of addressing anxiety or lack of motivation about learning (McGivney, 1996, Eldred $\boldsymbol{e t}$ al., 2005), and/or as a way of building autonomy (McNair, 1996).

In other words the earlier focus of this tradition was concerned with a democratic process of deciding the 'what' of a particular course of adult learning and maximising the resources of knowledge and experience available to the group: more recent studies are more concerned with promoting learner participation in order to make any learning process more effective, in terms both of accountability to taxpayers and to individual learners themselves. This practical perspective is supported also by Tusting and Barton (2003), whose survey of models and theories of adult learning concludes with seven key ideas about how adults learn: that adults have their own motivations for learning, based on their existing knowledge and experience, that adults have a drive towards self-direction and autonomy, that adults can learn about their own learning processes, that all real life activities contribute to adult learning, that adults reflect and build on their experience, that reflective learning is unique to each person and often incidental and idiomatic, and finally that learning can be transformative, enabling people to reorganise their experience and see situations in new ways.

The writers reviewed in this section fall into two categories: those who treat dialogue as central to all teaching and learning, and those who write about particular pedagogical objectives that can be achieved through using dialogue. The first group treat dialogue between learners as well as between learners and teachers, as of central importance; the second group focus more on the role of dialogue between teacher and learner(s). We discuss each group in turn in the following subsections.

\section{Dialogue seen as central to all teaching and learning}

Alexander (2004) claims that learning is a social process where the true direction of learning is not from the individual to the social, but from the social to the individual' (Vygotsky in Alexander, 2004). For him, teachers are not merely facilitators, secondary to the process as theories of 
andragogy would have it, nor mere transmitters of learning. Instead, learning is a process with teachers and learners as interactive participants: both learner engagement and teacher interventions are essential. Nevertheless, Alexander believes that "what learners say is more important than what teachers say', implying that dialogue enables teachers to facilitate future planning of the learning process on the basis of their interpretation of what learners say. As Alexander's focus is primarily on the education of children, this is an argument for dialogue based on its efficacy for school learning rather than its political desirability; however, he also points out that if it is effective for children's learning, then it will also be for adult education, including the education of teachers. Alexander characterises dialogic teaching as collective, reciprocal, supportive, cumulative, and purposeful, viewing knowledge as problematic and open rather than given and closed.

In a similar vein, Marr (2000) argues that:

A socio-cultural educational perspective sees learning as induction into 'discourses' or 'communities of practice' through interaction with more expert others. At the heart of any discourse is the language and symbols that carry its special meanings. To become a member of the discourse one must begin to learn its language (Marr, 2000).

In relation to numeracy teaching, Marr argues that students need opportunities to learn the language of mathematics through talking and dialogue in order to support subject learning, as well as to improve their capacity for learning, autonomy or motivation. She argues that learning activities that provide access to and practice in subject discourse are more pressing in mathematics than other subjects, because of the relative absence of explanatory written texts available to students:

Whereas most other subject areas rely on an extensive canon of write prose (to be found in textbooks, encyclopaedias and school libraries) to provide the impression of stability and permanence to knowledge, this is noticeably absent in mathematics. Textbooks tend to be pastiches of repetitive activities and fragments of knowledge (Marr, 2000).

This produces 'a heavy reliance on the teacher's verbal explanations to carry the knowledge and understanding of the subject. Reliance on the spoken mode begins to explain the 'catechistic' type of interaction so prevalent in mathematics classrooms' (Marr, 2000). If transmission dominates mathematics in order to define and control the curriculum, it is not surprising that interactive, open-ended and investigative dialogic activities are relatively uncommon. 


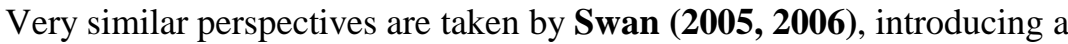
collection of resources aiming to support teachers of mathematics in post-16 education to develop their practice. Swan also sees the main task as to move from 'transmission' to 'connective and challenging' modes of teaching, and from 'passive' to 'active' modes of learning. He doesn't see dialogue as a simple two-way process between equals: for him the teacher has a critical pro-active and leadership role, demanding complex and high level skills. If the dialogue is to be purposeful, the teacher needs to make its purpose clear, encourage an exploratory and reflective mode of discussion, encourage 'discussion of alternative methods and understandings', welcome mistakes and misconceptions as opportunities for learning, ask probing, challenging questions of learners, and finally, to draw out the important ideas arising from each session (Swan, 2005, 2006).

Absolum's (2006) work is based on long-term development work in 10 New Zealand schools. It is included in this review because his is a fully worked-out guide to the use of formative assessment approaches in teaching and learning that appears to be applicable to any sector. While he doesn't refer explicitly to lifelong learning, he bases his work on learning theorists such as Argyris and Schon (1974) and Sadler (1989), whose theories focus on learning in general, rather than in any specific context or phase of life. That his book is relevant to a consideration of adult learning is also suggested by the fact that his discussion is explicitly applied to the teaching and learning of all age groups within schools, more or less without distinction. He argues that to be effective, learning must enable the learner to own the learning process, and to be significant, it must result in the learner owning what is learnt. His ideas link the work of Black and Wiliam with the work of Argyris and Schön (1974) on organisational learning. At the centre of what he sees as an 'archway of teaching and learning capabilities' he puts the development of 'learning-focussed relationships' between teacher and learners, and between learners themselves: the key mechanism for this is continuous, interactive dialogue.

Many other reports also highlight the significance of learners' feelings about learning, and of the relationships between teachers, learners, and others: 'relationships matter in learning, including teacher/student and student/student relationships, also networks of support learners are part of' (Barton et al., 2004, Ivanic et al., 2006). 'Feelings and emotions shaped people's experiences of learning: for some this made engagement, particularly in more formal, structured learning very difficult; other people talked about formal learning provision as a safe haven from other overwhelming issues in their lives' (Barton et al., 2006). Teachers must be able and willing to engage with the complexity of learners' different and developing states of mind and feeling about learning, because 'There is a 
complex relationship between teaching and learning: learners don't learn what teachers teach' (Barton et al., 2004).

This point is made in different ways by a number of commentators: Barton and Papen (2005) argue that for effective learning to take place, teachers must be willing to engage with wider aspects of people's lives, and Nonesuch (2006) points out that 'whether you are a therapist or not, the emotions in your maths class are not going away.' She sees this issue as a key part of pedagogy: students' feelings about learning must be made explicit if they are not potentially to be a barrier, and this is another way in which the teacher needs communicative skills of the highest order. Her work draws strongly on that of Ginsburg and Gal (1996), who propose 13 principles for effective adult numeracy teaching, many of which depend on the facilitation of dialogue in the classroom, including the need to address students' attitudes and beliefs regarding learning and mathematics, to determine what students already know, to encourage the practice of estimating skills, and group activities such as searching for multiple solutions to the same problems, etc. Most of these strategies are also evaluated and explored in great detail by Swan (2006).

Ivanic and Tseng 2005) also take a radical view of the importance of dialogue in adult learning: 'Learning is not predictable as a product of input, but created through constant negotiations between individuals, social environments and broader social influences'. They suggest that teachers need to pay attention to the beliefs about learning, teaching, language literacy and numeracy that learners and teachers bring with them to the learning-teaching encounter, and that teachers should identify learners' intentions as a key factor in learning events. 'Social interaction is the key mechanism through which learning takes place. Teaching is best characterised as the creation of 'learning opportunities' through the management of interaction' (Ivanic and Tseng 2005). Belzer (2004) suggests that adult literacy learners' constructions of previous learning contexts can function as "screens" between the learner and effective learning. Contextual features of current learning contexts may pass easily through a learner's screen, may be a misfit creating ambivalence and tension, or may exceed the boundary of the screen's frame. This perspective, like the ones referred to above, proves problematic to the notion of the simple transmission of learning in these contexts, and can only be addressed by rich communicative interaction between learners and teachers. Baxter $\boldsymbol{e} \boldsymbol{t}$ al. (2006) record students discussing the greater confidence they felt as a result of being known individually by the teacher, in sharp contrast to school and some previous adult experiences. They valued both individual relationships with their teachers and also group working, which allowed for supportive relationships to develop between the students themselves. 
An influential figure is Freire (1972), who criticises what he calls the 'banking system' of education in which teachers deposit knowledge into passive learners, based on a static, positivist view of objective knowledge and power relations. For him, liberating education comprises shared acts of cognition, problem-posing and dialogue through which unequal power relations challenged and overcome. Dialogue portrays reality as a process of transformation, not a static entity.

From this perspective, teaching based on dialogue is ongoing formative assessment, where reflection and negotiation between all participants focuses on what is learned and how successful the process is. The programme content is neither a gift nor an imposition of bits of information deposited in the students, but rather an organised, systematised and developed representation of things that people want to know more about. Teachers engage in dialogue in order to understand learners' objective situation and to develop learners' awareness of that situation. Teachers must develop materials and activities that enable learners to pose problems, to facilitate dialogue aimed at understanding the problems and moving towards solutions. Teachers therefore need to establish a learning context in which their authority is not oppressive, so that learning takes place on the learners' own territory, using dialogue and content led by them.

A Freirean perspective on teaching mathematics is provided by Benn (1997a, 1997b), who argues that dialogue in maths teaching with adults is essential to overcome dependency and isolation, and that this can take the form of talking, reading, or writing. This suggests, implicitly, that teaching through dialogue is indistinguishable from continuous formative assessment. For her, traditional mathematics teaching epitomises Freire's concept of 'banking education', in which teaching consists of 'telling' the learners about knowledge taken as given and fixed. Instead, she argues that mathematics needs to acknowledge the social values it embodies, that learners should be empowered to create their own knowledge and that the mathematics curriculum should be concerned with the generation and solution of real-life mathematical problems and questions by learners. Teachers must 'walk the fine line of managing learning experiences in order to meet learners' expectations whilst sensitively offering challenges to develop a deeper conceptualisation of mathematics'.

Finally in the first group, we find an argument that sees the dialogue at the heart of democratic adult learning processes as a vital element of living in 'risk society'. Jansen and Van der Veen (1996) present a critique of post-modern theory, arguing that under conditions of modernity people are freed from traditional social and ideological bonds but subjected to the anonymous standardising rationalities of the state and the market. Individuals are expected to take responsibility for their own lives, making 
their own decisions, in contexts in which all sources of information are potentially unreliable. The paper sees adult education as having a valuable potential function as a broker in problem-solving networks, raising issues of values, contracts between educators and learners, and new approaches to professionalism demonstrating both distance and involvement. It calls for reframing experiential learning, in which expert knowledge and learners' experiences are subjected to critical and constructive group examination, through dialogue in which both have equal status. Adult Education in this light will stick closer to the daily hopes and worries of learners, and be more prepared to further dialogue between conflicting experiences, interests and ideological images. Teachers' roles will be to stimulate reflection in a Socratic way, by raising awareness of the crucial questions to ask instead of pretending to know the answers. This echo of Benn's view of the equivocal certainty of traditional mathematics education demonstrates the similarity of this view with Freire's perspective; in both cases the very broad view taken of adult education within societies undergoing radical change offers relatively undefined guidance about the specific role of the teacher in this situation.

\section{Dialogue as useful for specific teaching and learning objectives}

This indistinct picture is perhaps clarified by the views of commentators on dialogue in the second group, who focus on three specific functions for the dialogic approach to teaching and learning. These in turn see dialogue as the means for teachers and learners jointly to research problems of understanding and to develop new knowledge and critiques of existing knowledge; as the joint evaluation of performance; and as the means by which teachers can gain understanding of learners' previous experience, so as to use this understanding for planning and differentiation. Seeing teaching and learning processes as research is perhaps a familiar idea in the context of higher education, though apparently 'a relatively low proportion of academics read the research journals on teaching their subject' (Laurillard, 1997).

For example, Ivanic $(\mathbf{1 9 8 8}, \mathbf{1 9 9 6})$ suggests that the teacher's quest to find out the nature of a problem in understanding either literary conventions or the rules of conventional punctuation, should be seen as a research project. This cannot be undertaken without the full participation of the learner, not just as research subject, but as researcher too, through dialogue. In the context of teaching writing, Ivanic argues that teachers should treat learner-writers as authorities, and that helping learners write what they mean necessitates talking, as a way of 'researching' the content and literary conventions the learner wants to use. Dialogue therefore facilitates cooperative formative and diagnostic assessment of strengths, weaknesses and 
barriers to learning and this is integral to teaching and learning. 'Most student and tutor pairs or groups talk a lot about the feelings and difficulties involved in writing. This sort of 'language awareness' is being more and more widely recognised as an essential component of learning. What is different... is to recognise these insights as 'research findings' as' knowledge' (Ivanic and Simpson, 1988).

Ivanic's later publication (1996) argues that non-standard punctuation is often based on perfectly logical thinking, and that standard punctuation is not in itself inherently logical. It is therefore crucial for teaches to discuss the thinking behind their mistakes with learners in order to help them understand standard punctuation. An instructive example of dialogue as formative assessment suggests that 'Introspection about strategies (for achieving the correct use of punctuation) is a useful teaching method in itself. Learners are thinking about meaning - they are logical even if they are mistaken.'

A similar view is proposed by Fowler and Mace (2005), who promote the idea of teaching and learning as research through joint mutual investigation between learners and teacher. They argue for the particular relevance of this approach for adult literacy, and their view supports not only Freire's account of learning, where the content of learning is being constructed, but also more 'autonomous', cognitive models of learning, in which the content is given but the learner's orientation to it is being investigated for learning purposes (i.e., a model of formative assessment). The research model promoted is ethnographic, requiring a range of data from different sources and of different types, and a 'grounded' research methodology (Glaser and Strauss, 1967), in which findings 'emerge' gradually from the data. It argues that this type research can deliver 'empowerment' to learners, as well as being a framework for improving literacy skills.

Three papers focusing on the teaching and learning of writing argue with different emphases for the importance of talking as part of the learning process: Kelly et al.'s (2004) review of research and practice finds that talking about writing supports effective learning, and for the importance of learners expanding their understanding of process aspects of writing, such as planning and revision, and in which they can re-examine assumptions they might hold which may block learning, such as the idea that writing is either right or wrong. Similarly, two American commentators argue that in the context of the learning of writing, it is essential to enable learners to make explicit unarticulated ideas and concepts about how people write (Russell, 1999), and to be involved in a process of 'co-constructing representations of their assumptions about the writing process' (Gillespie, 2001). Russell found that many students didn't understand that reading had any connection 
with writing, and observed that while many teachers of writing for adult literacy learners encourage their students to focus on content rather than form, most students want above all to avoid making 'mistakes', and that it is very hard to convince students that mistakes do not matter as part of learning. 'Teachers and learners appear to be speaking two different languages, perhaps different dialects of the language of writing instruction' (Russell, 1999).

Dialogue is also a medium for collective assessment of a performance. Moss (1995) provides a detailed exploration of the role of the learner as writer using the teacher as editor, in language experience learning situations. The paper shows how feedback that edits individual students' own words is problematic both for creative writing and the pursuit of the 'correct' use of English. However, the process of negotiation between a teacher and learner which aims to facilitate the production of a finished and 'correct' but also authentic piece of work (central to formative assessment, and similar to the process of assessing a dramatic or musical performance), can be a powerful means of supporting future learning, confidence, and motivation. Condelli (2002) and Roberts et al. (2004) make similar points in relation to ESOL learners. They point out that the most significant mode of learning for ESOL learners is through group interaction.

In adult literacy education, Mace (1979) argues that dialogue between teacher and learner enables the teacher to understand as fully as possible the nature of the learner's previous experience of schooling and assessment. She uses extended quotations from adult literacy students to show the importance of schooling for their levels of motivation for engagement in formal learning, and in forming their attitudes and ideas about assessment, and their perceptions of success. She implicitly recognises the notion of 'assessment careers' proposed by Ecclestone and Pryor (2003). She argues that teachers have to understand the particular ways this experience impacts on learning as adults in order to find effective strategies for individuals and the group. Again, this view of dialogue corresponds closely with ideas about diagnostic assessment of a very broad range of needs, experiences and starting points.

For Reder (1994), it is absolutely essential that teachers and programmes of learning engage with learners' culture and backgrounds. $\mathrm{He}$ cites educational and anthropological research which contradicts theories of learning suggesting that learners simply lack skills which they need to acquire: rather, whatever their age, experiences and cultural background, learners arrive already familiar with a range of literacy practices associated with their particular family and social environment, practices that Reder describes as 'context-specific'. Failure to recognise this has led programmes to make erroneous assumptions about the home lives of students from poor, 
minority or immigrant families as being 'deficient' environments for supporting literacy development, resulting in a mismatch between what learners are familiar with in relation to literacy practices, and what the programme teaches.

On the basis of this wide-ranging survey of research, Reder argues for the importance of what he calls 'practice-engagement theory', which proposes that teachers and programmes must understand how literacy practices develop through collaborative activity, that 'participation structures' are contexts for literacy development, that social meanings shape literacy development, and that literacy develops primarily through becoming conscious of and extending existing practices, rather than through the learning of 'new' ones. In particular, practice engagement theory provides accounts for how fluency in literacy practices can be developed without formal instruction. It follows from this that formal instruction needs firstly to be aligned as far as possible to the specific literacy practices that individual learners' are familiar with already, and secondly, to try to build learning on these practice-specific contexts rather than separately from them. Each of these requires teachers to investigate the specific practices and contexts that their learners are already familiar with, the profile of which may be quite different in each case (Reder, 1994).

One group of commentators, supporting the importance of dialogue in teaching and learning, point out that if a teacher is to initiate, support and learn from dialogue with learners, s/he will need complex communication skills. These papers consider in more detail what these skills are, and how teachers might be supported and trained to develop and maintain them. Alexander (2004), for example, argues that teacher training should be essentially dialogic in form, so as to exemplify and at the same time develop the necessary skills and dispositions. Beder (2005) reports that how teachers interact with adult basic education learners is an important factor in engagement, which is defined in his study as 'trying hard to learn'. His report says less about the nature of these interactions than about the difference made by their frequency, with implications for teachers with larger groups.

Belfiore and Folinsbee (2004), in an ethnographic study of adult learners in the workplace, show how a manager delivering formal training on new quality control systems needs to allow employees to voice criticisms of the present quality regime in practice, in order to gain credibility and engage the employees in the formal aspects of the course. Teachers and trainers in the workplace, whether professionals delivering formal programmes or peers supporting learning on the job, need to exemplify effective communicative practices themselves. The paper thus argues for the integration of training with work practice, and demonstrates the strong link 
between the organisational style and culture of the workplace, and effective learning at work. Merton (2001) reports on a study of basic skills provision among young adults that teachers' language should be 'easy to understand and avoid long words'. Choice of words and tone of voice seemed to influence how the young people performed under pressure, and their motivation to continue their learning. Ward and Edwards (2002) report that adult literacy and numeracy learners' prefer teachers who 'listen': Gardener (1985) also highlights the importance of listening to learners in the context of teaching writing, in order to ensure that judgements of value and of appropriateness (of tone, or of grammar) are arrived at mutually rather than imposed.

This issue is at the heart of the discussion by Zuss (1994), who, from a Freirean perspective, problematises a simplistic notion of dialogue in teaching:

'The privileging of certain modes of discourse and organisation of knowledge involves institutionalised norms of rationality, meaning making, and literate interaction - modes that, unevenly at best, include as well as exclude salient varieties of cultural expression....these values are inculcated, however implicitly and indirectly, by well-intentioned teachers and administrators, through privileged forms of language and linguistic interaction' (Zuss, 1994).

In addressing this problem, teaching and learning needs to be seen from a social constructivist perspective, in order to avoid psychological or social reductionism:

'It is vital to examine the experiential and cognitive resources individuals from diverse ethnic and subcultural origins bring to the cross-cultural classroom. Ethnographic description of classrooms alone, however, while essential, is not always sufficient to explain the uneven levels of literacy, or cultural capital, within and between first and second languages and their complex interplay within matrices of power, culture, and value' (Zuss, 1994).

From this perspective and in discussing the education of second language students, Zuss develops a critique of 'process approaches' to the teaching and learning of language and literacy, which he argues:

'emphasise 'freewriting', non-directive teaching, and the use of journals for personal writing experience (and) are intended to permit self-expression and the generation of student-centred texts in non-authoritarian contexts. In actual classroom practice, however, the process approach can serve to suppress the development of 
voice. Particularly in cross-cultural settings, emphasis on process over product, or 'organism' over mechanism, while generative of writing, can disregard the salient cultural choices members of discourse communities are likely to use in self-representation and expression' (Zuss, 1994).

'Talk is work in the language classroom', as one group of commentators has said (Roberts et al., 2004). Zuss's analysis serves as a reminder of how difficult this work can be: the emphasis on dialogue in teaching and learning has highly complex and demanding implications for both teachers and students in terms of addressing issues of discourse, power, identity, and agency, as well as learning, both in the classroom setting and in the wider world.

Finally in this section, it is important to highlight the position of commentators who argue that one of the pedagogical advantages of a dialogic approach is the expression, clarification and exploration of conflicting beliefs or viewpoints. Nonesuch quotes a small scale research study suggesting that the externalisation and expression of resistance to aspects of the learning situation can be a critical stage in negotiating a developmental process with the learner resulting in more commitment to learning rather than less (Nonesuch, 2006). Swan (2006), in a comparative study of different pedagogical approaches in mathematics, argues that it is often through the provocation of 'cognitive conflicts' that the most effective learning takes place. He reports on three experiments in which 'expository teaching' approaches were compared with 'conflict and discussion'. He finds that when learners' existing conceptual approaches were identified and subjected to conflictual comparison, markedly better scores for attainment and understanding were achieved, than with more traditional modes of expository teaching. He suggests that this greater effectiveness is due to 'the identification of and focus on specific conceptual obstacles, the emphasis on oral rather than textual explanation, the increased level of challenge offered, the intensity of discussion and involvement generated, and the valuing of intuitive methods and explicit recognition of conceptual obstacles' (Swan, 2006), each of which imply the centrality of dialogue in the process of learning.

\section{Summary}

Dialogue between teachers and learners is seen by different commentators either as a central element of all teaching and learning, or alternatively as important in achieving a range of specific pedagogical objectives. For the first group, social interaction is the key mechanism through which learning takes place, and teaching is the creation of 
opportunities for learning through the management of interaction. It enables learners to practise and acquire the languages of different communities of practice, to 'own' the learning process and what is learnt. Through it teachers can engage with learners' previous experiences, and thus their beliefs and feelings about learning. For the second group, dialogue is the means by which teachers get information to support planning and differentiation, through which learning can be a joint process of research between teacher and learner(s), through which teachers can find out about learners' misapprehensions and misconceptions, and through which teachers can understand the knowledge, skills and practices that learners already have. Both perspectives put a premium on the need for teachers to be able to use the highest and broadest levels of communicative skills.

\section{Peer assessment and self-assessment}

Commentators on self- and peer-assessment as elements in teaching and learning vary in their focus. One group sees adult education as a process through which learners aim to gain independence from the teacher, to become a wholly autonomous human being. In a limited sense, both Knowles (1983) and Freire (1972) share this belief, though for Freire the process cannot be fully completed unless it is accompanied by a revolutionary change in society. Knowles sees the individual adult learner in some sense as an existentially incomplete person, and the purpose and potential of adult education as a means of achieving completeness, after which, for example, they have the means and the confidence to exercise their own independent judgements, on the basis of their own knowledge and capacities.

This perspective is also shared closely by Carl Rogers (1993), for whom the educated person is one who has 'learned how to learn'. Freire sees traditional education as a means of preventing people achieving existential adulthood and autonomy, by confirming them in their unconscious dependence. For each the issue of capacity to be self-directing and selfcritical is an essential element of the desired state. Boud (2000) also has a focus on the future, in which present learners will be independent of the teacher, and will not need guidance to arrive at what they feel are satisfactory judgements. For all these writers, the issue is in an important sense a moral one, connected with our view of the rights of individual adults, connected, as Hostler (1986) points out, with the western conception of adulthood, originating in the European Enlightenment.

For Jansen and Van der Veen (1996), however, these ends are desirable not just for moral reasons but for practical ones: adult citizens living in 'conditions of modernity', that is, in 'risk society' (Beck, 1992), are 
subject to much weaker ties of family, class, church, etc, than in traditional and pre-modern societies, which gives more freedom of choice and decision to each individual.

'This means that individuals become more 'self-responsible' for the planning and organising of their lives. To use Beck's phrase, biographies become more 'self-reflexive', i.e. formerly socially conditioned biography transforms gradually into a more selfdecided and self-organised biography.' (Jansen and Van der Veen, 1996).

However, accompanying this freedom from traditional ties and norms, is the emergence of ever-more complex institutions and procedures that become increasingly disciplining and uniform. A prime example is the growth of the complex systems of standards, training, verification and formal certification that in recent times has transformed traditional education. Jansen and van der Veen argue that people need education primarily to support life as autonomous individuals in this complex, changing world in which there are fewer and fewer familiar, trustworthy and reliable sources of information and support; they see new forms of adult education, particularly those that help develop judgement, capability, problem-identification and solving, as vital in this transition.

In the light of these political perspectives on the purposes of adult education, developing the capacity for self-assessment and peer assessment is more significant for educators than teaching an imposed curriculum. Brookfield (1990) agrees that ultimately there is no certainty about quality, and that life (and teaching, and learning) is about making judgements. $\mathrm{He}$ too sees the role of teaching and learning for adults as foregrounding these capacities, and argues that self-assessment and peer-assessment should be central elements of all learning situations. In particular he recommends encouraging students to critically evaluate the decisions and assessments of the teacher. Absolum (2006) makes the same argument from the context of school students, emphasising that students must 'own' both the processes and the content of learning. He argues that self-assessment is an indispensable element of effective learning that is 'owned' by the students, and he offers many ways in which teachers can organise and support it.

Klenowski $(1995,1996)$, too, focuses on self-assessment as a critical component of effective learning. Her research was based on the assumptions that students' motivation is strengthened the more responsibility they are given for monitoring their own progress and devising their own strategies for improvement, that students learn by being active rather than passive, and that students are capable of being perceptive about each other's work. She sees self-assessment as essentially about judging the 'worth' of one's 
performance, and the identification of strengths and weaknesses in order to improve. Her research suggests that if formative feedback is to achieve the objective of making a difference to a perceived gap between actual and desired performance (Sadler, 1989), rather than just giving information about it, then the information must be transformed into action through a process of self-assessment, in which something like Ecclestone's (2004a) 'internalisation of the criteria' takes place. During the research selfassessment was analysed and graded descriptively, and key dimensions, including the use by students of explicit criteria, the interactive dialogue between each student and the teacher, and the giving of grades by each students to their own work, were identified. The project found overall that this approach impacted significantly on pedagogy, and that the students took increased responsibility for decision-making. Teachers received valuable information about students' self-perceptions which supported improved planning. In her second paper, Klenowski acknowledges the difficulties in implementing such approaches within unsupportive political and administrative contexts.

Claxton (1995) examines the three aspects of self-assessment identified by Klenowski from the point of view of the development of learning-tolearn or 'learning acumen', which, he argues, comprises resilience, resourcefulness, reflectivity and responsibility. The minimal sense of selfassessment, in which students merely learn to monitor their performance in terms of externally-specified criteria, may raise attainment without improving learning acumen, and may even damage it. His position is that self-assessment is essentially an intuitive process. Learning to see selfassessment as 'marking one's own work' by applying a checklist of criteria, prevents the development of this intuitive ability.

Both Ivanic (1988) and Moss (1995) see the development of selfassessment capabilities as a potential product of the search for authentic 'performance', in which a teacher may take the role of editor or facilitator or trusted critic, and help the creative process through promoting selfassessment. As Moss in particular points out, the danger is in failing to avoid the tacit or unconscious imposition of the teacher's values, rather than developing the student's own sense of 'what works'.

'Pupils can be asked to work through their ideas on what makes for a quality performance, apply that understanding and further refine it through peer assessment. In this way, sharing the criteria with learners becomes less about teachers stating objectives on the board and more about pupils being apprenticed into the guild' (Marshall and Wiliam, 2006) 
For Marshall and Wiliam, focussing mainly on school-based learning, peer- and self-assessment are key elements of pedagogy in the English classroom:

'Peer assessment is one of the main vehicles to promote selfassessment. Seeing how someone else has tackled the same assignment helps pupils reflect on their own performance. For this reason it is fairly common practice in English and has been one of the main starting points of the English teachers with whom we have worked [in our research project], for adopting formative strategies in their classrooms. They become more systematic, however, and less ad hoc in the way in which they engaged pupils in peer assessment as a means of enhancing its impact' (Marshall and Wiliam, 2006).

They point out that for this process to work successfully, the teacher needs to have constructed 'a safe environment in which pupils feel comfortable having others read their work, and in which collaboration and sharing of practice have become the norm. Some teachers encourage this by allowing their own performance to be critiqued....', but they also need to have modelled good feedback themselves, both in the way that they have talked with the class and through their own written comments. 'Pupils need to see examples of good practice to be able to know what to do' (Marshall and Wiliam, 2006)

Good and Holmes (1982) in a book largely aimed at students of adult literacy, argue strongly for the involvement of learners in assessment of their learning, rather than the use of rigidly prescribed, supposedly objective tests. They see assessment of progress as something to be done by teachers and students together, through discussion, and that therefore a good learning relationship between them is important. However, following Kohl (1998), Good and Holmes believe that people can teach themselves, that a teacher is not essential, and that any person reasonably competent in reading can help anyone else learn. The book provides a range of techniques for selfassessment in the context of improving literacy, using a framework they call ASK in which the terrain of learning is seen as being made up of 'attitudes', 'skills', and 'knowledge'. They also provide a simple system of descriptive levels: 'beginning', 'not bad', and 'with ease', derived from Kohl (1998), to make self-assessment as straightforward as possible.

Much more recently, the growing emphasis on 'personalised' learning, combined with the increased expectation that all learning should be accredited, has led to the development, by government-funded agencies, of procedural systems supporting teachers in planning and recording the learning of their individual students, in which it is expected that students 
play a key role in setting their own learning targets, and in monitoring their own progress towards them. Two important examples of this are Grief (2003) and Greenwood and Wilson (2004), the first focussed on adult literacy, numeracy and ESOL, and the second on adult learning in general. Both these systems are similar, and consist of a sequence of procedures in which students work with their teachers to articulate their learning goals, set themselves targets for achievement, and to monitor and record their progress towards those targets. A key element of each is the working document known as an Individual Learning Plan (ILP), against which progress and achievement are monitored throughout the programme of learning. Both reports elaborate the benefits for learners and teachers of involving the learner 'at all stages of the process', and Grief recommends a simple selfassessment framework for learners using the concepts of 'emerging', 'consolidating', and 'established' in the use of identified skills. When teachers and students work together on planning learning, assessing progress, and adjusting learning activities, as well as mutually discussing the extent to which learning goals are being achieved, these procedures have the potential to promote formative and sustainable learning.

The other key purpose of both publications is to help relevant adult education programmes to provide records of learning, progression and achievement that will enable them to be fundable, and to satisfy the evidence requirements of awarding bodies. This is necessary for adult education courses which are not accredited through external assessment, and which because of this do not fit easily into a funding and accountability system which assumes that in general all learning leads to national qualifications. In this respect, these procedural systems clearly serve the purposes of summative assessment. Both systems were piloted in large numbers of adult learning programmes, and these publications report that they were by and large well-received by students and teachers. These systems raise important questions about the tensions between formative teaching and learning activities, and the recording of progress and achievement for summative and accountability purposes. Both reports implicitly support the view that these different purposes can be integrated: that learning and achievement is enhanced by the involvement of students in assessment of their learning, and that learning is focussed by the emphasis on well-defined targets. However, whether they deal decisively with the problems identified for example by Torrance (2005) and Ecclestone (2004a) is uncertain.

From the high-level system-wide perspective of these commentators, such procedures allow or even encourage the bureaucratisation of the processes of formative assessment, in which the dialogue between teacher and learners is focussed more on the need to record progress and 
achievement, than on learning itself, and the object of quality assurance becomes the document rather than the quality of the process it records. If teachers are to resist or avoid this tendency in using these procedures, especially in contexts in which the learners' orientation to success in learning is complex and highly-differentiated, it is even more important that they are highly-sensitive to the differences between formative and summative purposes in learning. Furthermore, because of the need to serve funding and accountability systems in which learning is seen as a wholly individual project towards the acquisition of qualifications, these systems have little to say about social, collective or group aspects of learning, except that the ILP can in theory be used to record learning that was 'unintended' or otherwise outside the goals set at the beginning of the programme. They also do not address the issues raised by Roberts et al. (2004), Windsor and Healey (2005), and Spiegel and Sunderland (2006), about the extent to which it is appropriate to involve ESOL learners in complex discussions about learning and assessment, or similar issues raised by Russell (1999) and Belzer (2004) in relation to learners with strongly held but erroneous convictions about learning and assessment.

Taylor et al. (2006), Fowler and Mace (2005), Breen (2001b), Moss (1995) and Kelly et al. (2004) are all concerned in different ways with the collaborative aspect of learning: between teacher and learners, and between learners. Kelly et al.'s review of the literature on the teaching of writing finds that many writers stress the importance of learners being encouraged to work collaboratively to enhance learning, and that collaboration provides opportunities for immediate feedback from peers, and supports learners taking risks, each of which is seen as having benefits for learning. Teachers also need to take up a facilitating, collaborative role, and one version of this is for the teacher to act as a scribe. Moss (1995) describes in detail this process of close collaboration between a teacher and learner in developing and evaluating writing work, and demonstrates its complexity in terms of ethics as well as of pedagogy. The emphasis in Taylor et al., Fowler and Mace, and Breen is on collaborative learning being seen as a research activity, partly as a means of structuring self- and peer-assessment into it, and partly as an enriching element. The object of research may be the processes of learning themselves, or the evaluation and exposition in performance terms of pieces of work produced through learning activities.

Finally in this section, both Reder (2005) and Comings et al. (1999) draw attention to evidence for the amount of what they call 'self-study' undertaken by those involved in formal learning programmes, and also by those who are not. Both argue that policymakers and practitioners should pay more attention to ways of supporting self-study. They argue that one of the characteristics of a successful learner is 'self-efficacy', noting that this is 
a more precise and useful term than self-confidence, and that it connotes the capacity for self- and peer-assessment. One of the ways they suggest that formal programmes can support self-study and the development of 'selfefficacy', is to focus explicitly on the development and practice of self- and peer-assessment as integral elements of learning.

\section{Summary}

In this section, it is suggested that self- and peer-assessment activities in teaching and learning are a necessary part of the process of students' gaining autonomy, in the sense of being able to use the skills and knowledge learned effectively in real-life situations, without the support of a teacher. Different commentators argue that autonomy is desirable for moral, political and social reasons. Self- and peer-assessment are also seen as necessary but not sufficient for ensuring that superficial and instrumental learning is to be avoided.

\section{Learners' understanding of assessment and the language of assessment}

The commentators referenced in the last section argue for the importance of self- and peer-assessment, not just in principle, but in practice. Yet, Ecclestone (2004a) argues that all assessment practice has the potential to support learning or merely to record it. There is a critical difference between understanding the assessment process so as to use it instrumentally to achieve the short-term goal of certification, and 'internalising' it, in order to go beyond short-term objectives, support future learning, and build learners' capacity for autonomous and authentic judgements about the quality of their work, for themselves.

This difference is what Claxton (1995) suggest that Klenowski (1995) may be ignoring.

Although many of the commentators reviewed speak of the importance of learners gaining familiarity with the tools of assessment as part of the process of building their capacity and autonomy, only Claxton, Ecclestone and (Boud, 2000) seem clearly to articulate this issue - that the narrow aims of systems for assessment of learning can be served just as effectively (possibly more effectively) when students are involved in the assessment process, understanding the processes and the criteria, using self-assessment, peer-assessment, and so on.

This important and often overlooked argument shows that it is not student involvement per se that makes the difference but the nature and 
quality of that involvement. As Claxton points out, it is straightforward in principle to apply a checklist for the involvement of learners in assessment, and to use it for the purposes of assessment of learning, rather than assessment for learning. A key question for the field and for research is whether the instrumental use of processes such as self-assessment is actually inimical to authentic learning, learning for the future, etc, as Ecclestone and Claxton suggest, or whether the two perspectives can be sustained alongside one another as is implied by commentators who do not raise this issue.

Another way of illustrating this point is provided by McNair (1996), who discusses what he calls the 'learning outcomes movement' which has transformed further and adult education in the UK over the past two decades by successfully arguing for assessment criteria to be made explicit, as part of the process of increasing and widening access and attainment. He asks how far this explicitness in principle supports learner autonomy. Learning outcomes are seen as a form of language, which on the one hand makes clear communication possible, but on the other defines limits and is the means by which societies and communities are excluded by power. But challenging this power is more than a matter of confronting traditional privilege - the attempt to make language more accessible, and widen the community, inevitably threatens its precision. The article concludes that explicitness alone is not enough to develop autonomy - the key question is not 'does my performance satisfy the criteria?' but 'do we agree that this is right?' McNair therefore concludes, with Brookfield (1990), that authentic autonomy is inseparable from values, depends on the cultivation of the capacity for judgement, and is irreducible to standardised criteria or procedures, however liberal, democratic and well-intentioned.

Groves (2002) has a further telling critique of the 'learning outcomes movement', on the grounds that they assume that framing explicit assessment criteria is in principle unproblematic. He reports on an smallscale enquiry into the language of the course performance criteria, which all students surveyed found off-putting, 'jargonised' and hard to understand. Across a range of skill areas the criteria scored significantly higher on the Gunning Fog index of comprehensibility than a classic text of philosophy, Wittgenstein's Tractatus (1922). The report concludes that adult learners are encountering language written in the discourse of teachers, with institutional values embedded implicitly. Yet this language is presented as transparent and objective. Groves suggests that teachers should beware of inaccessible language for assessment criteria, and that the search for 'neutral', transparent language for this purpose is futile (ironically, according to Wittgenstein [1953] there is no such language). This is a fundamental problem, for as he points out: 
'One cannot blame adult education teachers for following a trend upon which their jobs depend, and that seems so accountable, scientific (the term positivist comes to mind) and certain. It may be that all that is required is greater attention to clarity of course structures and terminology, but I would also suggest more thought needs to be given to holistic and 'problem-centred' assessment processes in which the meaning of language is rooted more explicitly in the contexts of use.' (Groves, 2002)

Whether or not they make these points, most commentators agree that student involvement in the assessment processes, through using the tools of assessment themselves, is a necessary if not sufficient condition for authentic learning. These include Fordham et al. (1995), Lindsay and Gawn (2005), and McGivney (1996), who maintains further that students with less success in previous education have less familiarity with academic convention and the language of assessment, and that the benefits of authentic involvement in assessment for them are potentially even greater, though initially the process will have to be handled sensitively, a point also made by Merton (2001).

Lindsay and Gawn (2005) note that for many students, improving their understanding of assessment processes as part of learning will need to be taught. Others, as we have seen, draw attention to problems created by some students' strongly-held and perhaps erroneous pre-conceptions about learning and assessment: these imply also the need to 'teach' assessment in a careful and sensitive way (Barton et al., 2005, Belzer, 2004, Gillespie, 2001, Russell, 1999, and Kelly et al., 2004). This can be particularly important in relation to the involvement of ESOL students in assessment, primarily in respect of the language of assessment (Windsor and Healey, 2005, Roberts et al., 2004, Spiegel and Sunderland, 2006), a point made in more detail later.

Roberts et al. (2005), in a report on seven case studies in which adult literacy, numeracy or language were embedded in vocational training programmes, citing the work of Chaiklin, Lave and Wenger (1991, 1996), argue that at their best, vocational training courses:

'offer learners both the acquisition of practical skills and a new 'professional' identity, or, as some of the case studies describe, offer learners membership of a new 'community of practice'. This means learning to be like a professional; learning what is worth knowing, how far they can draw on their existing expertise and what are the risks and challenges in taking on this new identity. This new professional identity is what motivates such learners.....learners are both 'doing things' and understanding the culture of their chosen 
jobs - the behaviour, values, and ways of communicating - for an example, as joiners, as childcare workers, or as Indian head massage practitioners' (Roberts et al., 2005).

Although the focus of this report is mainly on the integration of literacy, numeracy and language teaching and learning into vocational training courses, rather than on student understanding of assessment, it is clear that Roberts and her colleagues are seeing vocational learning expansively as potentially including not just content knowledge but an understanding of the values of the relevant community of practice, including the ability to make sensible and acceptable judgements about the quality of work carried out within the trade: this implies that training in assessment, through activities involving peer- and self-assessment are an essential element of such courses.

Finally, Boud (2002) argues that we need to develop a new language more appropriate for assessment for learning. He points to the damaging nature of what he calls (after Rorty, 1989) the 'final' language of assessment: a vocabulary which uses terms such as 'good', 'right', 'rigorous', 'professional standards' and the like.

'Even though it is apparently positive, it is language that leaves no room for manoeuvre. It has the final say. It classifies without recourse to reconsideration or further data. And it does not allow for further possibilities. Not only are terms such as these, even more so in the negative or implied negative versions, damaging, but they are also empty rhetoric. They are content-less and communicate nothing of substance. From the point of view of formative assessment they do not provide any information which can be used directly to improve learning' (Boud, 2002)

\section{Summary}

Three main points are made in this section. Firstly, it is not student involvement in assessment per se that makes the difference but the nature and quality of that involvement. Secondly, learners' understanding of the language and processes of assessment, and preparing them for participation in self- and peer-assessment activities, will need to be taught carefully and sensitively. Thirdly, involving students in assessment of their own and others' learning is part of building learner autonomy, but this is anything but a technical process. Authentic autonomy is inseparable from values, depends on the cultivation of the capacity for judgement, and is irreducible to standardised criteria or procedures. 


\section{Feedback and marking of work}

Action without feedback is completely unproductive for the learner (Laurillard, 1997, p. 61).

Most commentators see feedback as a central element of teaching and learning (see for example Newmarch, 2005, Eldred, 2005, Lindsay and Gawn, 2005, Hillier, 2002, Spiegel and Sunderland, 2006). This section falls into 7 parts: the need for feedback to be 'attuned' to the situation of specific learners if it is to be effective, learners' views on feedback, guidelines for teachers giving feedback, the idea of feedback as based on judgement rather than certainty, feedback from peers, the effects of feedback on learners' self-esteem, and marking. An important aspect of the Black Box research programme (Black and Wiliam, 1998a, 1998b) is that different kinds of feedback produce different results in different situations: that feedback (of which marking written work or assignments is one occasion) is in a dynamic and interactive relationship with the purposes and motivation of the learners, and also with the 'official' purpose of the programme of learning. The tension between these three aspects of the learning situation is also critically affected, according to this and earlier research, by what each learner understands about the nature and purposes of the assessment process itself; thus these findings make a strong case for assessment being:

'an integral part of the education process, continually providing both "feedback" and "feedforward" and ought therefore to be systematically incorporated into teaching strategies and practices at all levels' (DES, 1988).

But one implication of this perspective is that the specific approach adopted to the generation of information for feedback - for example, whether the teacher gives numerical 'marks' or written advice when they are marking, or whether verbal or written comments are focussed on the ego of the learner or on the actual task in hand - needs to be 'tuned' to the specific situation. If the teacher is not aware of these nuances, or hasn't the skills to adjust his or her approach accordingly, then it is argued on the one hand that the formative benefits for learning of the feedback may not be realised, and on the other hand that the learners' motivation may be affected negatively. Many of the texts reviewed here implicitly address this problem in relation to adult learning, as part of their overall perspective in which the individual learner's needs and experience is the starting point.

But schools-based research suggests that teachers need highlydeveloped skills and understanding of learning and assessment in order to address this issue effectively; a generalised commitment to putting learners at the centre of the process is unlikely to be sufficient. In a recent smallscale study of secondary-school students aiming to compare the learning of 
a group who were given qualitative feedback on their work but no numerical marks, with that of three control groups who were given marks as a normal part of the feedback process, the treatment group's attainment was slightly lower by the measures used (Smith and Gorard, 2005). More significant, possibly, was the fact that most of the students were hardly aware that the research was taking place, and had little understanding of what the point of it was; when interviewed as part of the study, most of the students in the treatment group were clearly unhappy about not getting marks. This suggests that students become habituated to certain kinds of feedback, and may feel anxious if this suddenly changes, unless they have a relatively sophisticated understanding of the assessment process. This study's outcomes appear to contradict one of the key recommendations of the Black Box research (that qualitative and constructive feedback will support learning more effectively than raw assessment scores), though it is only a single, small scale study. However, it strongly supports the case against a superficial focus on feedback and marking, and one in which the learners are not involved in its implementation and do not understand it.

Turner and Watters' (2001) study of 169 learners' views on achievement in non-accredited learning found that they preferred the term feedback rather than assessment, which was seen to connote judgemental and unsympathetic attitudes. Feedback was highly valued, and this distinction is a matter not just of language but approach. Learners were more interested in why they were learning than how successful they were being. Feedback was seen as enriching learning rather than being an act of judgement.

As so much of adult learning historically has not been accredited, it is not surprising that feedback has been recognised in guidelines for teachers. Hillier (2002) discusses the importance of constructive and practical feedback in all kinds of assessment, summative as well as formative, rather than simply qualitative remarks. Feedback should therefore:

- focus on the issue, not the person;

- be specific, based on examples;

- enable teachers to mark examples of the work and relate these to an overall summary;

- be constructive and offer ideas to improve;

- check that the learner knows what to do next

- not make sweeping statements;

- not make negative comments without helpful suggestions; 
- not be too lengthy and detailed;

- not use red pen and cross large parts of the work out;

- not finish with a negative comment.

McGivney (1996) synthesises findings from a range of studies that agree that adults favour continuous assessment because it provides them with regular feedback, reveals how well they are doing and indicates areas that need improvement. Adults appreciate:

- $\quad$ specific instructions on what is needed in an essay;

- clear explanations of grading schemes;

- rapid turn-around in grading and returning assessments;

- practice in examination techniques and provision of model responses;

- frequent and regular feedback on performance.

Students with less success in previous education are less familiar with academic convention and the language of assessment, and want positive feedback that is detailed and constructive. The Mary Ward Centre (2001) provides a systematic guide to initial, formative and summative assessment aiming to support tutors of non-accredited programmes at the centre. It outlines an administrative system for monitoring, recording, and moderating assessments in such programmes, and provides a wide-ranging justification for such a system, based partly on the findings of a research study of the perceptions of learning and progress of students on uncertificated courses. Formative assessment is seen as ongoing informal (usually oral) feedback to individuals and groups and is distinguished from initial diagnostic assessment and summative assessment by not having to be formally recorded. The guide also provides 25 distinct methods for assessing learning, based on Donley and Napper (1999). This earlier publication provides a discussion of assessment in adult learning under the questions, who, how, why and when, followed by a section on how to give feedback, and then presents and compares a series of techniques, games and approaches, which are analysed under the following headings: paper or nonpaper based; formal or informal; carried out initially, on course, or at the end of the course; teacher-, self- or peer-assessed; and whether it best assesses skills, attitude, or knowledge.

Jenny Rogers' well-known book on adult learning (2001) has a chapter on giving feedback, in which she argues that: 
'Giving feedback and criticism, praising and commenting, these are all so important in learning that the topic deserves a whole chapter to itself. Teaching adults is enormously complicated by the difficulty of 'criticising' an equal. Not giving the right quantity or quality of feedback is one of the main reasons why adult learning fails....' (Rogers, 2001)

She links feedback strongly to progress in learning, without which 'adults lose interest'. She presents feedback as a key part of a learning cycle, which moves from Motivation to Performance, to Feedback, to Improved Performance, and back to improved Motivation. Feedback should be prompt, encouraging, give clear reasons for success or failure and constructive, practical guidance about how to improve. It should mostly be given privately, at least at first. Feedback should offer facts and descriptions of the performance, not opinions about it. Teachers should not simply give qualitative comments, even if they are positive, and they should resist the temptation to correct the work themselves. Finally, the process of determining what needs to be done next, to build on success or to correct mistakes, should be agreed with the learner. This is partly to ensure that they understand the teacher's advice, not least so that feedback will affect future learning positively. Rogers asserts that 'without feedback, learners cannot learn, and a tutor cannot be said to be teaching'.

Absolum (2006) emphasises the role of the learner in the feedback process. He argues that 'learning-focussed feedback affirms the learner's ownership of the learning, focuses on the learning intentions and success criteria, is provided at the right time, confirms what has been learnt and supports the next step, provides specific suggestions for improvement, does not swamp the learner with excessive or ill-directed prompts, and allows the learner to act on the feedback, for example by going back to improve a piece of work. He argues that learners should be able to influence both the process and the content of the feedback, and goes on to problematise task-oriented feedback, when the classroom becomes 'a centre for activities rather than of learning':

With an expectation to do things, the role of the teacher is to manage and organise the activities. Everything else follows from this. Feedback is not descriptive and critical about where the learning is at, but evaluative about how well the tasks have been done. Even when the task is to learn the times table or spelling list ...' There is still a task orientation rather than a learning orientation with an emphasis on how well it was learnt (success or failure) rather than on how well the learning is going.....because task orientation is so much part of our personal educational 
histories it is difficult to easily distinguish a task focus from a learning focus (Absolum, 2006).

Kelly et al.'s review of research on the teaching of writing found many commentators who suggest that teachers need to intervene during rather than at the end of writing, though one warns that inappropriate feedback can affect motivation negatively. The review found that many writers suggest that learners should be encouraged to work collaboratively to enhance learning: collaboration provides opportunities for immediate feedback from peers, and supports learners taking risks (Kelly et al., 2004).

A recently-published short handbook for ESOL practitioners points out the challenge to ESOL tutors of giving feedback in a way that can be understood formatively by language learners, who may not be familiar with the language of assessment, and may be unfamiliar or even resistant to the idea that they might be pro-active in their learning (Windsor and Healey, 2005). Spiegel and Sunderland (2006), in another handbook for ESOL teachers, show how continuous monitoring of learning allows formative judgements about progress to be made, enabling adjustments to planning as necessary: it stresses the necessity of feeding back these judgements to learners. Brookfield (1990) also argues that teaching is about making judgements, however carefully objectives and criteria for success are defined. From this perspective, 'talking about non-judgemental teaching, non-directive teaching, or non-evaluative teaching, is conceptually nonsensical'. Useful assessment is constructive, specific, task-oriented, future-oriented, encouraging, given immediately, given regularly, justifiable, and educative in itself. Brookfield suggests improvements to assessment techniques: the collective assessment of experience, opening criteria to negotiation, getting students to assess their teachers' assessments and promoting self and peer assessment.

Hostler (1986) stresses the value of teacher feedback and provides guidelines for it but links the involvement of students in peer feedback to the development of learner autonomy. He argues that assessment should be an integral, everyday feature of teaching, not appearing as anything out of the ordinary, or raising any anxiety. He recommends involving students in their own assessment as a group, through mutual feedback, preparing presentations and demonstrations for other students, and role play. Hostler points out that mere observation often provides enough evidence for useful feedback.

Young (2000) reports on a small scale study of the effects of feedback on feelings amongst access students. She found that lecturers working with adults have to balance the need to provide feedback and assess work, with a concern to protect vulnerable students. All the students found the first 
assignment problematic, but thereafter there were great variations, related to varying levels of what Young depicts as 'self-esteem'. Students varied in their attitudes to receiving feedback, their perceptions of its messages and whether it was important to receive positive comments. For some students, feedback was 'only work'; others felt their whole sense of self was at stake.

Very little work has been found on the marking of adults' written work. Although written feedback on assignments is commonplace in higher and further education, homework which generates a need for formal marking is not widespread in adult education where there is an assumption, made explicit in the case of the Mary Ward Centre (2001), that there is only time for oral feedback. However, it is becoming more common, particularly in literacy, numeracy and language programmes, to provide individual tutorials, albeit short, and to use written records of comments on assignments, perhaps carried out in class time, as the basis for these. Record-keeping for the purposes of accountability has become widespread as programmes not leading to external qualifications now have to provide auditable evidence of students' progress.

Gardener's (1985) comments on marking reflect a Freirean perspective, where value is seen as being constructed by learners with the support of the teacher, rather than being imposed from outside. Marking in response to learners' work is seen as integral to the teacher's role. It needs to be futureoriented and constructive, and should be used to increase learners' skills and understanding of judgement, assessment and value, for more effective learning in the future, and for empowerment. 'Marking for correctness should be as light as possible....marking for communication, meaning and shape should be as full as possible'. Boud (2002) comments on the authoritarian and 'final' language of feedback and marking:

'It is not only final vocabulary that is unhelpful for learning, but the very act of objectifying feedback. The picking up of a red pen is not just a metaphor for marking....to position ourselves as the ultimate authority, which we do when we speak or write as if we possess the truth which must be communicated to the student, is to create an unsurmountable barrier to communication....if we share our subjective response then the possibility of human interaction and dialogue is signalled. If we shout....then all is closed' (Boud, 2002)

\section{Summary}

This section deals with seven distinct aspects of feedback: that feedback needs to be 'attuned' to the situation of specific learners if it is to be effective, the importance of learners' views on feedback, effective guidelines for teachers giving feedback, the idea of feedback as based on 
judgement rather than certainty, the value of feedback from peers, the effects of feedback on learners' self-esteem, and guidance for marking written work. Overall it argues that teachers' planning needs to be focused on ways to generate evidence about students' understanding and motivation, which can then inform a constructive process of feedback, questioning, and dialogue.

\section{Questioning and checking learning}

Classroom questioning extends teachers' understanding of the aims of diagnostic and formative assessment into an area that they usually construe as 'teaching'. Alexander (2004) draws together a number of school-based studies which see questioning as integral to effective teaching and a key element of a 'dialogue of enquiry'. Brown and Palincsar's notion of 'reciprocal teaching' offers four linked strategies structure discussion, evaluate new material and assess understanding: questioning to provoke discussion, clarifying to tackle problems in understanding, summarising what has been learned so far, and predicting the information that will follow (Brown and Palincsar, 1989). Lindfors (1999) brings out the need for the 'dialogue of enquiry' to encompass challenge and disagreement as well as consensus. Barnes and Todd (1995) argue that teachers need to foster 'both the spirit and procedures of a 'joint enquiry' through which learners construct shared meanings from their different frames of reference (quoted in Alexander, 2004).

Swan (2005) identifies effective questioning as a fundamental principle of teaching and learning. Talking about mathematics teaching, he points out that:

There have been many studies of teachers' questioning. Typically, most questions are low level, testing the ability of learners to recall facts and procedures. Such questions are also called 'closed', meaning that they permit just one single correct response. Fewer questions promote higher-level reflective thinking, such as the ability to apply, synthesise or explain. Such questions are called 'open' because they invite a range of responses. The research shows that a variety of lower level and higher-level open questions is much more beneficial than a continuous diet of closed recall questions. A second finding is the importance of allowing time for learners to think before offering help or moving on to ask a second learner....longer wait times are associated with significantly improved achievement (Swan, 2005).

He also suggests that it is possible to distinguish between two kinds of assessment: convergent and divergent. Convergent assessment is associated 
with closed questions of the form 'Can you do this?', and is often characterised by tick lists and can-do statements. Divergent assessment, characterised by open questions of the form 'Show me what you know about...' to which the answers are not pre-determined. Swan argues that divergent assessment is particularly useful for formative purposes (Swan, 2005).

In his discussion of the importance of dialogic teaching for learners of English as a second language, Breen (2001a) warns that closed questioning can foreclose learning. He surveys a range of feedback techniques and distinguishes between different kinds of classroom talk: between learner interactions in which their discourse is 'woven into the teacher's text', (as in the case of questions to the whole group - an example of effectively closed dialogue) and interactions in which learners frame their own discourse. $\mathrm{He}$ argues that supporting the capacity to develop this learner-centred discourse, for example about the learning process itself, is a key element of effective language teaching. Rogers (2001) also warns against closed questions, suggesting that questions beginning with 'show me', or 'how', or 'why' are more likely to help assess whether the learner has absorbed the learning point. She identifies four types of questions to avoid: double questions which confuse, leading questions which suggest the answer the teacher would like to hear, 'advice in disguise' questions which can prevent learning and create opposition in the student's mind, and rhetorical questions which imply contempt or ridicule towards any answer than the one implied. On the other hand, Rogers offers guidelines for powerful questions: that they are very short and simple, perhaps only 6 or 7 words, and that many of the best questions start with 'what', obliging the student to find their own words and which cannot be answered with 'yes' or 'no'.

Swain et al. (2006) report on a study aiming to develop teachers' ability to assess the mathematical understanding of adult learners and to integrate formative assessment into routine practice through observation and questioning. They point out that it is one thing to ask the right questions, but another to know what to do with the responses: 'more effort needs to be spent in framing questions that are worth asking, exploring issues which are critical to the development of learners' understandings, followed up by activities that provide opportunities to extend these understandings. In this way, teachers shift their main role from presenters of content to facilitators exploring ideas that the learners are involved with.' The project suggested that questions might be challenging (how/ why did you do that?), checking (do you know what a denominator is?), uncovering thinking (can you explain this pattern?), offering strategies (have you thought about using smaller numbers?), functional (have you got a ruler?), or re-assuring (are you happy with that?). Sometimes a 'devil's advocate' question (are you 
sure?) was useful. As the project developed, teachers began to think beyond the questions themselves, to issues such as giving the learners time to answer, being able to act on the responses to move learning on, and how to encourage students' questions, both to the teacher and to each other, raising the interesting idea that students might be taught questioning techniques too, thus developing their own discourse for understanding learning, at the same time as improving their subject learning.

Similar points are made by Hodgen and Wiliam (2006), also dealing with mathematics teaching. They point out that students can be encouraged to talk through questioning and listening:

- $\quad$ By listening more to pupils, teachers learn more about what pupils know and how well they know it

- More pupils have more opportunity to express their ideas through longer contributions. They have more opportunity to listen to and compare their ideas to those of others, and thus more opportunities to learn from their peers

- By being listened to, pupils realise the teacher is actually interested in what they say and are thus encouraged to say more.

- Talking less gives the teacher more time to think about the interventions he or she does make.'(Hodgen and Wiliam, 2006)

They go on to give a series of examples of the kinds of questions that could be used to achieve these aims in a mathematics classroom. They also point out, however, that:

'Of course, questioning is more complex than simply generating questions. Responsive questioning - responding in the moment to pupils' ideas - is very complex. There are no easy answers to this, but teachers in [our research project] found collaboration sharing, talking about and reflecting upon questioning with other teachers - to be a very valuable way of increasing their repertoire of questions and their ability to use these questions in the classroom' (Hodgen and Wiliam, 2006)

\section{Summary}

The main point made in this section is that using the right types of question in the classroom can enhance learning directly, by encouraging students to think, to construct hypotheses, to summarise what has been learned so far, and by provoking discussion, challenge and disagreement as well as establishing consensus. Teachers need to develop their repertoire of 
questioning techniques, and in particular to use 'open' rather than 'closed' questions. Examples of these are given from a variety of sources. The analogous idea of 'convergent' and 'divergent' assessment is also introduced.

\section{Planning and differentiation}

Most commentators on adult learning agree that a key benefit of formative assessment activities is to support future planning of teaching and learning, and provide more information to enable the teacher to 'differentiate' these plans to suit individual learners in groups that are often extremely heterogeneous in age, ethnicity, first language, previous experience of learning, and motives for attending. Indeed a key aspect of Black and Wiliam's definition of formative assessment (1998b) is that for classroom activities to be formative they must lead to adjustments in the teaching and learning strategy. Rogers (1992) also states that supporting ongoing planning by suggesting directions for changes, along with improving teaching performance, and as an essential element of learning, are the primary purposes of assessment and evaluation, and Degener (2001) agrees, writing from a strongly Freirean perspective on the characteristics of critical pedagogy in adult literacy programmes:

'Program evaluation would take place on a regular basis, not only at the end of the semester. Teachers and administrators would get feedback from adult learners at the individual and group levels. This feedback would be used to refine the program structure and the class instruction continually. As students' needs change, so would the program. Students would be able to see how their input affects the program and would thus see themselves as active participants. Programs might also develop formal structures, such as a student board....' (Degener, 2001).

The same point is made by Spiegel and Sunderland (2006), who stress that continuous monitoring of learning allows formative judgements about progress to be made, enabling adjustments to planning as necessary.

Klenowski (1995) shows that 'the introduction of the skills of selfassessment offers another dimension to the current learning environment, providing students with opportunities to take increased responsibility for a more active role in their own learning.' Her study suggests that if selfassessment is to optimise student autonomy and self-direction, it needs to be fully integrated into the learning process rather than treated as a 'bolt-on' element. This supports the importance of developing a classroom 'culture' conducive to this kind of learning, which was looked at in the first section of this chapter. 
Mace (1979) argues that teachers cannot plan effective learning for each individual learner unless they have worked as hard as possible to understand what knowledge and experience they each have, what they feel confident and unconfident about, and crucially, their feelings about their previous experiences of learning and assessment (referred to increasingly as their individual 'learning and assessment careers' (see for example Ecclestone and Pryor, 2003). For Ivanic (1996), formative assessment aids planning when teachers understand each learner's state of understanding of the content of learning: they need to find out more about the mental models of the subject learners bring to the learning situation, whether these are accurate or not. In relation to learning conventionally correct punctuation, this insight may only be revealed after complex interaction and dialogue with the learner: without this, planning is likely to be unfocussed and ineffective, and may even confirm the learner in their mistaken model of the issue. Very similar findings are made by Barton et al. (2006) in their study of 134 literacy students in community-based settings: it charts the wide range of experiences that learners bring to learning situations, and notes that people may have widely differing reasons for getting involved in learning and are often faced by profound and challenging barriers to persisting in their learning, including physical, mental, social, emotional and economic constraints. Teachers need to be able and willing to engage with these factors in their students lives: if they cannot or will not, then they will not be able to utilise their students' experiences for learning, and they will not be able to connect with their learners' feelings and ideas about learning, and thus may not be able to find the most effective teaching approaches. Belzer's (2004) notion of the significance of already held ideas about learning that can act as 'screens' which 'filter' the teacher's intentions and compromise lesson planning, implies that teachers must carefully investigate the ideas that different learners have about learning. Ivanic and Tseng (2005) argue that 'teachers should identify learners' intentions as the key factor in learning events', and Millar's 2004 study found that good teachers 'amend the curriculum, responding to learners' needs.'

Roberts et al. (2004), Windsor and Healey (2005), and Spiegel and Sunderland (2006) all point out that an emphasis on individualised teaching and learning may not support the needs of adult ESOL students. They report that recognising the differentiated needs of learners does not imply that these needs are best met through individualised learning: this perspective also problematises the widespread use in the UK of individual learning plans (ILPs) for ESOL learners. On the other hand, Roberts et al. (2004) also argue that 'Learners are often more resourceful and knowing than either the teacher or the task allows for, and tasks are too narrow for learners' resources', which suggests they observed deficiencies in planning of a different kind. 
Wilcox and Zielinski (1997) focus on the varied effectiveness of classroom tasks in helping the teacher assess the learners' understanding of mathematical concepts. They argue that getting students to complete imitative exercises requiring them to duplicate technical procedures may only yield scant information about their mathematical understanding. In a different type of geometry problem, students applied a range of different strategies to a real-life situation. The strategies adopted in trying to structure the problem provided direct insight into the understandings of the different students, and therefore supported the teacher in future planning as well as the learning of the student. They emphasise the importance for learning and for planning, of getting students to explain their reasoning, and to justify their procedures and persuade others of the reasonableness of their solutions.

Finally in this section, standardised assessment tools primarily designed for the purposes of accountability may also provide useful information to support teachers in planning and differentiation: Kruidenier (2002) argues that comparative research studies are needed into the relative effectiveness of the various different standardised assessment tools at present widely used in the US, for this purpose.

\section{Summary}

In this section, various ways in which planning and differentiation can be served by classroom assessment activities are surveyed. Some emphasise various types of information useful for lesson and course planning that can be obtained, others the scope assessment activities can provide for enabling learners to contribute to planning. It is suggested that getting students to complete simple imitative exercises may yield less useful information about the state of their knowledge and understanding than more complex, openended, and collaborative activities. Notwithstanding this, standardised assessment tools can also provide information useful for planning.

\section{Improving motivation and confidence, autonomy, and citizenship}

These themes are routinely linked, with varying emphases, by many reports on the beneficial effects of formative assessment activities in adult education. Typical of the majority of studies is Hostler (1986), who asserts that we conceive adults as autonomous and self-directing, with a consequent right to participate in decisions which affect them: learning which recognises this also builds students' own confidence to participate, thus developing autonomy in a virtuous circle.

This philosophical argument is supported by a range of studies, including Barton et al. (2004, 2005, 2006), Belfiore and Folinsbee (2004), 
Benn (1997b), Condelli (2002), Fordham et al. (1995), Freire (1972), Jansen and Van der Veen (1996), Lindsay and Gawn (2005), Swain et al. (2005), and NRDC (2005). Ward and Edwards (2002), whose research on learners' perceptions of progress in literacy and numeracy learning found that learners related their progress to their ability to perform in real life contexts. Their confidence and skills to participate in learning processes developed as learning progressed, and this was more closely associated with the style of interactions between individual learners, the teacher and other students, combined with a sense of being better able to cope with real-life tasks, rather than with the acquisition of qualifications. Swain et al.'s study (2006) of adult numeracy classes, referred to in more detail earlier, found a direct link between the kinds of questioning teachers use to check learning, and improved learner motivation, verifying the findings of Black et al. (2003) for the school sector.

In an earlier paper, Swain (2005) reports on a study investigating the ways in which numeracy learning has the potential to transform adult students' identities, which is linked conceptually to the notion of 'learning careers' (Ecclestone and Pryor, 2003). The study found that $75 \%$ of the 35 students in the sample reported that they had changed in some way as a person through learning maths. The changes took different forms, the most common being increased self-confidence, and perceptions of greater independence and autonomy. These effects were linked in the study to participatory learning processes, the use of real-world contexts and materials. Some students were found to have developed pride and confidence associated with their numeracy studies, for many see mathematics as a signifier of intelligence. It is suggested that these changes are closely connected and shaped for individual students by their motivation, discussed in more detail below.

Clarke (1991), reporting on a small-scale qualitative research study investigating how students in $\mathrm{ABE}$ provision perceive the notion of autonomy in relation to their learning, argues that 'If independence is one of our aims, a learner-centred approach must be about a lot more than asking a learner what, and how s/he he wants to learn.' She then quotes Good et al. (1981), who remind us that the capacity to be an independent learner is a development issue distinct from and additional to subject learning:

'The student needs to learn how to learn. This often implies changes in attitudes as well as techniques, and such changes can only be fostered over time, through debate, discussion, reassurance' (Good et al., 1981).

Clarke notes that students may need support in coming to terms with a new 'educated' identity, and doubts whether highly-structured, competency- 
based approaches to literacy and numeracy learning allow for the time required for such formative processes. In her study, $80 \%$ of the students in the sample identified reducing their dependence on others to perform practical tasks as an important motivator for their attendance at programmes. There was little evidence to support Carl Rogers' view (1977) that the 'habit' of dependency was obstructing their application of their learning. The research also found little evidence of resistance to person-centred learning, except that the students tended to describe the teacher as an expert rather than as a facilitator. The students unequivocally aspired to a greater degree of autonomy in their lives, but this didn't necessarily imply that they wanted to be wholly independent learners. They valued interactions and support both from the teacher and from other learners.

Whitty (1993) highlights the complex and sometimes contradictory role played by qualifications in relation to learner motivation: reporting on a small-scale survey of attitudes to certification among adult literacy students, she found that for $80 \%$ of the learners in the sample certificates were important to them, but that all of them said that certification was not the only reason for studying - gaining independence and confidence in communications skills was seen as more important than certification by $80 \%$, though many saw the certificate as helping with confidence.

The quest to find ways of measuring outcomes for uncertificated adult education programmes, and the fact that learners often cite increased confidence' as a key motivating factor, led to a research project into the nature and importance of confidence for effective learning (Eldred $\boldsymbol{e t}$ al., 2005), which worked with 350 learners in 41 groups in 8 different adult community learning organisations. The project developed and piloted a diagnostic tool intended to encourage reflection among learners about the nature of confidence, as well as providing a means of recording changes in confidence over time. A series of guidelines for teachers were developed, most of which highlight the importance of sharing information and feelings between learners through discussion, and through using purposeful dialogue so as to involve learners in planning and evaluating their learning.

The points made by Clarke, Whitty and Eldred et al., and the findings of their studies highlight the interrelatedness of learners' confidence, motivation and self-esteem, and the consequent complexity of the task of the teacher, particularly when their learners have not had positive previous experiences of education. Derrick (2004), writing about the links between assessment and achievement in literacy, language and numeracy learning, points to evidence from a range of research studies that formative assessment approaches are essential if the real complexity and interrelationship of these issues is to be addressed: 
'These studies have found that effective formative assessment contributes to the development of self-esteem and willingness to take on educational challenges among learners: this chimes with the experience of adult literacy, numeracy and language teachers, that the more learners can consciously link their classroom activities with everyday literacy, numeracy and language practices, the more effective their learning is. In this view, formative assessment can help learners develop consciousness, reflectiveness and articulacy about their learning and their everyday practice, not just to improve those practices, but as part of developing their capacity to learn in general' (Derrick, 2004).

Derrick agrees with Clarke about factors in the framework within which teachers are working which inhibit their ability to work in this way, mentioning the heavy political and bureaucratic emphasis on summative assessment and measurable outcomes, the tendency for adult learners to enrol for multiple short programmes (in each of which bureaucratic and time-consuming assessment processes have to be repeated), and the evidence that tests used exclusively as summative assessment tools, can demotivate learners, particularly those who most need to be motivated and encouraged (Derrick, 2004).

Kruidenier (2002), in a paper which surveys the most widely-used assessment tools in the USA, notes that motivation is a key issue for literacy learning, and that none of the assessment tools discussed seeks to assess it. He suggests that this is one indication that the primary focus of assessment in the US is on skills performance measurement rather than on 'assessment for instruction'.

Beder (2005), researching the factors that affect the 'engagement' of adult basic education learners (defined as 'focussed effort on instructional tasks'), and seen as necessary but not sufficient for learning, found that how teachers interact with learners is a key factor in engagement.

Roberts et al. (2005) argue that a key motivational factor for learners can be the possibility of a 'new professional identity' offered by a vocational training programme acting as an entry point to a new 'community of practice'. This new professional identity is often in contrast to their former experience as 'school pupils', and can enable them to overcome their antipathy to the process of trying to improve their literacy or numeracy skills, by helping them see them in context as an element of the new community of practice.

The most detailed treatment of these issues is provided by Ecclestone (2002). She proposes a framework for theorising autonomy, motivation and formative assessment, drawing on a wide range of research studies from 
different psychological traditions, and in particular Prenzel et al. (2000) on types of motivation, and Carr and Kemmis (1986) on autonomy. Six types of motivation are posited by Prenzel and his colleagues: amotivated (lacking any direction for motivation, from indifference to apathy); external motivation (learning takes place only in association with reinforcement, reward, or to avoid threat or punishment); introjected motivation (learning happens when learners internalise an external supportive structure, but this is not self-determined); identified motivation (learning occurs not due to any specific incentive, but because it is recognised as important in attaining a goal the learner has set); intrinsic motivation (learning results from the perception that the incentives to be gained are intrinsic to the content or activity); and finally interested motivation (learning recognises intrinsic value, but also takes place 'in accordance with subjective and meaningful attributes assigned to the object or object-specific skill') (Prenzel et al., 2000). She links this typology with three types of autonomy: procedural (involving the ability to effectively handle externally-originated systems of control, such as qualification frameworks, assessment criteria, etc); personal or practical autonomy (based on knowledge of one's strengths and weaknesses, learning habits and potential choices for action and progression); and critical autonomy (for many the ultimate goal of education according to Ecclestone, because it links notions of democratic citizenship with the exercise of critical intelligence by individuals.)

These two spectra of theoretical constructs are finally linked by Ecclestone with a range of formative assessment activities, and the whole framework applied to a series of studies of different GNVQ groups. Her book concludes by examining the extent to which policy and practice in post-16 vocational education have created 'assessment regimes' rather than mere assessment models and in turn, 'assessment careers' which play a key role in the motivation and learning of post-16 learners over time. It looks at ways of improving formative assessment practices in colleges and offers recommendations for the design, assessment and implementation of assessment regimes, and finally discusses the implications of these findings for lifelong learning.

Five studies relate formative assessment practices, directly or indirectly, to the wider political debate about citizenship. Alexander (2004), talking about dialogic teaching and assessment for learning in schools (though he is clear that his discussion is applicable also to lifelong learners) argues that:

'The interactive skills which children begin to develop through effective dialogic teaching - listening attentively and responsively to others, framing and asking questions, presenting and evaluating ideas, arguing and justifying points of view - are also among the core skills of citizenship.... mastery of the... language, and the 
ability to express one's ideas, question the ideas of others, and hold one's own in conversation and argument are unambiguously conditions both of the educated person and the active and responsible citizen '(Alexander, 2004, pp. 31-32).

The arguments already cited from McNair (1996), and Jansen and Van der Veen (1996) about the skills and capabilities needed by autonomous individuals faced with the uncertainties of 'risk society' are also clearly relevant to recent debates about citizenship, social responsibility and civic participation. Merrifield (1998) focuses on the potential of adult literacy programmes for supporting these skills and aptitudes through approaches to accountability that emphasise local mutuality and reciprocal negotiation about value, rather than reliance on impersonal and technocratic systems that accept abstract numerical indicators as sufficient measures of accountability. She argues that improved participation and citizenship will be one of the results of an accountability system based on the principle of mutuality: one that is negotiated between the stakeholders; that matches responsibilities with rights; and one in which every player knows what is expected of them and has the capacity to be accountable (Merrifield, 1998).

Finally in this section, Ecclestone (2004b) challenges commentators who seem to generalise about the 'vulnerability' of learners and prioritise warnings about damaging their 'self-esteem' over the need to challenge them with new knowledge and activities. She argues that an unhealthy preoccupation with the emotional well-being of the student gets in the way of learning, with stultifying consequences for the learner and teacher alike, creating 'a new sensibility that resonates with broader cultural pessimism about people's fragility and vulnerability'. Ecclestone is far from recommending 'an uncaring view of some people's lack of confidence or vulnerability'. Her challenge is to the facile notion, which she sees as sharply at odds with the resilience so powerfully advocated by Freire, that esteem should be conferred upon a passive learner by an education system more or less exclusively preoccupied with issues of identity and emotional well-being.

\section{Summary}

Most studies assume a close link, at least implicitly, between learner motivation, confidence and autonomy, and benefits in terms of citizenship, through the social and philosophical idea of adulthood prevailing in western societies. This section suggests that formative classroom assessment activities can provide a vehicle for gains simultaneously in motivation and autonomy, and gives examples from the literature. Qualifications can play a contradictory role in this process, in providing certification of success along 
the way, but by also tending to divert attention from learning 'for the future' and broader and more sustainable learning. A key discussion is about the scope for changes in learners' identities embedded in this process. Attention is drawn to a typology of motivation which can be used to provide a framework for theorising autonomy, motivation and formative assessment. Finally improved benefits for citizenship are linked with systems in which educational accountability is a process in which learners participate as part of their learning.

\section{Using different types of assessment formatively}

'Assessment efforts should not be concerned about valuing what can be measured, but, instead, measuring that which is valued.' Banta et al., 1996, quoted in Spiegel and Sunderland (2006)
'Most learners did not want to take any exams and the overwhelming preference was for ongoing assessment.... some form of assessment to measure and recognise learning gain was valued but most learners preferred this to be an ongoing process based on discussion and portfolio building supported by tutor feedback and individual reflection....people said they did not want to be exposed to the stress and pressure of tests and exams' (Ward and Edwards, 2002).

None of the writers surveyed in this review argue that adult learning should not involve assessment of some kind. Most of them differentiate between formative and summative assessment, though they may not use these terms. What varies is how they understand this difference. Kruidenier (2002) distinguishes clearly between 'assessment for accountability' and 'assessment for instruction', and notes that while vast amounts of research and development has been focussed on the development of standardised assessment tools for the purpose of accountability, there has been virtually none on assessment for instruction.' Ward and Edwards distinguish between 'ongoing assessment' and 'exams', in terms of when the assessment takes place; they also note that learners prefer assessment 'based on discussion and portfolio building supported by tutor feedback and individual reflection' to 'tests and exams', differentiating in terms of procedures. Hillier (2002) makes the same distinction about timing:

'Formative assessment occurs when you assess learning throughout a programme of learning. Summative assessment occurs at the end of a programme of learning, or a module of learning. Formative assessment helps you and your learners find out how much progress they have made during the course of a learning programme. 
Clearly, the longer the programme, the more use can be made of formative assessment' (Hillier, 2002).

Distinguishing between formative and summative assessment on this basis clearly implies a perspective that is primarily technical - activities that take place at different stages in the learning programme. Hillier also makes a distinction between informal and formal assessment: 'informal assessment may take place throughout a programme of learning which also uses formal assessment methods' (Hillier, 2002). She notes that not all adult learning programmes require formal summative assessment, and cites the example of a course preparing parents for childbirth. For Hillier, 'formal' assessment always contributes to the identification of achieved outcomes as specified by the programme, whereas 'informal' assessment does not necessarily do this: she provides a useful chart illustrating these differences:

\section{Types of assessment}

\begin{tabular}{|l|l|l|}
\hline & Formative & Summative \\
\hline Informal & $\begin{array}{l}\text { Where are we so far? What do we want } \\
\text { to do next? }\end{array}$ & What did we learn? \\
& $\begin{array}{l}\text { Example: a fitness class for people with } \\
\text { arthritis }\end{array}$ & $\begin{array}{l}\text { Example: an introduction to art } \\
\text { history class }\end{array}$ \\
\hline Formal & $\begin{array}{l}\text { How much of the assessment } \\
\text { specification/learning outcomes have we } \\
\text { achieved? } \\
\text { Example: an NVQ portfolio development } \\
\text { workshop }\end{array}$ & $\begin{array}{l}\text { Did we achieve all the learning } \\
\text { outcomes? What grade/level have } \\
\text { we attained? }\end{array}$ \\
\hline
\end{tabular}

Source: Hillier, 2002, p. 196.

Hillier also provides detailed discussions of a wide range of assessment methods, including tests, examinations, assignments/essays, projects, multiple choice, oral examination, discussion, role play, simulation, case study, presentations, demonstrations, skills tests, lab tests/demonstrations, investigation/research, portfolios of evidence. She argues that these fall into two categories, those that measure performance and those that measure knowledge and understanding, and this constitutes a third way of distinguishing between types of assessment, by looking at its purpose. She argues that the type of assessment used in any situation should be 'fit for purpose': as the chart above suggests, the most important factor in deciding which kind of assessment to use seems to be whether the programme of learning has an externally-set raft of learning outcomes, such as an NVQ or an A level, or not, such as a childbirth preparation class. 
Hillier's chapter constitutes a comprehensive introduction to a wide range of assessment methods that are suited to different purposes. Implicit in her treatment, however, is the view that there are no inherent tensions in this range of activity: whatever the situation, the right approach to assessment, and the right methodology, is available and relatively straightforward.

Common in the more recent literature, on the other hand, is the view that the relationship between formative and summative assessment is in tension, or even in conflict. In this view, classroom assessment is problematic rather than straightforward, especially in the powerful regulatory contexts in which adult learning has usually been situated since the early $90 \mathrm{~s}$.

Brown (1994), as we have already seen, while agreeing with Hillier that any type of assessment tool can be useful for either summative or formative assessment (he provides examples of interactive language tests for use with ESOL learners), nevertheless emphasises strongly the importance for teachers of distinguishing between assessment for learning and assessment of learning, which he describes respectively as 'informal' and 'formal' assessment. Kruidenier, too, believes that it is important to distinguish clearly between 'assessment for performance measurement and assessment that aims to enhance learning' (Kruidenier, 2002).

Ecclestone (2004a) also disagrees with Hillier in this respect. She argues that formative and summative assessment must be distinguished conceptually so as to avoid confusion in practice. She introduces the idea that different procedures and forms of summative assessment have different effects on both teaching and learning practices in the classroom, and on our understanding of the role and nature of assessment. She points out that the transition from formative to summative assessment is increasingly blurred, particularly in programmes where summative results accumulate from coursework and assignments. This leads to the widespread belief that formative assessment is synonymous with 'continuous assessment' or courses without end examinations. She suggests that formative assessment is either too narrowly conceptualised as feedback on students' work, or targetsetting in relation to summative criteria, or on the other hand too broadly conceptualised as pedagogy to encourage reflection amongst learners about their learning. To counter these misconceptions, she offers a list of researchbased principles for assessment designed with diagnosis and formative feedback in mind:

- Diagnostic assessment should focus on a person's potential, not on fixed traits.

- Learners need their own diagnostic skills to become independent and able to judge their own work. 
- Learners need to know how to 'internalise the criteria', by knowing how to distinguish between high-quality and poor work.

- The notion of 'closing the gap' (Sadler 1989) between where the learners are and the quality of work they are aiming for is crucial to internalising the criteria.

- Information gained by teachers from formative diagnosis does not become feedback until it makes a difference to learners' performances.

- Learners have to engage proactively with feedback in order to understand what it means to get better.

- Feedback is neither diagnostic nor formative unless learners can act on it, without action, feedback remains a summative statement of achievement or weakness (Ecclestone, 2004a).

Ecclestone's work, characterised by a 'realist' position on the need to make firm distinctions between formative and summative assessment practices, is based on a very detailed picture of the interrelationship between pedagogy, organisational imperatives, and the requirements of political and bureaucratic systems demanding more or less information for accountability and performance measurement. She challenges teachers to strive to maintain the highest levels of pedagogical creativity in spite of widespread technical and professional barriers and misunderstandings she identifies as:

- Written and oral feedback to learners which they don't understand.

- Too much feedback, covering such a wide range of points that learners lose heart.

- Feedback that merely confirms learners in their existing sense of themselves as learners, so that they see no need to act upon it.

- What meeting the standards really means in detail is understood by teachers tacitly and informally, rather than made visible, collectively discussed and reviewed continually.

- $\quad$ The pressures of achievement targets can render formative feedback as little more than instrumental advice on how to 'pass the test'.

- Many teachers' unwillingness to take part in development activities.

- Learners often see formative advice as summative confirmation of shortcomings or achievement. 
- Learners' attitudes towards and confidence in classroom questioning activities is highly differentiated depending on their past experience and their ideas about their ability.

- Learners may respond differently to feedback at the beginning of a learning programme and at the end.

- Learners may not see self- or peer-assessment as legitimate if they see assessment as part of the teacher's job (Ecclestone, 2004a).

Other commentators take a range of positions on this issue. Among these are Derrick (2004), who makes the case for more attention to be paid to formative assessment in both policy and practice, and for changes to be made to the 'high stakes' achievement context in order to remove discouragement from teachers in carrying out effective formative assessment activities as part of teaching and learning. McGivney (1996) does not distinguish explicitly between formative and summative assessment in her study of adult student 'drop-out', though she does find that students favoured what she calls 'continuous assessment' as opposed to 'end of year examinations', which were seen as threatening and judgemental. Rogers (2002) argues that formative and summative assessment are not distinct processes in principle: what matters is what assessment is used for, though this view may unduly reflect the situation as it was earlier, when most adult education was not subjected to formal summative assessment.

Fordham et al. (1995) also take the view that if assessment is learnercentred, then summative and formative assessment are equally important and useful. They argue that 'if we are concerned only with measuring progress, we tend to look only for evidence that can be quantified, such as statistics, grades and percentages. If learning is assessed in both qualitative and quantitative ways, the information produced is more complete and more useful.' This does not exclude formal testing methods, so long as learners are treated as adults. They maintain that assessment should be discussed with learners themselves, and that this process will materially contribute to their learning. They suggest that progress profiles enable learners and teachers to record aims and measure progress against them in a constructive, direct way and argue that learners themselves should decide how their progress should be measured.

Boud (2000) is also critical of the dominance of summative assessment, but for slightly different reasons. His view is that the key function of all assessment, whether formative or summative should be to build learner capacity for the future. The purposes of assessment should be extended to include the preparation of students for what he calls 'sustainable assessment'. This encompasses the abilities required for assessment 
activities that accompany learning throughout life in formal and informal settings. Boud therefore argues that all assessment activities should simultaneously support the present learning programme as well as increasing learners' understanding of assessment processes and their abilities to engage in future self-assessment. A key feature of assessment procedures and systems is the extent to which they are 'future-oriented' and therefore contribute to 'sustainable assessment' practices.

Brown (1994) writing about language learning, argues that assessment should at all times aim to develop and maintain the intrinsic motivation of the learner, and gives examples of 'intrinsically motivating language tests which involve co-operative group assessment using authentic tasks'. He subscribes to the view that any assessment technique can in principle be used for either summative or formative purposes. He argues that it is very important for teachers to make the distinction between teaching (which involves continuous 'informal' assessment which is formative) and formal testing (summative assessment), because of the importance of intrinsic motivation: 'For optimal learning to take place, students must have the freedom in the classroom to experiment, to try things out, to 'test' their own hypotheses about language without feeling that their overall competence is being 'judged' in terms of these trials and errors.' He likens summative assessment to tournament games, or concert recitals, as opposed to daily practice and learning through 'play'. In an evaluative survey of assessment systems being used in adult literacy in the USA, Kruidenier, like Brown, emphasises the importance of motivation to learning, and points out that none of the most widely-used summative assessment tools aim to assess motivation. He concludes by arguing that assessment should not be used solely to satisfy requirements for accountability but should be fully integrated into instruction (Kruidenier, 2002).

Finally in this section, Beveridge (1999) suggests that external summative assessment (especially criterion-referenced assessment) requires education to be accountable to learners and can help demystify assessment for students who have been labelled failures in the past. She argues that the apparent contradiction between the instrumental objectives of competence and the liberal values of discussion and critical enquiry may be more imagined than real. Funding regimes increasingly demand the former, but the critical and creative autonomy of the educator can also promote the latter.

\section{Summary}

This section highlights the widely varying positions commentators take on the relationship between formative and summative assessment. Most 
argue that in highly-regulated contexts it is important that teachers have a sophisticated understanding of both concepts, in order to optimise sustainable, rather than short-term and instrumental learning. A variety of classroom formative assessment activities are presented, as well as a list of problematic situations and barriers to learning that teachers should try to avoid.

\section{Practising assessment: learning for the future}

A number of commentators identify a key element of formative assessment as the process in which learners practice their newly-acquired skills, and co-operate in evaluation of each other's performance. This may take place in the classroom (for example, ESOL students taking part in a conversation of mutual interest, and afterwards discussing and evaluating each other's use of vocabulary idiom, slang, pitch, etc), or outside. It is this process which links classroom learning with the application of learning in real life contexts (see for example Barton $\boldsymbol{e t}$ al., 2004, 2005, and 2006, Ivanic et al., 2005, 2006, Roberts et al., 2004, 2005). Morton et al. (2006) in their study of research on teacher education programmes, argue that teachers 'should avoid assuming that knowledge is first 'learned' in one context before being used in another'. For Absolum (2006), this is a highly practical issue: 'Students need to be skilled assessors of their own learning and that of their peers', and so need practice in assessing their own skills and that of others.' This type of classroom practice, rather than taking time away from learning, enhances it (Absolum, 2006, Alexander, 2004, Baxter et al., 2006, Breen, 2001b, Brown, 1994, Ivanic and Tseng, 2005, Morton et al., 2006, Moss, 1996, Roberts et al., 2005, Tout and Schmidtt, 2002, Marr, 2000). From the perspective of Reder's 'practice engagement theory', learning activities aim to be extensions and developments of existing literacy practices in which learners participate outside the context of formal instruction. A key dimension of these 'real world' practices is the simultaneous mutual evaluation of their efficacy by participants. Practice engagement theory argues that this evaluative dimension is another, closely linked literacy practice, and therefore needs to be incorporated into formal instruction. In particular:

'By striving to integrate social meanings with patterns of social interaction, practice engagement theory provides a conceptual framework that can be particularly useful in addressing the development and expression of literacy in multicultural contexts and societies..... by emphasising the patterns of individuals' access to and participation in various roles within specific literacy practices, engagement theory seeks to account for the rich variety and 
patterning of literacy within as well as across cultural groups' (Reder, 1994).

He concludes by warning that 'conflicts between the students' school, home, and community environments can have devastating consequences. At the same time, it is possible for well-designed....literacy programmes not only to avoid attaching negative social meanings to literacy but actually to endow literacy with positive social meanings.' Reder's work is a powerful call, not just for sensitivity to the background of students, but for teachers and programmes to seek to understand the ways in which their students engage with literacy practices already, and to build their tuition and plan their classroom activities around these practices rather than around a preordained 'standardised' curriculum (Reder, 1994).

Purcell-Gates et al. (2004) take up a similar perspective, in a report on research into effective adult literacy provision which demonstrates the value of using 'authentic' texts in learning situations, rather than what they call 'school-only' texts and tasks, activities for learning which have no real-life application or purpose. The research demonstrates clearly that the notion of authenticity in this context varies for each learner, depending on the specific experiences of using texts and literacy practices that he or she brings to the learning situation, and thus supports the importance of a pedagogy in which formative assessment practices based on dialogue and engagement between the teacher and learners, are central. However, the book's main objective is to compare and evaluate the 'cognitive' and 'social practices' positions of literacy learning, which it sees as unproductively polarised in theoretical debates. In this context, if formative assessment approaches to teaching and learning are agreed to have such features in general as dialogue between teachers and learners, student agency in learning, and constructive, real-life tasks followed by feedback and self- and peer-assessment, then this approach may have the potential to provide a pedagogical bridge between psychological and ethnographical perspectives on learning.

Formative assessment as learning for the future is given a number of different emphases by the writers in this survey. For some it is highly specific and practical, such as the need for feedback or marking to be constructive and task-focussed, so that learners immediately receive practical guidance on how to improve their skills or performance: literally, what they might do next. Gardener (1985), Brookfield (1990), Hillier (2002), McGivney (1996), and Rogers (2001) fall into this category. For another group the particular focus is the way formative assessment processes can give information to the teacher for planning future learning: Ivanic (1988, 1996), Mace (1979), Moss (1995), and Rogers (2002) in particular form this category. A third group focuses on strategies for raising the learner's capacity to learn in general, perhaps through developing self- 
assessment, listening, or discussion skills. In this group we find in particular Alexander (2004), Boud (2000, 2002), Brookfield (1990), Clarke (1991), Claxton (1995), Fordham et al. (1995), Good and Holmes (1982), Hostler (1986), Klenowski (1995), Knowles (1983), Rogers (1993), and Ward and Edwards (2002). The foci of each of these three groups of references have been covered already. Finally, there is a fourth group who value formative assessment approaches in teaching and learning because they are connected in a much broader way to developments at the level of society in general, and therefore in some sense are addressing their comments to present and future policymakers, rather than specifically to teachers and learners. Among these are Alexander (2004), Boud (2000, 2002), Derrick (2004), Ecclestone (2002, 2004b), Groves (2002), Jansen and Van der Veen (1996), McNair (1996), Merrifield (1998), Skager (1978), and Torrance et al. (2005). Most of these writers have been covered in detail earlier in the review, but one aspect of Boud's work has not. He asserts that sustainable assessment:

'encompasses the abilities required to undertake activities that necessarily accompany learning throughout life in formal and informal settings....Formative assessment [needs] to meet the specific and immediate goals of a course as well as establishing a basis for students to undertake their own assessment activities in the future' (Boud, 2000)

He describes this process as 'double duty'. The orientation of this model is learning for the future, and posits a world in which knowledge is dynamic and changing, uncertainty and risk are normal conditions of life for everyone, and in which learning is integrated into all aspects of living. In this model, the teacher initiates a process through which the learner or learners develop expertise in assessment of their own learning and of the world around them. The learning process is seen not as something with a beginning and an end, but something ongoing, as continual preparation for dealing with new challenges and new situations, and in which assessment skills and activities are inseparable from planning, decision-making and organisation in general. Boud's position is that models of assessment that are too narrowly focussed or which are dominated by short-term learning objectives or by objectives unrelated to learning, such as accountability, are wasteful in broad social terms as well as unproductive and possibly misleading for learners.

\section{Summary}

This focus of this section is on learning for purposes beyond the immediate course or qualification aim, for situations perhaps as yet 
unknown. This encompasses the idea that learning is for real-life application as well as for passing exams; it follows that learners need to practise evaluating their skills and knowledge in practice, and that this is a legitimate and valuable classroom activity. Practical benefits of this perspective include helping students and teachers decide what to do next, developing people's understanding of 'learning to learn', and identifying barriers to learning or system improvements that might be the focus of future policy. It is further suggested that this aspect of formative assessment might be seen as a bridge between cognitive and socio-cultural perspectives on learning. Finally, formative assessment is shown to serve both present (known) and future (uncertain) learning objectives, a process described as 'double duty'.

\section{Conclusions and messages for teachers}

\section{Formative assessment and learners of adult literacy, numeracy and language}

Of the 99 texts surveyed in this review, 55 focus specifically on adult learning in either literacy, numeracy, language programmes, or on programmes that combine these subjects. The degree of compatibility between the two sets of texts is striking, and this suggests that the issues addressed in this review are primarily issues of pedagogy, and applicable in general terms to all subjects, levels and contexts of study. One idea that appears regularly throughout all parts of this literature, explicitly in the various Black Box publications, and also in a systematic study of the effects of assessment systems on learning (Harlen and Deakin Crick, 2002, is that the deleterious effects of summative assessment processes on deeper learning and learner motivation are more pronounced in relation to learners at lower levels of attainment. It is therefore probable that for many learners of literacy, numeracy or language, there is evidence for two propositions:

- Any damaging effects of summative assessment processes that can be shown to exist are likely to be more potent for these learners.

- Any benefits of formative assessment approaches are likely to be more pronounced in relation to these learners.

It has been suggested that there may be a further aspect of this particular observation, in relation to numeracy students: an international group of teachers of adult numeracy discussing this question felt that in the context of mathematics learning these effects might be even more strongly felt, as it is commonly (if mistakenly) held that mathematics is about eternal truths and can only be taught through a transmission approach in which learners are 
more likely to be treated by teachers as passive recipients of knowledge (Notes from a workshop discussion at Adults Learning Mathematics International Conference, Belfast, June 2006).

One group of commentators problematises the otherwise universally held view that involvement of learners in planning, monitoring and assessment of their learning is a good thing. They identify two issues with respect to ESOL learners in this context: the possibility that their language level would prevent them from sufficiently comprehending the concepts needed to participate in formative assessment activities; and cultural barriers to accepting the role of self-assessor in relation to their own learning, even with the support of the teacher. None of these commentators argue that the perspective of student involvement is mistaken in this context, rather, that teachers need to handle these activities with sensitivity and care.

Apart from this, nothing found in any of the texts surveyed suggests that there is any inconsistency with pedagogical implications between the needs of literacy, numeracy and language learners and those of other adult learners. Rather, there is a strong suggestion that formative assessment perspectives and practices might be even more strongly appropriate for these learners, both in terms of the benefits of using them, and the costs of not using them. Nevertheless, the tension between instrumental or sustainable formative assessment is as crucial for these learners as for others.

\section{Messages for teachers}

We will now summarise the main messages for teachers which emerge from the texts surveyed and the discussions in the last chapter. There was widespread congruence among the texts about the general range of approaches recommended and about the issues teachers need to understand and address. However, few of these texts are based on systematic research. The majority are either based on small-scale studies, usually qualitative, or are handbooks or other training materials designed to support teachers' professional development, or are 'arguments to policy'.

The majority of these texts make judgements and recommendations from the perspective of experienced practitioners. These guidelines therefore represent primarily a distillation of practitioner wisdom and experience rather than the results of systematic research: such research remains to be done. The degree of congruence across a wide range of studies, however, is an encouraging indication of the value and validity of their conclusions.

All these guidelines, potentially, can help teachers develop and improve formative assessment practices, on the assumption that this will not only improve student achievement and attainment, but also the capacity of 
students to learn effectively in the longer term, by developing their autonomy and motivation. However, there are a number of significant tensions and areas that need further insights and analysis if we are to help teachers and students develop effective formative assessment skills.

\section{Two aspects of formative assessment in the context of adult learning}

The review suggests that there are broadly two distinct aspects of formative assessment in teaching and learning. The first of these consists of practices and activities in which the purpose is to produce evidence for the planning of future learning and/or for constructive feedback and review: these might include activities such as assignments, tests, role-play, performances, observations, questioning, etc. It is important to note that these activities can also be used primarily for purposes that are not essentially formative or to support learning, for example to fulfil bureaucratic requirements or to serve the purposes of summative assessment. Secondly, formative assessment can take the form of learning activities which aim to develop the autonomy of the learner(s) by giving them practice in the use of relevant skills and knowledge in real-life contexts, and particularly in the assessment and evaluation of their performance and those of others, in those contexts.

In the first of these roles, formative assessment is the main means by which teachers find out and continue revising what needs to be taught and how best to teach it, given the different and developing profiles and personalities of their learners. This kind of assessment starts at the beginning of learning programmes, or even before this, and should be continuous throughout learning, so that the teacher can constantly update her/his information about what has been learned and the developing understanding and motivation of the learner, and adjust the teaching plan accordingly, both on a moment by moment basis, and from lesson to lesson. This type of assessment aims to improve the process of teaching and learning, by continually increasing the accuracy of its focus, as the learners' skills, knowledge and motivation develop. It is interested not just in what happens within the course, but in events and episodes in the learners' lives outside the course and the influence they may have on learning. The key activity of this type of assessment is dialogue between the learner and teacher, and the teacher's role is to enable, stimulate and develop this dialogue through such means as constructive and open-ended questioning, and through generating thinking and reflection about learning.

The second type of assessment activity distinguished here adds a critical dimension to learning itself, as something which, when practised by learners themselves, adds to the acquisition of knowledge and skills the development 
and exercise of judgement: judgement of performance, appropriateness, accuracy, and authenticity. It is through these activities that learners practice and develop their capacity to make critical, aesthetic and practical judgements of the quality and effectiveness of their newly-learned skills and knowledge. If they are not encouraged to develop these skills as part of their learning, what they learn will be de-contextualised and more difficult to transfer between different situations outside the classroom. Learners will be less able to differentiate between the appropriate use of skills and application of knowledge in different settings, and particularly in new or unfamiliar situations. The focus of this type of assessment is on fluency and successful performance, the evaluation of which may in part be a matter of personal judgement or opinion. This fluency can only be developed through practice, and learners need to be provided with relevant conceptual tools, as well as practical collaborative experience of making, exchanging and discussing judgements of the quality of their own and others' work. This type of assessment activity involves learners talking together and with their teacher about practice in different contexts, and about learning, assessment, and success criteria, developing the ability to reflect on and evaluate their own and others' practices. This type of assessment aims to help the learner to improve their own learning: its focus is on autonomy, on successful performance outside formal educational contexts.

\section{Clear understanding of the difference between formative and summative assessment}

Teachers need as clear an understanding as possible about these concepts and practices, in order to plan and organise learning effectively.

\section{Dialogue between teachers and learners}

Teachers should structure learning as far as possible as dialogue between themselves and their students, and between students. This is most effective if it is open-ended and exploratory rather than a series of routine exchanges, and encourages students to see themselves and their peers as architects and engineers of their own learning. The subjects of this dialogue are how people learn, remember, approach problems, and evaluate their learning, as well as appropriate subject knowledge and formal assessment criteria. Some researchers have found that identifying and discussing conflicting theories, viewpoints and approaches to problems within groups, can be highly effective in improving understanding that goes beyond merely getting the 'correct' answer, as well as increasing motivation and engagement. 


\section{Communication skills}

Teachers need continually to be evaluating, maintaining and extending their communication skills, with a particular focus on listening for empathy and understanding, and on questioning and feedback to develop learning, as well as on exposition, explanation and transmission of information. Communicative practices that work with one group may not work so well with another. The most effective teachers continually exemplify and model communicative practices that promote and develop learning and motivation, through their own behaviour.

\section{Feedback and marking}

Feedback, whether verbal or written, should focus on the task rather than the person, be constructive and practical, and be returned as soon as possible. The purpose of drawing attention both to excellence and to problems is to develop the learner's own understanding of quality and ability to distinguish it, whatever the subject and context. Giving grades or marks can demotivate students, especially those who are least confident, and particularly if the grades are made public and compared. Grades, marks, and evaluative remarks that do not provide information or advice about how to improve performance, should in general be avoided.

\section{Questioning and checking learning}

Teachers should foster both the spirit and procedures of a 'joint enquiry' through which learners can construct shared meanings from the necessarily different frames of reference which each of them brings to the common learning task. Teachers should develop a repertoire of questioning techniques, and share ideas with colleagues to maintain and develop this repertoire. Double questions, leading questions, rhetorical questions and closed questions (those looking for a unique correct answer) discourage learners from reflecting on the problem, or from revealing that they do not understand it. These kinds of questions can even foreclose learning and should be avoided. Much more useful are open questions that require students to find their own words. These might take the form of challenging (how/ why did you do that?), checking (do you know...?), uncovering thinking (can you explain this?), offering strategies (have you thought about....?), or re-assuring (are you happy with that?). Sometimes a 'devil's advocate' question (are you sure?) can be useful. In this way, teachers shift from being presenters of content to facilitators exploring ideas that the learners are involved with. Students can be encouraged to think and talk more by the right kind of questioning and listening, and this is likely to 
produce useful outcomes in terms of knowledge about the students' understanding and their pre-conceptions, as well as time for the teacher to think about responsive strategies, while they listen to their students.

\section{Summative assessment tools used formatively}

Even those commentators who see formative assessment as essentially in tension with summative assessment, nevertheless agree that summative assessment processes can be utilised to produce benefits for formative purposes. In general, this involves finding ways to get students to 'get beneath' and 'go beyond' the bald results of the summative assessment processes and try to understand how they work and reflect on what they mean. An effective way to do this is to get students to develop their own marking schemes and collectively to evaluate them, or to try in groups to construct their own assessment tasks, or 'perfect answers'. A key element of this is that it is a group activity, conducted through dialogue with peers as well as with the teacher.

\section{Planning and differentiation}

Teachers can use formative assessment activities to find out more about their learners' motivation and understanding, so as to inform planning and differentiation, both in the long term and immediately. If these activities are not used to inform planning, some commentators say that formative assessment is not taking place: certainly an opportunity is being missed.

\section{Developing an atmosphere and culture conducive to learning}

Formative assessment activities depend for their effectiveness on students being relaxed and feeling secure enough to face challenges and take risks in asking questions or advancing propositions that may reveal their lack of understanding. A key part of the teachers' role is to create an atmosphere in which students are willing to take these risks. The main way in which this atmosphere is developed is through the behaviour of the teachers themselves, in terms of the way they ask questions of and respond to students, the extent to which they set up peer discussions and group activities, and the way they give verbal and written feedback.

\section{Types of assessment}

There is widespread confusion and disagreement at the level of official specifications, practical guidelines and academic research about the meanings and purposes of formative and summative assessment, and the 
learning activities through which they are carried out. Teachers need to develop their understanding of both formative and summative assessment, so as to avoid the danger of formative assessment activities actually simply serving the purposes of accountability and certification rather than supporting deeper, sustainable learning.

\section{Peer assessment and self-assessment}

Developing the capacity for self-assessment and peer assessment through exercising these capacities as part of formal learning, is integrally related to the task of teaching of a curriculum, whether imposed or negotiated with learners. Self-assessment and peer-assessment should be central elements of all learning situations, and in particular, students should be encouraged critically to evaluate the decisions and assessments of the teacher. This may need to be introduced with particular awareness of possible cultural barriers to taking a more active and participatory role in learning.

\section{Learners understanding of assessment and the language of assessment}

The narrow aims of summative assessment can be served just as effectively when students are involved in the assessment process, understanding the processes and the criteria, using self-assessment, peerassessment, and so on. It is not student involvement per se that makes the difference, it is the nature and quality of that involvement. The language of assessment criteria may be intended to be neutral, accessible and unthreatening, but in its concern to be precise, it often becomes highly technical and inaccessible to learners in practice. Encouraging learners to develop, discuss and evaluate their own assessment criteria and assessment materials, as well as collectively designing 'perfect' answers, will at the same time help them understand and critique the language of official assessment criteria.

\section{Collaborative learning activities}

There is evidence that collaborative discussions, tasks and activities, organised around conceptual obstacles, including disagreement and debate, rather than predominantly individual and more or less silent working, can have benefits for many learners. The evidence suggests that such approaches are likely to be even more effective with learners who have not done well previously as a result of 'transmission-oriented' teaching they may have encountered before. 


\section{Improving motivation and confidence, autonomy, and citizenship}

Improving confidence in learning is a key aim of most adult students, who are generally highly-motivated to learn. 'Traditional' transmission modes of teaching in which students are seen as passive recipients of learning, are unlikely to be effective for many adult learners. More productive are approaches in which learners are active participants in the processes of learning, and particularly in the assessment of those processes. Focussing on assessment and assessment of learning as key elements of the process can help develop motivation, confidence and autonomy, which may produce further benefits in terms of citizenship.

\section{Learning to assess}

Teachers should at all times aim to balance the short-term demands of summative assessment with a view to addressing the needs of learners in the longer term. This implies focussing on the capacity of learners to plan, develop and evaluate their own learning and that of others. It requires going beyond the immediate demands of the subject, and looking at the way assessment systems work. Modelling this as part of learning, by getting students to develop their own marking schemes and assessment criteria, for example, is one way of achieving this.

\section{Tensions between the 'spirit' and 'letter' of formative assessment}

Different traditions, political pressures for targets and professional confusion and disagreement about the purposes of formative assessment are creating tensions between the spirit of formative assessment as a way of engaging learners deeply with their learning in order to develop critical and cognitive autonomy, and the letter of formative assessment that often uses the language of individual empowerment towards the narrow transmission of pre-defined learning targets.

\section{Subject-specific formative assessment}

There is strong evidence that it is possible to articulate and disseminate useful techniques and activities for formative assessment in any subject in adult education and training, which take account of the particular skills and knowledge needed, the broader purposes of adult learning and the tensions highlighted in this review. 


\section{Teacher training and continuous professional development}

Effective teacher training and CPD aims to model good practice in the classroom, so it follows that all the messages emerging about effective teaching and formative assessment in the context of adult learning, can also be applied to teacher training and CPD contexts. In this case the trainer (if there is one) takes the role of the teacher, and the teacher the role of student. These messages are likely to be even more important in the context of initial teacher training, where it is essential that the trainers model good practice in teaching and learning. For CPD the formative assessment approach suggests the value of 'teacher learning communities' (Wiliam, 2007), groups of 8 to 10 colleagues who meet regularly over time to discuss their use of formative assessment and observe one another in the classroom. In this way their learning and professional development would be structured as self-directed collaborative learning, research and evaluation tasks.

\section{Future research}

Detailed exploration of meanings, purposes and activities of formative assessment that develop specific subject skills and knowledge, and their effects on adults' motivation, engagement and autonomy is needed: the generic practices and activities here are easy to define but their effects in different learning cultures and on adults' learning careers are not yet clear (see Ecclestone et al., in progress). In particular, research is needed into the specific ways in which learning and formative assessment in adult literacy, numeracy and ESOL programmes is affected in the UK by the powerful influence of the Skills for Life multiple choice testing regime. Finally, research into the ways in which adult education teachers develop formative assessment skills and insights, in the context of a heavily casualised, parttime workforce is also needed.

\section{References}

ARG (2002), "Assessment for Learning: 10 Research-based Principles to Guide Classroom Practice", Assessment Reform Group 2002, http://arg.educ.cam.ac.uk/CIE3.pdf

Argyris, C. and D. Schön (1974), Theory in Practice: Increasing Professional Effectiveness, Jossey Bass, San Francisco.

Assessment Reform Group (1999), "Assessment for Learning - Beyond the Black Box", University of Cambridge School of Education. 
Banta et al. (1996), Assessment in Practice: Putting Principles to Work on College Campuses, edited by T. Banta, J. Lund, K. Black, F. Oblander, Jossey Bass, San Francisco.

Barnes, D. and F. Todd (1995), Communication and Learning Revisited, Heinemann.

Beck, U. (1992), Risk Society - Towards a New Modernity, Sage, London.

Black, P. and D. Wiliam (1998), "Assessment and Classroom Learning, Principles, Policy and Practice", Assessment in education, Vol. 5(1), pp. 1-78.

Black, P. and D. Wiliam (1998b), "Inside the Black Box - Raising Standards through Classroom Assessment", Department of Education and Professional Studies, Kings College, London.

Black, P. and D. Wiliam (2003), "In Praise of Education Research: Formative Assessment", British Education Research Journal, Vol. 29(5).

Black, P., C. Harrison, C. Lee, B. Marshall and D. Wiliam (2003), Assessment for Learning - Putting it into Practice, Open University Press, Maidenhead.

Black, P., R. McCormick, M. James and D. Pedder (2006), "Learning how to Learn and Assessment for Learning: A Theoretical Inquiry", Research Papers in Education, Vol. 21, 2, pp. 119-132.

Brookhart, S. (2001), "Successful Students' Formative and Summative Uses of Assessment Information", Assessment and Evaluation in Higher Education, Vol. 8(2), pp. 154-169.

Brown, A. and A.S. Palincsar (1989), "Guided Co-operative Learning and Individual Knowledge Acquisition", in L. Resnick (ed.), Knowing, Learning and Instruction, Lawrence Erlbaum Associates, Hillsdale NJ, pp. 393-490.

Carr, W. and S. Kemmis (1986), Becoming Critical - Education, Knowledge and Action Research, Falmer, London.

Chaiklin, S. and J. Lave (1996), Understanding Practice: Perspectives on Activity and Context, Cambridge University Press, Cambridge.

Comings, J. (2003), Establishing an Evidence-based Adult Education System, NCSALL, Harvard.

Crooks, T.J. (1988), "The Impact of Classroom Evaluation Practices on Students", Review of Educational Research, Vol. 58(4), pp. 438-481. 
Cullen et al. (2002), "Review of Current Pedagogic Research and Practice in the Fields of Post Compulsory Education and Lifelong Learning", J. Cullen, K. Hadjivassiliou, E. Hamilton, J. Kelleher, E. Sommerlad and E. Stern, Tavistock Institute, London, www.tavinstitute.org

Derrick, J., K. Ecclestone, J. Merrifield (in press), "A Balancing Act? The English and Welsh Model of Assessment in Adult Basic Education", in P. Campbell (ed.), Assessment Practices in Adult Basic Education, Canadian Adult Literacy Secretariat/Grass Roots Press.

Ecclestone, K. (2002), Learning Autonomy in Post-compulsory Education: The Politics and Practice of Formative Assessment, London, Routledge Falmer.

Ecclestone, K. (2004), "Learning in a Comfort Zone: Cultural and Social Capital in Outcome-based Assessment Regimes", Assessment in Education, Vol. 11, 1, pp. 30-47.

Ecclestone, K. (2006), "Commitment, Compliance and Comfort Zones: The Impact of Formative Assessment on Attitudes to Learning in Postcompulsory Education", Keynote lecture to the European Association for Learning and Instruction Annual Conference, Durham, August $29^{\text {th }}$.

Ecclestone, K., J. Davies, C. Collins, J. Derrick and J. Gawn (in progress), "Improving Formative Assessment in Vocational and Adult Education: Teachers' and Students' Attitudes to Assessment and Learning”, Paper in progress from the Improving Formative Assessment Project, University of Nottingham.

Ecclestone, K. and J. Pryor (2003), “'Learning Careers' or 'Assessment Careers'? The Impact of Assessment Systems on Learning", British Educational Research Journal, Vol. 29 (4), pp. 471-488.

Edwards, R., P. Raggatt, R. Harrison, A. McCollum and J. Calder (1998), "Recent Thinking in Lifelong Learning: A Review of the Literature", Research Report RR80, DfES, London.

Fieldhouse, R. and associates (1996), A History of Modern British Adult Education, NIACE.

Gibbs, G. and C. Simpson (2003), "Does your Assessment Support your Students' Learning?", Centre for Higher Education Practice, Open University, www.brookes.ac.uk/services/ocsd/1_ocsld/lunchtime_gibbs_3.doc

Glaser, B. and A. Strauss (1967), Grounded Theory: Strategies for Qualitative Research, Sociology Press.

Good, M., R. Jenkins, S. Leevers and A. Pates (1981), "Basic Education: A Handbook for Tutors", National Extension College, Cambridge. 
Hargreaves, E. (1995), “Assessment for Learning: Thinking outside the Black Box", Cambridge Journal of Education, Vol. 35, 2, pp. 213-224.

Harlen, W. and R. Deakin Crick (2002), "A Systematic Review of the Impact of Summative Assessment and Tests on Students' Motivation for Learning", Research Evidence in Education Library, Issue 1, Institute of Education EPPI-Centre review (version 1.1), London.

Hodkinson, P., G. Biesta and D. James (2007) (forthcoming), "Learning Cultures and a Cultural Theory of Learning", Educational Review, special issue.

Kohl, H. (1998), Reading How To, Boynton/Cook.

Labov, W. (1969), The Logic of Non-standard English, in Tinker, Tailor...The Myth of Cultural Deprivation, edited by N Keddie, Penguin, Harmondsworth.

Laurillard, D. (1997), Rethinking University Teaching, Routledge.

Lave, J. and E. Wenger (1991), Situated Learning: Legitimate Peripheral Participation, Cambridge University Press, Cambridge.

Lindfors, J.W. (1999), Children's Enquiry: Using Language to Make Sense of the World, Teachers College Press, New York.

Marshall, B. and M.J. Drummond (2006), "How Teachers Engage with Assessment for Learning: Lessons from the Classroom", Research Papers in Education, Vol. 21, 2, pp. 133-149.

Pare, A. (1994), "Attending to Resistance: An Ethnographic Study of Resistance and Attendance in an Adult Basic Education Classroom", (thesis), University of British Columbia, Vancouver, www.nald.ca/fulltext/attendng/PAREV3.pdf accessed 25-03-07

Prenzel, M., K. Kramer and B. Dreschel (2000), "Self-determined and Interested Learning in Vocational Education", paper delivered at the final colloquium of the DFG Research Programme "Teaching - learning formal processes in initial business training", Gustav Stresmann Institute, Bonn, Germany, 29 June to $1^{\text {st }}$ July.

Rogers, C. (1977), "The Politics of Education", Journal of Humanistic Education, Vol. 1(1).

Rorty, R. (1989), Contingency, Irony and Solidarity, Cambridge University Press, Cambridge.

Sadler, R. (1989), "Formative Assessment and the Design of Instructional Systems", Instructional Science, Vol. 18, pp. 119-144. 
Stobart, G. (2005), "Validity in Formative Assessment", in J. Gardener (ed.), Assessment and Learning, Sage, London.

Torrance, H., H. Colley, D. Garratt, J. Jarvis, H. Piper, K. Ecclestone and D. James (2005), The Impact of Different Modes of Assessment on Achievement and Progress in the Learning and Skills Sector, Learning and Skills Development Agency.

Vygotsky, L.S. (1962), Thought and Language, MIT Press.

Wiliam, D. (2007), "Assessment for Learning: Why, What and How?", Professorial Lecture, Institute of Education, London.

Williams, R. (1993), "Border Country - Raymond Williams in Adult Education", in J. McIlroy and S. Westwood (ed.), NIACE, Leicester.

Wittgenstein, L. (1922), Tractatus Logico-Philosophicus, Routledge, London.

Wittgenstein, L. (1953), Philosophical Investigations, Blackwell, Oxford. 


\section{Appendix 1: Texts reviewed}

\section{Absolum M 2006: Clarity in the classroom: using formative assessment, Auckland: Hodder Education 2006}

This handbook for teachers, which is based on long-term development work in 10 New Zealand schools, argues that learning, to be effective, must enable the learner to own the learning process, and to be significant, must result in the learner owning what is learnt. Its ideas link the work of Black and Wiliam with the work of Argyris and Schon on organisational learning. It proposes an 'archway' of teaching and learning capabilities, made up of: building a learning-focused relationship, clarity about what is to be learnt, assessment for learning, promoting further learning, active reflection, and clarity about the next learning steps. The book consists of chapters which unpack these ideas, giving detailed examples of how they can be made to work in practice.

Type F

\section{Alexander R 2004: Towards dialogic teaching - rethinking classroom talk, Dialogos 2004}

Primary focus is on the education of children. Argues that learning is a social process, quoting Vygotsky: 'the true direction of learning is not from the individual to the social, but from the social to the individual.' The teacher is not merely seen as facilitator, nor as transmitter of learning, but teachers and learners as interactive participants.Both learner engagement and teacher intervention, are essential. The organisational component of whole class teaching is less significant for children's learning than the discourse and values associated with it. Quotes Palincscar and Brown's typology for discussion: questioning to provoke discussion, clarifying to tackle problems in understanding, summarising what has been learned so far, and predicting the information that will follow. Argues for a focus not just on questioning, but on what is to be done with the answers received from learners. Suggests that what learners say is more important than what teachers say. True dialogue entails challenge and disagreement as well as consensus. This works only if classroom culture has moved beyond the one-sided transmission relationship between teacher and learner. If this is the culture, then dialogic and challenging teaching may intimidate some learners. Dialogic teaching is: collective, reciprocal, supportive, cumulative, and purposeful. It views knowledge as problematic and open rather than given and closed. Notes overlap between dialogic teaching and learning, and assessment for learning. Links these two also with the development of citizenship. If valid for children, then also valid for adults, including teachers. Alexander concludes by criticising policy documents which focus only on teaching (or assessment) techniques, neglecting content - this connects his arguments with Ecclestone (education as therapy) and Torrance (assessment as learning).

Type F 


\section{Barton D, Ivanic R, Appleby Y, Hodge R, Tusting K et al.2004: Adult Learners' Lives project: setting the scene, London: NRDC Progress Report, April 2004}

This publication reports on interim findings from the first year of a longitudinal study of adult learners' lives, aiming to understand the connections that adults make between learning and their everyday lives. Its early findings include: relationships matter in learning, including teacher/student and student/student relationships, and also the networks of support learners are part of; that being in control is a key motivating factor in learning; and that there is a complex relationship between teaching and learning - learners don't learn what teachers teach. ESOL work with asylum seekers demonstrates graphically how factors in the rest of students' lives affect their learning, and how important it is that the teacher engages with these issues if the students wish them to. It is important that the learning environment is a safe space in which friendly and trusting relationships can be built up. Negotiation between teaching and learning based on upon responses to individual motivation for learning:that learning is a shared but individual enterprise, and that learners are active agents in their learning, are further emerging themes.

Type A, sample size: 8 groups in 3 cities

\section{Barton D and Papen U 2005: Linking literacy and numeracy programmes in developing countries and the UK, London: NRDC Research Report, September 2005}

This paper reports on a seminar in which adult literacy and numeracy projects from all over the world came together to share experience and to investigate commonalities. The report presents and discusses these experiences and examines their relevance for policy and practice in adult basic skills in the UK, with the broader aim of promoting international exchanges in the field of adult literacy. Recommendations based on the experience of work in developing countries include: that it is important to keep open debates about the goals and purpose of adult language literacy and numeracy work; that it is important to broaden the concepts of literacy and numeracy which underlie current policies; that family and community-based and integrated programmes often work better and are more sustainable than isolated programmes; that literacy and numeracy can be critical ingredients of learning between individual adults, families and communities in situations of conflict or post-conflict; that longer programmes have more long term effects; that authentic materials work best; that practitioner networks are an essential part of training and professional development; that assessment of learners and programmes needs to be broad; and that literacy learning needs to be clearly linked to the empowerment of women in particular. With particular reference to formative assessment, the report recommends that the environment for learning is integrated into the lives of the learners by building on real-life activities and tasks of the learners, and that teachers must be willing to engage with wider aspects of learners' lives.

Type B 


\section{Barton D, Appleby Y, Hodge R, Tusting K, Ivanic R 2006: Relating adults' lives and learning: participation and engagement in different settings, London, NRDC Research Report, April 2006}

This report comes from the Adult Learners' Lives project, a longitudinal study of the links between learning and learners' lives. One part of the second stage of the project focussed on adults learning in community-based settings such as a drug rehabilitation centre, a homeless centre, and a domestic violence support group. 282 people participated in the research, including 134 students. The report explores the wide range of experiences that learners bring to learning situations, and argues that people have widely differing reasons for getting involved in learning, and are often faced by profound and challenging barriers to persisting in their learning, including physical, mental, social, emotional and economic constraints. Teachers need to be able and willing to engage with these factors in their students lives: if they cannot or will not, then they will not be able to utilise their students' experiences for learning, and they will not be able to connect with their learners' feelings and ideas about learning, and thus may not be able to find the most effective teaching approaches.

Type A, sample size: 282 (134 students)

\section{Baxter M, Leddy E, Richards L, Tomlin A, Wresniwiro T, Coben D 2006: Measurement wasn't taught when they built the pyramids - was it? The teaching and learning of common measures in adult numeracy, London: NRDC Research Report, April 2006}

This report charts the tensions between measures as used in society and the concept of measurement used in the mathematics curriculum. Most studies of the mathematics involved in measurement are identified as such by researchers, but not by the adults whose activities are being investigated. It cites Lave, pointing out that mathematics is rendered 'invisible' to those most closely involved in the activity. This phenomenon varies across societies and cultures, but is most clearly observed when 'mathematics disappears into modern technologies'. Clearly in this situation, making the mathematics visible may be one of the teacher's most important jobs - or is it? The report argues for the importance of gearing teaching to students' experience and cultural practices that support their intuitive approaches to measurement. Mathematics itself is complex, messy, limitless, beyond any single person's full understanding; the curriculum (perhaps necessarily) is assumed to be simplified by being rendered into elements and levels. All these points support the argument for the importance of interactive communication between teachers and students, and for teachers to find out how students use mathematical processes in their real lives.

Type A, sample size: 76 students in 8 groups 


\section{Beder H 2005: Research on factors that shape engagement, Focus on Basics,} Vol 7 Issue D

This project explores what factors shape whether ABE students engage in instruction. Engagement is defined as 'focussed effort on instructional tasks' and is seen as necessary but not sufficient for learning. It also examines the relationship between engagement and drop-out. The project finds that 'teacher conduct' is an important factor in engagement: that how teachers interact with learners is an important factor in engagement.

Type A, sample size: 6 groups

\section{Belfiore ME and Folinsbee $S$ 2004: Workplace Learning and Literacies in Practice, in Reading Work: Literacies in the New Workplace, ed ME Belfiore,} TA Defoe, S Folinsbee, J Hunter, N Jackson, Lawrence Erlbaum Associates This chapter is based on an ethnographic study of adult learners and deals with training in two workplaces. It brings out the different effects of formal mandatory training programmes and practices, and informal peer development observed by the researchers and discussed in interviews with workers and managers. It argues that the source of these differences is the degree of involvement of the workers in the training itself, and the management style of the workplace in relation to quality input from the workers, both of these being indicators of dialogic practice. Training is seen as more effective in terms of management objectives and of sustainability if it starts with the realities of the workplace and individual workers, rather than starting with a formal curriculum and attempting to transmit it into passive trainee subjects. Examples are given of ways in which production process improvements suggested by the employees demonstrate that they are critical thinkers and system analysts, suggesting that training and quality improvement processes should be participatory rather than teacher or manager-led and top-down. In particular it is shown how a manager delivering formal training on new quality control systems needs to allow employees to voice criticisms of the present quality regime in practice, in order to gain credibility and engage the employees in the formal aspects of the course. The paper thus argues for the integration of training with work practice, and the strong link between organisational style and culture, and effective learning in the workplace.

Type A, sample size: 2 groups

\section{Belzer A 2004: "It's not like normal school": The role of prior learning contexts in Adult Learning, Adult Education Quarterly Vol 55 No 1 2004, pp. 41-59}

This article explores the ways in which prior experience in formal learning contexts influence adult learners' views of their current context. Using interview data from five women participating in a General Educational Development program, this study suggests that these learners' constructions of previous learning contexts function as "screens" between the learner and the learning. Contextual features of current learning contexts may pass easily through a learner's screen, may be a misfit creating 
ambivalence and tension, or may exceed the boundary of the screen's frame. The outcomes of each situation are discussed and an argument is made for conscious examination of the screen.

Type A, sample size: 5 students

10. Benn R 1997a: Reading, writing and talking about mathematics, in D Coben, ed Adult Learning Maths - a Research Forum, Proceedings of ALM-3, the Third International Conference, Brighton UK, pp24-29, London Goldsmiths College/ALM

This paper argues that dialogue in maths teaching with adults is essential to overcome dependency and isolation. This can take the form of talking, reading or writing. The paper references Freire: 'Banking Education resists true dialogue. Implicitly argues there is no clear division between formative assessment and teaching through dialogue. The teacher providing 'answers' is seen as an example of banking education. Type B

\section{Benn R 1997b: Adults count too, NIACE 1997}

Constructivism seen as opposite to positivism, with the focus on the learner's understanding at any point in the learning process, rather than on what is seen as factual knowledge by positivism. Thus social interactions are crucial in the construction of knowledge, and the teacher's role is to provide experience. Questions are raised about 'telling' learners anything. The teacher must walk the fine line of managing the learning experience so that the learners' expectations, whatever they are, are met whilst sensitively offering mathematical challenges aimed at the conceptualisation of mathematics. Benn argues that mathematics education needs to acknowledge the social values it embodies, and that learners should be empowered to create their own knowledge and that the mathematics curriculum should be concerned with human mathematical problem-generation and -solving, and should reflect 'fallibility'.

Type B

\section{Beveridge $M$ 1999: Instrumental objectives and liberal values: squaring the circle, in Popular Education and social movements in Scotland today, ed Crowther, Martin, Shaw, NIACE 1999}

This study of teaching Communications to a group of unemployed adults suggests that the apparent contradiction between the instrumental objectives of competence and the liberal values of discussion and critical enquiry may be more imagined than real. Funding regimes increasingly demand the former, but the critical and creative autonomy of the educator can also promote the latter. In the contemporary Scottish context the curriculum of cultural studies presents peculiarly rich opportunities for squaring this particular circle.

Type A, sample size: 1 group 


\section{Boud D 2000: Sustainable assessment: rethinking assessment for the learning} society, Studies in Continuing Education, 22(2) 151-167

Assessment practices in higher education institutions tend not to equip students well for the processes of effective learning in a learning society. The purposes of assessment should be extended to include the preparation of students for sustainable assessment. Sustainable assessment encompasses the abilities required to undertake activities that necessarily accompany learning throughout life in formal and informal settings. Characteristics of effective formative assessment identified by recent research are used to meet the specific and immediate goals of a course as well as establishing a basis for students to undertake their own assessment activities in the future. To draw attention to the importance of this, the idea that assessment always has to do double duty is introduced.

Type B

\section{Boud D 2002: The unexamined life is not the life for learning: rethinking assessment for lifelong learning, Professorial Lecture, Middlesex University} (available at www.lle.mdx.ac.uk/ICLML/Boudlec.pdf\#search=\%22unexamined\%20Boud\%22, accessed 22-09-06)

Argues that assessment is an essential and inseparable part of learning, and that we need to acknowledge that it is uncomfortable, associated with power, that we need assessment but don't want it. The way to resolve these tensions is through sustainable assessment. This involves recognising that assessment always does more than its ostensible purpose, that it always an act of communication about what we value. Assessment activities have to double duty by - encompassing formative assessment for learning as well as summative assessment for certification; having a focus on the immediate task and on implications for equipping students for lifelong learning in an uncertain future; and by attending both to the learning process and the substantive content domain. Boud suggest we have to go beyond present thinking and explore (not just pay lip service to): learner-centred teaching; addressing the hurt of assessment; a connoisseurship of outcomes, appreciative, but not smug or embarrassed; and a proper discourse for assessment, avoiding 'final' vocabulary, and the objectification of feedback.

Type B

\section{Breen M 2001a: Overt participation and covert acquisition in the language classroom, Learner contributions to language learning - new directions in research, Harlow, Pearson Education}

This paper deals with ESOL learners' participation in pedagogic discourse. Communicative language teaching (CLT) advocates spontaneous learner communication through talk on topics and issues that are immediately meaningful to them. The paper argues that learning (in this case language learning) is tangibly aided by this kind of approach. It surveys a range of feedback techniques, in this case not 
distinguishing between teaching and formative assessment. It distinguishes between different kinds of classroom talk: for example between learner interactions in which their discourse is 'woven into the teacher's text', (eg in the case of questions to the whole group - an example of effectively closed dialogue) and interactions in which learners frame their own discourse. It is argued that supporting the capacity to develop this learner-centred discourse, for example about their own learning, is a key element of effective language teaching.

Type B

\section{Breen M 2001b: The social context for language learning: a neglected situation?, in English Language Teaching in its Social Context, ed C Candin and N Mercer, Cambridge University Press}

This paper argues that classrooms are specific cultures and demand an anthropological approach from researchers. It suggests that language learning can be enhanced if the learning process is structured as collaborative research by teachers and learners. Type B

\section{Brookfield S 1990: The Skillful Teacher: on Technique, Trust, and Responsiveness in the Classroom, Jossey-Bass, especially Chapter 10: Giving Helpful Evaluations.}

Brookfield argues that teaching is centrally about making judgements, however carefully objectives criteria for success are defined. 'Talking about non-judgemental teaching, nondirective teaching, or non-evaluative teaching, is conceptually nonsensical'. He quotes Freire on the difference between authoritarian and authoritative teaching, the second achieving its aim through the credibility, trust and authenticity teachers establish in the learners' eyes. Useful evaluation is seen as constructive, specific, task-oriented, future-oriented, encouraging, given immediately, given regularly, justifiable, and educative in itself. Brookfield suggests a number of ways of improving evaluation technique: experience being evaluated, open criteria to negotiation, get students to evaluate their teachers' evaluations, and promote self and peer evaluation.

Type B

\section{Douglas Brown H 1994: Teaching by Principles: an interactive approach to language pedagogy, Upper Saddle River: Prentice Hall Regents}

This handbook aims to 'synthesise the accumulation of knowledge about teaching English as a second or foreign language into a practical, principled approach for prospective and new teachers'. It emphasises the importance of learning being meaningful to the learner, of the development of intrinsic motivation, that learning is about developing identity and is a challenging process, that effective and sustainable learning requires the confidence to take risks, that what learners bring with them in terms of culture, language and experience is the most significant factor in learning, and that learning is not just about accuracy, but about fluency of skills in use. It 
contains a chapter on assessment that calls for a clear distinction between formative and summative assessment, and gives examples of 'intrinsically motivating language tests' involving co-operative group assessment involving authentic tasks, that give optimal feedback, and include self-assessment.

Type D

19. Clarke $J$ 1991: Autonomy and dependence in adult basic education, RaPAL bulletin No 16, Autumn 1991, reprinted in Insights from research and practice, ed M Herrington and A Kendall, NIACE 2005, pp204-210

This article is based on a small-scale qualitative research study $(\mathrm{N}=15)$ investigating how students in ABE provision perceive the notion of autonomy in relation to their learning. 12 of the 15 identified reducing their dependence on others to perform practical tasks as an important motivator for their attendance at programmes. There was little evidence to support Rogers' view that the 'habit' of dependency was obstructing their application of their learning. The research also found little evidence of resistance to person-centred learning, except that the students tended to describe the teacher as an expert rather than as a facilitator. The students unequivocally aspired to a greater degree of autonomy in their lives, but this didn't necessarily imply that they wanted to be wholly independent learners. They valued interactions and support both from the teacher and from other learners.

Type A, sample size: 15 adult basic education students

\section{Claxton G 1995: What kind of learning does self-assessment drive?} Developing a nose for quality: comments on Klenowski, Assessment in Education 2(3) 339-343

Klenowski (1995) identifies three aspects of 'self-assessment. This commentary examines these from the point of view of the development of learning-to-learn or 'learning acumen', which, it is proposed, comprises resilience, resourcefulness, reflectivity and responsibility. The minimal sense of self-evaluation, in which students merely learn to monitor their performance in terms of externally-specified criteria, may raise attainment without improving learning acumen, and may even damage it. Self-evaluation is essentially an intuitive process. Learning to see self-evaluation as 'marking one's own work' by applying a checklist of criteria prevents the development of this intuitive ability.

Type B

\section{Comings J, Parrella A, and Soricone $L$ 1999: Persistence among adult basic education students in pre-GED classes, NCSALL Reports No 12, at www.ncsall.net/fileadmin/resources/research/report12.pdf, accessed 31-12-06.}

This report is concerned with understanding and supporting persistence in adult literacy learning. It found that adults who had been involved in previous efforts at basic skills education, self-study, or vocational skills training were more likely to 
persist than those who had not, and the strongest correlation was with those who had undertaken self-study. It also found that adults with specific goals such as helping their children or getting a better job were more likely to persist than those without such a goal. These findings suggest that experience with education may increase an adult's self-confidence about learning, and that motivation, especially as demonstrated by undertaking self-study or by being clear bout the goal for attendance, is a support to persistence. The paper goes on to suggest specific ways in which programmes can support adult learner persistence by building what it calls 'self-efficacy', which it sees as a more useful and focussed term than 'selfconfidence'.

Type A, sample size 150

\section{Condelli L 2002: Effective instruction for Adult ESL students: findings from the 'What Works' Study, accessed 31-12-06 from www.nrdc.org.uk/uploads/documents/doc_54.pdf}

This study aimed to identify ways in which adult ESL programmes can provide effective instruction to improve the English language and literacy skills of students, by examining the effectiveness of different types of instruction, and by linking 'educational inputs', such as teaching strategies, with 'educational outcomes', including increases in test scores, for ESL literacy students. The study was designed to inform improvements in instruction and programme design. The project's key findings on instructional practices were:

- 'Bringing in the outside' - in classes where teachers made connections to the 'outside' or real world, students had more growth in reading basic skills development

- Use of the students' native language for clarification - in classes where teachers used students' native language for clarification during instruction, students had faster growth in reading comprehension and oral communication skills

- Varied practice and interaction strategy - where the teacher taught concepts in a variety of modalities and allowed student interaction, students had faster growth in oral communication skills

- Emphasis on oral communication - where the teacher explicitly emphasised oral English communication skills in instruction, students had more growth in this area

Other key findings were that longer scheduled classes produced more growth in reading comprehension and oral communication skills, but less growth in basic reading skills; that students that attended a higher proportion of scheduled time (in hours) had more growth in reading comprehension and oral communication skills; that students with more years of education and higher incoming English language and literacy skills had more growth in skills, though the effect of years of schooling was limited to growth in basic reading skills development; and that 
younger students developed basic reading and English oral communication skills faster than older students.

Type A, sample size: 495 students in 38 groups

\section{Degener $S$ 2001: Making sense of critical pedagogy in adult literacy education, in J Comings, B Garner, and C Smith (eds), NCSALL annual review of adult learning and literacy, 2, 26-62. San Francisco: Jossey Bass 2001.}

Degener argues that, given the constraints and limited resources common in ABE, adult education programmes cannot be classified as strictly critical or non-critical; instead, programmes operate along a continuum between the two positions. The author uses six elements as a framework for analyzing programmes and outlines characteristics of programmes falling at different places along this continuum. Degener concludes the chapter by noting the need for more research on classroom practice and pedagogy within ABE programmes. As she notes, research is needed to better understand how critical pedagogy is implemented in programmes and how such an approach can impact learner outcomes and perceptions of their experience. Research aimed at answering such questions would help to inform practitioners who seek to develop a more critical pedagogy over time. In addition, findings in these areas could potentially influence policy by providing examples of the utility of non-standardized measures of success, thereby taking into account the specific backgrounds, needs and interests of individual students and balancing current trends toward standards-based education and standardized assessments.

Type B

\section{Derrick 2004: Making the Grade: assessment and achievement in adult literacy, numeracy and language, in Lavender, Derrick and Brookes, Testing, Testing, 123, NIACE 2004}

This discussion paper covers issues affecting learning for adults with low level skills and competencies, some of whom may have negative past experiences. The conceptual paradigms of assessment of learning, and all that this entails - the framework of national tests - targets - competencies and measurement of skills is discussed in relation to its impact on the adult learners and compared and contrasted with the paradigm of assessment for learning, with its inherent trait of placing the learner at the centre of the experience of facilitating learning. The article concludes that a broadening of what is considered to be an achievement - what counts towards national targets and structural improvements to the distinction between basic skills and key skills, would go some way to improving matters in a outcomes based paradigm. Formative assessment is seen as the preferred method to stimulate learners and that a toolkit should be developed. It is recommended that the link between college funding and college performance and learners achievement be broken.

Type C 


\section{Donley $J$ and Napper $R$ 1999: Assessment Matters in Adult Learning, NIACE 1999}

This handbook aims to give adult education tutors information and ideas about assessing adult learning. It can be used either as a reference source for information about assessment or as a practical tool for tutors to photocopy and use their teaching. After a brief discussion on the meaning of assessment, the pack goes on to look at why assessment is necessary, who can assess, when assessment should take place and what forms it can take. The pack offers help to tutors in: recognising the assessment work they are already doing; developing ideas about other ways to assess, including nonpaper-based methods; thinking of different ways of recording assessment; and providing useful and sensitive feedback after assessment.

Type D

\section{Ecclestone K 2002: Learning Autonomy in Post-16 Education: the politics and practice of formative assessment}

This book contributes to our understanding of the political and social impact that assessment practices have on the way learners are taught and learn. With its multi-layered insights into factors affecting the stimulus for lifelong learning, it draws out the intertwinement of policy, with assessment design, and its impact on institutional providers, and groups of learners. There is a section dedicated to assessment and motivation in GNVQs and it examines the aims and goals, limiting factors for motivation in this regime, and provides interesting accounts from student about teaching methods and factors affecting their personal motivation, which, from a practical perspective could be useful to adapt into guidance for delivery models. Although it is an ideal book for anyone wanting to understand the wider and broader big picture, it is not a book that simply provides quick fix answers to practitioners wishing to implement formative assessment practices, in fact, it raises more questions than answers on all levels.

Type A, sample size 2 groups

\section{Ecclestone $K$ 2004a: Understanding assessment and qualifications in post- compulsory education, NIACE, Chapter 3}

Pressures for retention and achievements targets in Post-16 educational settings link initial screening and diagnostic assessment directly with the right kinds of support during a learning programme. At the same time, the transition from formative to summative assessment is increasingly blurred, particularly in programmes where summative results accumulate from coursework and assignments. This leads to the widespread belief that formative assessment is synonymous with 'continuous assessment' or courses without end examinations. This chapter identifies the different stages for diagnostic assessment within a learning programme; examines the links between assessment and learning; highlights some barriers to effective diagnosis and formative feedback; and identifies strategies for improving diagnostic and formative assessment within institutions.

Type B 
28. Ecclestone K 2004b: From Freire to fear: the rise of therapeutic pedagogy in post-16 education, in The Disciplining of Education: New languages of power and resistance, ed Satterthwaite J, Atkinson E, and Martin W, Trentham Books 2004 This paper argues that an unhealthy pre-occupation with health - specifically, the emotional well-being of the student - gets in the way of learning, with stultifying consequences for the learner and teacher alike, creating 'a new sensibility that resonates with broader cultural pessimism about people's fragility and vulnerability'. Ecclestone is far from recommending 'an uncaring view of some people's lack of confidence or vulnerability'. Her challenge is to the facile notion, which she sees as sharply at odds with the resilience so powerfully advocated by Freire, that esteem should be conferred upon a passive learner by an education system more or less exclusively preoccupied with issues of identity and emotional well-being. Type B

\section{Eldred J 2005: Developing embedded literacy, language and numeracy: supporting achievement, Leicester: NIACE 2005}

A short handbook for Skills for Life practitioners and provider organizations about programmes offering vocational qualifications in which learners may have additional needs in terms of literacy, numeracy and language skills. It emphasizes the importance of learners being involved in setting their own learning goals and targets, and describes formative assessment as part of the delivery element of programmes. The book focuses mainly on the organizational challenges of recording progress and achievement in embedded programmes, but also emphasizes the importance for adults of ongoing high quality feedback.

Type D

30. Eldred J, Ward J, Snowdon K, Dutton Y 2005: Catching Confidence - the nature and role of confidence ways of developing and recording changes in the learning context, Leicester: NIACE 2005

This publication reports on research into the nature and importance of confidence for effective learning, working with 350 learners in 41 groups in 8 different adult community learning organisations. The project developed and piloted a diagnostic tool intended to encourage reflection among learners about the nature of confidence, as well as providing a means of recording changes in confidence over time. A series of guidelines for teachers are included in the report, most of which highlight the importance of sharing information and feelings between learners through discussion, and through using purposeful dialogue so as to involve learners in planning and evaluating their learning.

Type A, sample size 350 


\section{Evans K, 2002: The challenges of 'making learning visible': problems and issues in recognising tacit skills and key competences, in Working to Learn, ed Evans, Hodkinson and Unwin, Kogan Page 2002}

Evans deals here with the contribution of the organisational context to workplace learning: organisations are seen as on a spectrum between technocratic or democratic. Implicit or hidden dimensions of knowledge and skill are key elements of mastery. Evans argues that systematically utilising all the skills and knowledge of workers, including the tacit, is more likely to be effective in 'democratic' as opposed to 'technocratic' models of the learning society. These models are differentiated primarily along the spectrum of participation, involvement, and ownership of decisions taken in workplaces and in society as a whole. For Evans, the key concept (and practical goal of training and education) is transferability of skills and knowledge between different contexts. She argues that the greater the tacit dimension of these skills and knowledge (all knowledge has both tacit and explicit dimensions), then the more transfer has to involve high levels of social interaction, demonstration, 'showing how' - manuals and written accounts are of little help.

Type B

\section{Fordham P, Holland D, Millican J 1995: Adult Literacy, a handbook for development workers, Oxfam/VSO, especially Chapter 9}

This chapter is in a resource book aiming to support development workers with no formal training in adult education or literacy, who encounter the need for literacy in the communities with which they work. It explicitly promotes the idea of participative assessment, arguing that this is more appropriate as well as more effective and useful, for adult learners. 'Real activities for teaching and learning are more meaningful than text-book exercises'. It argues for going beyond measurement - 'If we are concerned only with measuring progress, we tend to look only for evidence that can be quantified, such as statistics, grades and percentages. If learning is assessed in both qualitative and quantitative ways, the information produced is more complete and more useful.' But this does not exclude formal testing methods, so long as learners are treated as adults. It points out that assessment should be discussed with learners themselves, and that this process will materially contribute to their learning. Assessment is about supporting learners rather than simply judging them. Typical approaches include class meetings for group review, individual interviews, and observations of classes. It suggests that progress profiles enable learners and teachers to record aims and measure progress against them in a constructive and hands-on way. It is critical of the artificiality of standards compared to the demands of real life situations. It suggests that learners themselves should decide how their progress should be measured. This book draws on the experience of VSO and Oxfam projects and fieldworkers throughout the developing world.

Type D 


\section{Fowler $\mathbf{E}$ and Mace $J$ 2005: Outside the Classroom, researching literacy with adult learners, Chapter 4, Leicester: NIACE 2005}

Promotes the idea of teaching and learning as research through joint mutual investigation between learners and teacher, and the particular relevance of this approach for adult literacy. The chapter supports Freire's account of learning, where the content of learning is being constructed, but also more 'autonomous' models of learning, in which the content is given but the learner's orientation to it is being investigated for learning purposes, i.e. formative assessment. The research model promoted is ethnographic, requiring a range of data from different sources and of different types, and a grounded research methodology, in which findings 'emerge' gradually from the data. It argues that this type research can deliver 'empowerment' to learners, as well as being a framework for improving literacy skills. The chapter concludes with a number of detailed case studies of individual learners.

Type D

\section{Freire, P 1972: The Pedagogy of the Oppressed, Sheed and Ward, chapters 2 and 3}

These two chapters confront opposing philosophies of education, the first being what F calls the 'banking system', in which teachers deposit unproblematised nuggets of knowledge into passive learners, based on a static, positivist view of objective knowledge and power relations in the world. Liberating education on the other hand consist of shared acts of cognition, problem-posing, dialogue between learners and teachers, through which the world is re-created and unequal power relations are eliminated.

Dialogue requires love, humility, faith in man (sic), hope, and critical thinking, which sees reality as a process, as transformation, rather than as a static entity. It produces trust. Without dialogue there is no communication, and no true education. No distinction is made between dialogue and teaching - teaching is ongoing formative assessment, reflection and negotiation between all participants about what is learned and how successful the learning process is. The programme content of education is neither a gift nor an imposition - bits of information to be deposited in the students but rather the organised, systematised and developed representation to individuals of the things about which they want to know more. Carried on by A with B, mediated by the world. Teachers engage in dialogue in order to know both the learners' objective situation and their awareness of that situation. For Freire teachers have to establish a learning context in which the authority of the teachers is not oppressive - such as that learning takes place on learners' territory, using discourse and content led by learners. Meta-cognition - learning to learn - discourse about learning - is central to the whole process.

Type $\mathrm{C}$ 


\section{Fuller A and Unwin L 2002: Developing pedagogies for the contemporary learning workplace, in Working to Learn, ed K Evans, P Hodkinson and L Unwin, Kogan Page 2002}

In the context of increasing recognition by social scientists that the workplace is a major site for learning, this chapter focuses on how people learn from and teach others about work tasks. It argues that the act of learning to do one's job in the workplace is worthy of close attention, and that much of this learning takes place through explicit pockets of activity which make use of a range of pedagogical methods. It also argues that pedagogical skills can be found in all types of workplaces, at all levels in an organisation, and that they are not restricted by age. The paper thus challenges the traditional conceptions of 'novice' and 'expert' generally associated with models of skills formation, and in particular, apprenticeship. The paper focuses deliberately on the term 'pedagogies' to counter both the experiential learning tradition which sees workplace learning as almost entirely informal, and the Human Resources Development tradition which is concerned mostly with improving the effectiveness of 'off the job' training, often through the use of new technology. Both these traditions play down the role of pedagogy, which, research drawn on in this paper shows, continues to be a salient part of working life.

Type B

\section{Gardener S 1985: Conversations with Strangers, ALBSU/Write First Time 1985}

This pack of materials aiming to support adults developing their writing is mainly addressed to developing writers themselves, ie learners, but it recognises that many of the contexts in which people improve their writing are adult education classes, including adult literacy classes, and one section is addressed explicitly to teachers. This section highlights the importance of listening to learners, in order to ensure that judgements of value and of appropriateness (of tone, or of grammar) are arrived at collectively rather than imposed. The perspective is Freirean, in that value is seen as being constructed by learners with the support of the teacher, rather than being imposed from outside. Marking as a response to learners' work is seen is a vital part of the teacher's role. It needs to be future-oriented and constructive, and should be used as a vehicle for increasing learners' skills and understanding of judgement, assessment and value, for more effective learning in the future, and for empowerment. 'Marking for correctness should be as light as possible....marking for communication, meaning and shape should be as full as possible'.

Type D

\section{Gillespie M 2001: Research in writing; implications for adult literacy education, in J Comings, B Garner, and C Smith (eds), NCSALL annual review of adult learning and literacy, 2, 63-110. San Francisco: Jossey Bass 2001} This chapter traces the history of writing research with a variety of learners - children in the American school system, college students classified as 'basic' writers, second 
language learners, and adult literacy learners - focussing on issues and trends of most interest to adult literacy educators. Gillespie then discusses what these trends mean for the field of adult literacy, where educational approaches based on writing research are still relatively rare. Through examples she shows how a growing number of practitioners are beginning to integrate the teaching of writing more fully into their classes with adult students. She notes that while modern teachers encourage students not to worry about form, to ignore their mistakes, and to focus on the content of their writing (their espoused theory is that students need to practice using their own words authentically), the students are mostly concerned with avoiding mistakes and writing the 'right' way. What is needed, she suggests, quoting Russell (1999), is a different model of teaching writing to adult literacy learners, one that allows learners and teachers to co-construct representations of their assumptions about the writing process, and that makes explicit the connections that may be unclear'.

Type B

\section{Ginsburg $L$ and Gal I 1996: Instructional strategies for teaching adult numeracy skills, National Centre on Adult Literacy Technical Report TR96-02. Philadelphia: University of Pennsylvania, available at www.literacyonline.org/products/ncal/pdf/TR9602.pdf, accessed 23-03-07.} This report identifies 13 instructional strategies that address issues of assessment, development of mathematical skills, and the development of problem-solving skills. These include: determining what students already know, addressing and evaluating learners' attitudes and beliefs about learning and about mathematics, the importance of 'hands-on' activities, developing estimation skills, the importance of mental maths and the need to connect different skills and concepts, seeing computation not as an end in itself, but as a tool for problem-solving, developing calculator skills, group working and communication between students, situating problem-solving in real-life contexts to facilitate transfer of learning, developing mathematical literacy in relation to reading graphs and tables, and assessing a broad range of mathematical skills and knowledge using diverse methods. The strategies reflect research on how adults learn, the cognitive processes involved in learning mathematics, and the mathematical concepts that are important for adults to learn for educational and real life purposes. It argues that implementation of these strategies within adult numeracy classrooms will necessitate a revolution and redefinition of teachers' roles within the classroom and will require both collegial and institutional support.

\section{Good $M$ and Holmes J 1982: How's it going? An alternative to testing students in adult literacy, London, ALBSU 1982}

A guidebook for teachers and students of adult literacy that argues strongly for the involvement of learners in assessment of their learning, rather than the use of rigidly prescribed, supposedly objective tests. Sees developing progress as something to be done by teachers and students together, through discussion, and thus that a good learning relationship' between them is important. It is aimed primarily at learners, and 
provides a range of techniques for self-assessment in the context of improving literacy, using a framework called ASK - attitudes, skills, knowledge = learning. It implies that people can teach themselves, that a teacher is not essential. It uses a level system - beginning, not bad, with ease, taken from Kohl (Reading How to). The tutor's job is seen as secretary, editor, enthusiastic observer, and giver of useful techniques for learning

Type E

\section{Greenwood $M$ and Wilson $P$ 2004: Recognising and recording progress and achievement in non-accredited learning, Evaluation report on the RARPA pilot projects April 2003 - March 2004, Leicester: NIACE 2004}

Reports on action research aiming to investigate ways in which the achievements of learners on non-accredited adult education programmes could be recorded so as to satisfy the requirements of funding agencies, and to improve quality assurance systems for progression and achievement in non-accredited provision. Pilot projects evaluated a 'staged process' consisting of identification of the aims of each learner, initial assessment to establish the learner's starting point, the identification of learning objectives for each learner, the recognition and recording of progress and achievement during the programme (described as formative assessment), and finally, the end of programme learner selfassessment, tutor summative assessment and overall review. At each stage the learner is central to the process. The project found that provider organizations were positive about the staged process, found it fit for purpose and contributed to organizational improvement; staff had mixed responses; and that it clearly benefited learners by raising their awareness of the learning process. These benefits were maximized where learners experienced the staged process as an integral part of the 'normal' teaching and learning on their programme. In particular the project found that learners enjoyed setting their own targets and the ongoing process of reviewing their learning. Recognising achievement was of major benefit to learners with a negative educational history. They gained in personal confidence and developed a sense of themselves as successful learners that changed attitudes towards both learning and their own goals.

Type A, sample size: 237 learners on courses of mostly 10-19 hours of teaching time, and mostly at Entry and Level 1, 22 providers ACL and WBL providers, 10 curriculum areas

\section{Grief S 2003: Planning Learning, Recording Achievement, a guide for practitioners, London: DfES 2003}

Doesn't use the phrase formative assessment, sees reviews as primarily of learner progress and targets rather than teaching approach. Emphasises keeping written records, recording 'other learning', and the inclusion of learners' views. Elaborates the benefits for learners and teachers of involving the learner 'at all stages of the process'. Recommends a simple self-assessment framework using the concepts of 'emerging', 'consolidating', and 'established' in the use of identified skills.

Type D 


\section{Groves 2002: They can read the words but what do they mean?, Adults Learning 13(8) 18-20}

This article reports on a small-scale research project based on interviews with 12 adult students on NVQ programmes. The focus of the enquiry was the language of the course performance criteria, which all students found off-putting, 'jargonised' and hard to understand. Across a range of skill areas the criteria scored very high on the Gunning Fog index (up to 15, average 12.8). This was compared with a classic text of philosophy, Wittgenstein's Tractatus, which scored 10.9. The report concludes that adult learners are encountering language written in the discourse of teachers, with institutional values embedded implicitly. Yet this language is presented as transparent and objective. It is suggested that teachers should beware of inaccessible language for assessment criteria, that the search for 'neutral', transparent language for this purpose is futile (according to Wittgenstein there is no such language), and that attention should be given to more holistic and 'problem-centred' assessment processes in which the meaning of language is rooted more explicitly in the contexts of use.

Type A, sample size 12

\section{Hillier 2002: Assessing Learning, Chapter 8 of Reflective Teaching in Further and Adult Education, Continuum, pp191-226}

In this chapter the phrase 'informal assessment' is used as synonymous with the Black and Wiliam definition of formative assessment. The chapter provides a range of examples of assessment methods, and discusses the importance of constructive and practical feedback in all kinds of assessment, rather than simply qualitative remarks. It is argued that feedback should: focus on the issue, not the person; be specific and give examples; mark examples on the work and relate these to an overall summary; be constructive and offer ideas to improve; check that the learner knows what to do next. Furthermore, it is argued that feedback should not: make sweeping statements; make negative comments without helpful suggestions; be too lengthy and detailed - the learner should not be overwhelmed; use red pen and cross large parts of the work out; finish on a negative comment.

Type D

\section{Hodgen $J$ and Wiliam D 2006: Mathematics inside the black box - assessment for learning in the mathematics classroom, London: Kings College London Department of Education and Professional Studies 2006}

This booklet is aimed at teachers of mathematics and is a digest of the results from a series of research studies mainly focussed on schools, investigating and developing formative assessment practices used by teachers in a range of subjects. It emphasises the importance of dialogue, challenging activities, questioning and listening, differentiation, peer discussion, feedback and marking, and self- and peer-assessment, and gives practical examples in each case.

Type F 


\section{Hostler J 1986: Student autonomy in Adult classes, Manchester Monologue, University of Manchester Centre for Adult and Higher Education 1986}

A pamphlet discussing the link between approaches to adult learning, student autonomy, and democracy. It argues that the real basis for typical student-centred and democratic procedures in adult education is not so much about the psychology of learning, (or about outcomes), as about our conceptions of adulthood itself. We conceive adults as autonomous and self-directing, with a consequent right to participate in decisions which affect them. Learning which recognises this also builds students' own confidence to participate, thus developing autonomy in a virtuous circle. The chapter on assessment argues that within this conception, assessment should be an integral and everyday aspect of teaching, not appearing as anything out of the ordinary, or raising any anxiety in students. Hostler recommends involving students in their own assessment as a group, through the giving of mutual feedback, preparing presentations and demonstrations for the other students, and role play. He points out that simply observing students may provide enough evidence for useful formative feedback, without implementing any specific assessment activity. Guidelines for questioning learners within this model are also provided. He argues that students should know what the purposes of assessment are, and that they should have the right to choose whether or not they are assessed. Students should be encouraged to form opinions about their work and to learn to trust their own judgements. The more practice they have in making judgements of their own work against yardsticks provided by the teacher, the better prepared they will be for evaluating their achievements when they are working on their own.

Type B

\section{Ivanic $R$, Simpson $J$ 1988: Clearing away the debris: Learning and researching academic writing, RaPAL bulletin No 6 Summer 1988, reprinted in Insights from research and practice, ed $M$ Herrington and $A$ Kendall, Leicester: NIACE 2005, pp246-250}

This short article deals with teaching writing in adult basic education. It argues that teachers should treat learner-writers as authorities, and that helping learners write what they mean necessitates talking, as a way of 'researching' the content and literary conventions the learner wants to use, and that this talking necessarily leads to selfassessment of a formative kind. The article suggests that in particular the teaching and learning of writing has much to contribute to research on writing development, and adopts a model of co-operative formative assessment as an integral element of teaching and learning. 'Most student and tutor pairs or groups talk a lot about the feelings and difficulties involved in writing. This sort of 'language awareness' is being more and more widely recognised as an essential component of learning. What is different... is to recognise these insights as 'research findings' as' knowledge'. Type D 


\section{Ivanic R 1996: Linguistics and the Logic of Non-standard Punctuation, in Learning about Punctuation, ed N Hall and A Robinson, Multilingual Matters, pp148-169}

This paper, echoing Labov's famous paper on non-standard uses of spoken English, argues that non-standard punctuation is often based on perfectly logical thinking, and that standard punctuation is not in itself essentially logical. It is based on a small scale study of 10 adult literacy students on a short full-time learning programme, none of whom had any formal qualifications. It highlights the importance for teachers of engaging in dialogue with learners about the thinking behind their mistakes, in order to help them increase their understanding and knowledge of standard punctuation. Ivanic suggests that 'introspection about strategies (for achieving the correct use of punctuation) is a useful teaching method in itself. Learners are thinking about meaning - they are logical even if they are mistaken.' This process, Ivanic argues, also reveals the arbitrariness of the logic of standard punctuation, and the consequent illogicality of using inability to use standard punctuation as a criterion for employment for example. Type A, sample size: 10 adult literacy students in the UK

\section{Ivanic R, Tseng ML 2005: Understanding the relationships between learning and teaching: An analysis of the contribution of applied linguistics, London: NRDC Research Report 2005}

'Learning is not predictable as a product of input, but created through constant negotiations between individuals, social environments and broader social influences'. Teachers need to pay attention to the beliefs about learning, teaching, language literacy and numeracy that learners and teachers bring with them to the learningteaching encounter. Teachers should identify learners' intentions as a key factor in learning events. 'Social interaction is the key mechanism through which learning takes place. Teaching is best characterised as he creation of 'learning opportunities' through the management of interaction. The concept of 'learning opportunities' accounts for the way in which different learners learn different things from the same learningteaching event and provides a rationale for approaches to teaching which do not attempt to specify precisely what is to be learned'.

Type B

\section{Ivanic R, Appleby Y, Hodge R, Tusting K, and Barton D 2006: Linking learning and everyday life: a social perspective on adult language, literacy and numeracy classes, London: NRDC Research Report, April 2006}

This report comes from the Adult Learners' Lives project, a longitudinal study of the links between learning and learners' lives. The second part of the second phase of the project (see Barton et al.2006 for reference to the first part) focussed on learners in college classes. The project worked in-depth with 37 learners in five classes run by three colleges. As with the other reports from this project, a social perspective on literacy, language and numeracy learning was taken, in order to explore the way learners' lives interact with their learning. Some findings emerging from the research are: 
- That every learning -teaching context is different, and calls for different responses from teachers, specific to both context and the individual learners

- That teachers experience a tension between two types of professionalism: the requirement to meet institutional demands and the need to respond to learners' aims, interests and lives

- That the nurturing of good personal relationships is an essential factor in successful teaching

- Listening to learners requires time, recognition and patience

- Teachers need to make listening to learners and gaining knowledge of their lives, motivations, interests and capabilities, the cornerstone of their pedagogy

- Pedagogy needs to be responsive and flexible; not proscribed by too restrictive a curriculum, nor constrained by rigid targets and assessment procedures.

Type A, sample size 37

\section{James $P$ 1997: Narrative and cultural change: enabling transformative learning for adults, Australian Journal of Adult and Community Education, Vol. 37 (3) pp135-142}

This paper describes a participative action research study, undertaken in a course of preparation for secondary teaching in technology studies. Participants were groups of male, mature-age adults who had formerly been trades-people and the study attempted to address the tension between respecting course participants' culture and yet enabling transformative learning to occur. In the past, these groups had developed a reputation for resistance and negativism towards their course work. An ideology of toughness and excessive authoritarianism, together with sexism and racism, usually prevailed, moderate and reflective voices often being silenced. Such an ideology had potentially damaging consequences for the students of course participants. The role of culturallyspecific narrative is examined in providing a resource through which conditions for cultural change in learning groups and critical reflection might be realised.

Implications for adult education, particularly that associated with career transitions, are discussed. Evidence base: three groups, one of them a control group.

Type A, sample size 3 groups

\section{Jansen and Van der Veen 1996: Adult Education in the light of risk society, in The Learning Society, ed Raggatt et al. , Routledge}

Presents a view critical of post-modern theory, based on Risk Society analysis. This argues that under conditions of modernity people are freed from traditional social and ideological bonds but subjected to the anonymous standardising rationalities of the state and the market. Individuals are expected to take responsibility for their own lives, making their own decisions, in contexts in which all sources of information are potentially unreliable. The paper sees adult education as having a potential function as a broker in problem-solving networks, raising issues of values, contracts between 
educators and learners, and new approaches to professionalism demonstrating both distance and involvement. It calls for reframing experiential learning, in which expert knowledge and learners' experiences are subjected to critical and constructive group examination, through dialogue in which both have equal status. AE will stick closer to the daily hopes and worries of learners, and be more prepared to further dialogue between conflicting experiences, interests and ideological images and to stimulate reflection in a Socratic way, ie raising awareness of the crucial questions to ask instead of pretending to know the answers.

Type B

\section{Kelly S, Soundranayagram L, Grief S 2004: Teaching and learning writing: a review of research and practice, London: NRDC Research Report, June 2004} This report consists of three elements: a narrative review that looks at the ways in which studies that conceptualise writing and writing development, contribute to an understanding of how adult learners develop as writers; a systematic review of primary research addressing the question: 'What factors in adult literacy programmes enable learners to develop effective writing skills?'; and a review of current practice in the teaching of writing. Its findings suggest that writing should be seen as a process in which the writer interacts with what he/she has written, and that planning and revising a text are as much part of the process as physically writing it. It also suggests that writing is connected intimately to the writer's thoughts, feelings and identity, and cannot be separated from its social, cultural and political contexts. It found very little research evidence on the effective teaching of writing, or on the causal factors behind the development of effective writing skills. Learners tend to value mastery of spelling and punctuation, and find these most difficult to achieve. Teachers, on the other hand, value the expression of ideas in addition to correctness in writing. The study found that current classroom practice tends to focus on the 'sub-skills' of writing, and suggests that this may reflect teachers' concern to respond to the needs of the learners. The review also identified four factors which seem to be significant in the teaching and learning of writing, and which will be investigated in a later stage of the research: these are authenticity of materials and communication; collaborative approaches to writing; making the process of writing explicit to learners; and contextualisation of writing tasks and the relevance of teaching and materials to learners' lives. Type B

\section{Klenowski V 1995: Student self-evaluation processes in student-centred teaching and learning contexts of Australia and England, Assessment in Education, 2 (2) pp 145-163}

Student self-evaluation processes and their impact on pedagogy, in the promotion of sound reflective student practices, are the focus of this article. The ways in which students selfevaluate and teachers integrate these self-evaluative processes into their teaching practice in Australian and English contexts are analysed. The educational sites chosen for focus are engaged in implementing student-centred teaching and learning practices. The research 
draws on data analysed using case-study methodology. The introduction of the skills of selfevaluation offers another dimension to the current learning environment, providing students with opportunities to take increased responsibility for, and a more active role in their own learning. The research assumes that there is a need to examine how learning in the classroom is structured, and that it is this dimension to teaching and learning that makes a difference. A fundamental premise is that student self-evaluation is an educative activity.

Type A, sample size 2 groups of teachers

\section{Klenowski V 1996: Connecting Assessment and Learning, Paper presented at the BERA annual conference 1996}

Current developments in assessment are considered in this paper which examines how teachers can adopt a stronger role in the formative assessment process to improve teaching, and related learning outcomes for students. Research was conducted over the past three years to analyse the processes of student self-evaluation and portfolio assessment and their impact on learning. Three key findings emerged from the research. First was the effect portfolio and critical self-evaluation methods of assessment had on student learning. Second was a deeper understanding of the interrelationship of curriculum, assessment and pedagogy. The change in assessment methods required corresponding changes to the curriculum and pedagogy, the combined impact of this on student learning, was examined. Third was the perceived benefit of these alternative forms of assessment on learning and teaching from both the teachers' and students' perspectives.

Type A, sample size: 1 group of GNVQ students in FE in UK, 1 group of Cert Ed students in Hong Kong

\section{Knowles M 1983: Andragogy: An emerging technology for adult learning, in Boundaries of Adult Learning, ed Edwards R, Hanson A, and Raggatt P, Open University 1996}

This article argues that adult learning should be informed not by pedagogy but by andragogy, based on 4 principles: that adults move towards self-directedness from dependence; that the adults growing reservoir of experience constitutes a resource for learning; that readiness to learn in adults is oriented increasingly to the developmental tasks of their social roles; and that adults need a problem-centred approach to learning, rather than a subject-centred approach, as they are more concerned with immediate application of their learning. In particular, andragogical approaches imply a shift from teacher evaluation of learning to a self-evaluative process, based on re-diagnosis. The teacher therefore needs to be skilful in establishing a supportive climate in which hard-to-accept information about one's performance can be looked at objectively. The main thrust of modern adult educational technology is in the direction of inventing techniques for involving adults in ever deeper processes of self-diagnosis of their own needs for continued learning, setting their own objectives, and in evaluating their progress. The locus for responsibility in learning lies with the learner.

Type C 


\section{Kruidenier $\mathbf{J}$ 2002: Literacy Assessment in Adult Basic Education, in $\mathbf{J}$ Comings, B Garner, and C Smith (eds), NCSALL annual review of adult learning and literacy, 3, 84-151. San Francisco: Jossey Bass 2002}

This survey of assessment within the context of adult literacy deals with different views of the meaning of literacy and provides an overview of key concepts in assessment, which include standardization, norm-referencing, criterion-referencing, validity and reliability. The purposes of assessment are discussed and a distinction is made between assessment for performance measurement and assessment that aims to enhance learning: this distinction is then located in the context of the development of US policy on adult literacy. Assessment for instruction is discussed in detail - a range of different assessment tools, generally those widely used in the US, are evaluated for their usefulness to teachers in assessment for the purposes of supporting learning. It is noted that motivation, although important to literacy learning, is not measured by any of the tools discussed. There is a discussion of a range of means for assessing literacy practices, but it is pointed out that none of the most widely-used assessment tools can do this. It is asserted that assessment should not be used solely to satisfy requirements for accountability but should be fully integrated into instruction.

Type B

\section{Lindsay A and Gawn J, 2005: Developing literacy: supporting achievement, Leicester: NIACE 2005}

A short handbook for Skills for Life practitioners, containing a chapter on the assessment process which includes a section on formative assessment. Argues that ongoing (formative) assessment is good practice, and that it supports learners and teachers. Suggests it can often be built in to everyday teaching activities rather than treated as a separate activity. Learners need to understand the assessment process in order to get the best from it, and to be guided to practice new skills in real-life situations in order to maintain their learning.

Type D

\section{Mace J 1979: Working with Words, literacy beyond school, London: Writers and Readers Publishing Co-operative (especially chapter 4, Measuring the Journey)}

This chapter uses extended quotations from adult literacy students to show how important for many learners their previous experience of schooling is, for better or worse, for their motivation for learning and their attitudes and ideas about assessment, and their perceptions of success. It argues that for many students it is essential that adult literacy teachers understand this particular ways this experience impacts on their learning as adults, so as to find effective strategies for learning and teaching. This can only be achieved by talking and listening to learners and reflecting with them on these experiences, as an integral part of the learning process. There is also a discussion about the technical difficulties of finding objective evidence about successful learning, as performance really only counts 'out there'. Type C 
59. Marr B 2000: Talking volumes: enhancing talk, language and conceptual development in adult mathematics and numeracy classes, Literacy and Numeracy Studies: an international journal in the education and training of adults, 10 (1\&2), pp 55-70, also reprinted in Kelly S, Johnston B, and Yasukawa K, (eds): The Adult Numeracy Handbook - reframing adult numeracy in Australia, New South Wales Adult Literacy and Numeracy Australian Research Consortium 2003, pp 275-286

Marr notes that socio-cultural educational perspectives see learning as a process of induction into 'discourses' or 'communities of practice' through interaction with more expert others. Discourse consists of language and symbols, and needs to be learned through practice however, Marr states that in traditional mathematics classrooms, the students, those who need to learn the discourse of mathematics, have the least opportunity to speak it. She argues for the importance of learners having the chance to develop their skills of discourse within the subject they are learning, and especially in the context of mathematics.

Type A, sample size 1 group

\section{Marshall B and Wiliam D 2006: English inside the black box - assessment for learning in the English classroom, London: Kings College London Department of Education and Professional Studies}

This booklet is aimed at teachers of English and is a digest of the results from a series of research studies mainly focussed on schools, investigating and developing formative assessment practices used by teachers in a range of subjects. It emphasises the importance of classroom talk, discussion between students, feedback and marking, planning for feedback, sharing success criteria with learners, modelling quality through the progression of activities, peer- and self- assessment, and gives practical examples in each case. Type F

\section{Mary Ward Centre Strategy 2001: Assessment of Learning on non- accredited courses, London: Mary Ward Centre}

This strategy paper provides a systematic guide to initial, formative and summative assessment aimed at tutors of non-accredited programmes at the centre. It outlines an administrative system for monitoring, recording, and moderating assessments in such programmes, and provides a wide-ranging justification for such a system, based partly on the findings of a research study on students' perceptions of learning and progress on uncertificated courses, using student focus groups. Formative assessment is seen as ongoing informal (usually verbal) feedback to individuals and groups during the course, and is distinguished from initial diagnostic assessment and summative assessment by not having to be formally recorded. The guide also provides a detailed set of 25 distinct methodologies for assessing learning, any of which could be applicable to any kind of assessment. This chart is based on the 1999 NIACE publication Assessment Matters.

Type D 


\section{McGivney V 1996: Academic Support, Chapter 10 of Staying or leaving the course: non-completion and retention of mature students in FHE, Leicester: NIACE 1996}

This chapter does not distinguish between formative and summative assessment. It collates a range of earlier studies that agree that continuous assessment is favoured by adult learners because it provided them with regular feedback, revealed how well they were doing and indicated areas that needed improvement. It was also seen as less threatening than end-of-year examinations. The study reveals that students appreciate: specific instructions on what is needed in an essay; clear explanations of grading schemes; rapid turn-around in grading and returning assessments; practice in examination techniques and provision of model responses; frequent and regular feedback on performance. It is noted that students with less success in previous education have less familiarity with academic convention and the language of assessment, and want positive feedback that is detailed and constructive. Type B

\section{McNair $S$ 1996: Learning autonomy in a changing world, in Boundaries of Adult Learning, ed Edwards et al. , Routledge 1996}

This chapter looks at why learner autonomy matters, what is meant by autonomy, and the relationship between autonomy and the 'learning outcome movement'. It argues that universal learner autonomy is increasingly needed for reasons of efficiency in the learning process, because autonomous learners are more economically productive, and for reasons of equity. It is suggested that autonomy is: positive motivation; selfdirectedness evident in intrinsic motivation; a matter of degree; a quality which can be developed; demonstrated in a context; demonstrated in a sense of self, enabling individuals to make decisions; not necessarily individualistic - embraces collective and individual action; distinct from isolation - living alone is not the same as being autonomous. It then explores how far the 'learning outcomes movement' is capable of supporting learner autonomy. Learning outcomes are seen as a form of language, which on the one hand makes communication possible, but on the other defines limits and is the means by which societies and communities are excluded by power. But challenging this power is more than a matter of confronting traditional privilege - the attempt to make language more accessible, and widen the community, inevitably threatens its precision. The article concludes that explicitness alone is not enough to develop autonomy - the key question is not 'does my performance satisfy the criteria?' but 'do we agree that this is right?' This depends on the existence of a community of interest, which needs nurturing and maintaining. Type C

64. Merrifield J 1998: Contested Ground - performance accountability in adult basic education, NCSALL Report No 1, 1998

This policy paper lays out key issues in performance accountability and presents recommendations for policy and action. It is based on the literature from education, 
government, management, and other fields, and draws on interviews with researchers and adult education leaders. It argues that in the context of increased public accountability, politicians, researchers and practitioners need to agree on performance, develop mutual accountability relationships, build capacity to perform and to be accountable, and create new tools to measure performance. It argues that what is meant by good performance is not simply a technical question, but one about value. This has implications for accountability throughout the field, including the relationship between teachers and students. It is a complex question, because it is 'contested ground'. It is argued that an accountability system based on the principle of mutuality is one: that is negotiated between the stakeholders; that matches responsibilities with rights; in which every player knows what is expected of them and has the capacity to be accountable.

Type C

\section{Merton B 2001: Encouraging interest, Adults learning 12(5) 7-10}

Report of a small-scale action research project investigating the low take up rate of basic skills provision among young adults. Among the headings are findings on assessment: Most people fear tests and would prefer continuous assessment. Important is the feedback they get on a day to day basis. Advice on how to improve is valued, something lacking in their previous education. Teachers' language should be easier to understand and avoid long words. Choice of words and tone of voice seem to influence how people perform under pressure. What might make a difference would be 'not having to prove myself to anyone but me.' Achievements must be positively reinforced without patronising the learner.

Type A, sample size: 47

\section{Millar $\mathbf{R}$ 2003: Benchmarking best practices in adult learning centres,} Canadian Association for the study of Adult Education, Online Proceedings 2003 The report of a qualitative research study designed to identify best practices by observing, interviewing and analysing responses of a group of 6 teachers identified as being high quality practitioners, working in 5 different contexts, including 3 adult learning centres and two workplaces. Principles which emerged included: Respects for the learner as an adult, giving clear instructions and expectations, demonstrating specific personal qualities, providing time for the students to interact, ensuring that class structure is flexible, negotiating the curriculum, that good teachers like teaching, good teachers share themselves personally with adult learners, that good teachers are reflective, they self-evaluate and regularly change how they teach, they amend the curriculum, responding to learners' needs, they admit they make mistakes, they are learners themselves.

Type A, sample size: 6 teachers 


\section{Morton T, McGuire T, and Baynham M 2006: A literature review of research on teacher education in adult literacy, numeracy and ESOL, London: NRDC 2006}

This report reviews research on teacher education for teachers of adult literacy, numeracy and English for Speakers of other Languages (ESOL). Among its conclusions are the following points:

- Awareness of their own beliefs and values is significant for teachers in their work

- Teachers also need conceptual frameworks which allow them to articulate their own perspectives on teaching and learning

- Effective teaching and learning is not simply based on the 'application of scientific knowledge'. Teacher education programmes need to take into account the strong influence of context on learning, and should avoid assuming that knowledge is first 'learned' in one context before being used in another

- Teachers need to engage in developing personal practical knowledge and become involved in the 'protracted conversation' of learning how to teach

- Teacher learning should be seen as a career-long process

- Raising the level of subject matter in teacher education syllabuses will not necessarily improve practice

Type B

\section{Moss W 1995: Controlling or Empowering? Writing Through a Scribe in Adult Basic Education, in Literacy, Language and Community Publishing: Essays in Adult Education, ed Mace J, Multilingual Matters}

A detailed exploration of the role of the learner as writer using the teacher as editor in language experience learning situations. The paper shows how editing individual students' own words is problematic from the perspectives of both creative writing and of the pursuit of 'correct' use of English. However, the process of negotiation between a teacher aiming to facilitate the production of a 'finished' but also authentic piece of work (a paradigm of the process of formative assessment, and very similar to the role of a teacher in dramatic or musical performance), can be a powerful means of supporting future learning, confidence, and motivation.

Type A, sample size 1

\section{Newmarch B 2005: Developing numeracy, supporting achievement, Leicester: NIACE 2005}

A short handbook for Skills for Life practitioners, containing a chapter on the assessment process which includes a section on formative assessment. Argues that ongoing (formative) assessment is good practice, and that it supports learners and teachers. Suggests it can often be built in to everyday teaching activities rather than treated as a separate activity. Learners need to understand the assessment process in order to get the best from it, and to be guided to practice new skills in real-life situations in order to maintain their learning.

Type D 


\section{Nonesuch $K$ 2006: Changing the way we teach Math - a manual for teaching basic math to adults, available at www.nald.ca/library/learning/mathman/mathman.pdf, accessed 23-03-07} This handbook for numeracy teachers is written by a Canadian practitioner and researcher, based on her own experience of practice and on a study involving interviews with 100 other practitioners, aiming to answer the question: 'Why is it so difficult for numeracy teachers to put research findings into practice?' The handbook is organised around 13 principles for effective numeracy teaching proposed by Ginsburg and Gal (1996), including learner resistance, emotions and mathematics, hands-on learning, group work, real-life problems, and 'putting students in charge'.

\section{NRDC 2005: NRDC - Three years on: what the research is saying, National Research and Development Centre for adult literacy and numeracy, London: NRDC 2005}

Collates findings from NRDC research into effective teaching and learning in adult literacy, numeracy and language between 2002 and 2005. Its findings include that the majority of people bring negative experiences of school education and of authority to adult literacy and numeracy learning programmes, but have 'ordinary' goals and aspirations. Progress should be documented in terms of 'distance travelled' and related to people's own goals, which might or might not involve qualifications. It is crucial that provision does not recall previous negative experiences of education: ownership and shared accountability are important. The identity of adult learners is integral to understanding their needs and trajectories, and empathy and patience in teachers matter no less than technical competence. Addressing adults' needs and life experience is far more influential in guiding learning programmes than environment, finding or accreditation-related targets. Informality in learning helps to attract and motivate learners, whose experience of formal statutory education often includes failure and rejection. There is often no clear distinction between formal and informal learning.

Type B

\section{Purcell-Gates V, Jacobson E, Degener S 2004: Print Literacy Development - uniting cognitive and social practice theories, Cambridge Massachusetts: Harvard Univerity Press}

This book critically examines two broad theoretical approaches to literacy development, cognitive theories that focus strongly on psychological aspects of the learning process, and social practice theories which focus primarily on 'real-life' literacy practices. It argues that the two perspectives have become unnecessarily polarised, and that effective teaching needs to harness the insights of both viewpoints. The book reports on research which demonstrates the value of using 'authentic' literacy texts in learning situations, rather than what they call 'school-only' texts and tasks, activities for learning which have no real-life application or purpose. It shows 
clearly that the notion of authenticity in this context varies for each learner, depending on the specific experiences of using texts and literacy practices that he or she brings to the learning situation. It also argues for the recognition by social practices theorists of developmental stages in the acquisition of print literacy, demonstrated by research which measures progress in literacy learning as engagement with a wider range of literacy texts and activities in real life situations outside the classroom.

Type B

\section{Reder S 1994: Practice engagement theory - a sociocultural approach to literacy across languages and cultures, in Literacy across Languages and Cultures, ed Ferdman B, Weber R, and Ramirez R. Albany: State University of New York Press, pp33-74}

This paper takes a social psychological perspective, describing literacy as a social and cultural process comprising a set of culturally-defined practices. It summarises research showing how literacy practices vary across cultural groups within a society. It also develops a theory of literacy transmission and development that emphasises the roles of practice and engagement and discusses the implications of this research and theory for education. Reder argues for the importance of what he calls 'practiceengagement theory', which proposes that teachers and programmes need to understand how literacy practices develop through collaborative activity, that 'participation structures' are contexts for literacy development, that social meanings shape literacy development, and that literacy develops primarily through acquisition and extension of existing practices, rather than through the learning of 'new' ones. In particular, practice engagement theory provides accounts for how fluency in literacy practices can be developed without formal instruction. It follows from this that formal instruction needs firstly to be aligned as far as possible to the specific literacy practices that individual learners' are familiar with already, and secondly, to try to build learning on these practice-specific contexts rather than separately from them. Type B

\section{Reder S 2006: Giving Literacy Away, Again: New Concepts of Promising Practice, in Toward defining and improving quality in adult basic education: Issues and Challenges, ed A Belzer and H Beder, Mahwah, NJ: Erlbaum} This paper emerges from US-based longitudinal study of adult learning (LSAL), and argues that policy on adult basic education has focussed mainly on attempting to 'bring people to literacy' and has almost ignored the idea of 'bringing literacy to people'. It suggests that policy should also aim to build on people's efforts towards 'self-study', which he argues is widespread both among adults who participate in adult literacy programmes and those who do not. It proposes some new programmes designs that have the potential to expand and deepen participation in adult literacy education, and concludes with a description of an ongoing effort to implement a research-driven prototype of such a programme, called The Learner Web. The notion of learner 
autonomy is central to this report's concerns, in terms of programme design and pedagogy. It argues that people operate with higher levels of autonomy in relation to education, even at the lowest levels, than is often assumed.

Type A, sample size 940 .

\section{Roberts C, Baynham M, Shrubshall P, Barton D, Chopra P, Cooke M, Hodge R, Pitt K, Schellekens P, Wallace C, Whitfield S 2004: English for Speakers of Other Languages (ESOL) - case studies of provision, learners' needs and resources, London: NRDC Research Report, August 2004}

This report describes research which aimed to examine teaching in a wide variety of adult ESOL classes, and to establish some of the distinctive features of ESOL learners and provision so as to inform literacy and numeracy research. Its key findings were:

- Individualised teaching and learning may not support the needs of adult ESOL learners: talk is work in the ESOL classroom and the most significant mode of learning for ESOL learners is through group interaction

- Effective teachers of ESOL employ a series of measures to support the needs of ESOL learners in the classroom

- Most ESOL teachers juggle a variety of roles as well as teaching in relation to support for asylum seekers and refugees: they need more specialist knowledge and institutional support for these roles

- The use of everyday, culturally specific situations to contextualise mathematics problem may act as a barrier to attainment by ESOL learners in numeracy classes

- Teachers need to use strategies to encourage the use of learners' other languages within the teaching and learning of English

- It may be that the involvement of learners in planning and reviewing of their learning through individual learning plans is not meaningful, as language learners appear unable to reflect on and predict their language development, even when they have an advanced level of English

Type A, sample size: 8 groups in 5 distinct settings

\section{Roberts C, Baynham M, Shrubshall P, Brittan J, Cooper B, Gidley N, Windsor V, Eldred J, Grief S, Castellino C, Walsh M 2005: Embedded teaching and learning of adult literacy, numeracy and ESOL: Seven case studies, London: NRDC Research Report, August 2005}

This report describes research examining 'embedded' adult literacy, numeracy and language teaching, that is, teaching and learning of literacy, numeracy and language that takes place as part of learning on vocational training and education programmes. It looked at 7 different vocational programme areas, including Land-based skills, Entry to Employment (E2E), engineering, construction, complementary therapy, childcare, and nursing. The methodology for the research was ethnographic, and involved repeated classroom observations, and interviews with learners and teachers. 
Its key findings concern motivation and vocational courses, the organisation of literacy, language and numeracy learning, the relationship between the vocational subject and the literacy, language and numeracy curricula, and the teaching team. The report argues that student motivation for learning is supported and enhanced on courses where what is being offered includes not just new skills but a new 'professional' identity, or membership of a new 'community of practice'. The report makes use of the work of Lave and Wenger and of activity theory in showing how learners are socialised into both vocational skills and the literacy language and numeracy practices required to be a competent member of the group, and this changes learners' attitudes as they see literacy language and numeracy skills as part of the professional identity they aspire to. Embedding LLN in subject teaching is found to be 'an economic way of learning'. Learning takes place when LLN skills are linked to practical tasks, especially organised as groupwork, through which the learners see the relevance of those skills. Learning LLN skills through practical tasks was more effective than through mostly 'up-front' teaching by the vocational teacher. The relationship between the vocational subject and the LLN curricula is deep and complex, and not just about linking the two: in particular, LLN teachers have to learn, through participation in the vocational classroom, how LLN are used in particular vocational and professional contexts. The case studies describe how learners need and learn the 'situated' learning of LLN skills of their chosen job, but also how they need more general or 'transportable' LLN skills. Finally, the report argues that the qualities possessed by teachers and relationships between them are more important than general curricular models of embedded provision, that close working between teachers is essential for effective learning, that both kinds of teacher need to be strongly motivated to provide embedded provision, and that there needs to be time for them to work and plan together.

Type A, sample size: 102 students in 9 groups

\section{Rogers A 2002: Teaching Adults, Open University Press (Third edition), especially Chapter 11, Evaluation}

In this chapter in a handbook for practitioners and organisers of adult education, Rogers argues that the primary purposes of evaluation are to improve teaching performance, to support ongoing planning by suggesting directions for changes, and as an essential element of learning. His view is that formative and summative assessment are not distinct processes in principle: what matters is what evaluation is used for. Rogers also argues that in adult learning, being largely initiated by the learner and being task-oriented, evaluation is naturally embedded in the learning process, and is an essential tool through which adults develop new skills, knowledge and understanding of their learning. For Rogers, evaluation involves judgement about achievement, expectations, effectiveness and also the value of the learning experience. The chapter goes on to discuss what is evaluated and methodologies for evaluation. Type D 


\section{Rogers $C$ 1993: The interpersonal relationship in the facilitation of learning, in Culture and Processes of Learning, ed M Thorpe, $R$ Edwards and A Hanson, Milton Keynes: Open University}

This paper focuses on learning in a changing world, where the educated person is the one who has learned how to learn. The qualities of those who facilitate learning (rather than teach) are as follows: 'realness in the facilitator of learning; prizing, acceptance, trust; empathic understanding. The bases of facilitative attitudes are: 'puzzlement'; a trust in the human organism; living in the uncertainty of discovery. Reference is made to interview data from a range of students and teachers that supports the emphasis on interpersonal relationships between teachers and learners.

Type B

\section{Rogers J 2001: Adults Learning, Open University Press (fourth edition), especially Chapter 2, Giving Feedback}

'Giving 'feedback' and criticism, praising and commenting, these are all so important in learning that the topic deserves a whole chapter to itself. Teaching adults is enormously complicated by the difficulty of 'criticising' an equal. Not giving the right quantity or quality of feedback is one of the main reasons why adult learning fails...'

A guide to the role and practice of feedback in adult education. Situates feedback within the cycle of learning, discusses when and how to give effective feedback, and emphasises the importance of focussing on the task, not the person.

Type D

\section{Russell M 1999: The assumptions we make: How learners and teachers understand writing. Focus on Basics, 3(D), 20-23}

This paper is concerned with Russell's observation that while many teachers of writing to adult literacy learners encourage their students to focus on content rather than form, most students want above all to avoid making 'mistakes', and that it is very hard to convince students that mistakes do not matter as part of learning. 'Teachers and learners appear to be speaking two different languages, perhaps different dialects of the language of writing instruction.' In her research, she discovered that many students didn't understand that reading had any connection with writing. She argues that to address issues of conceptual difficulty requires teaching strategies that make explicit unarticulated ideas and concepts about how people write. Key issues are that teachers play down the importance of technical errors because they are often trying to avoid teaching 'decontextualised' skills, and that learners do not believe that they can correct their own work.

Type A, sample size: 22 (18 learners)

\section{Skager R 1978: Lifelong Education and evaluative practice, UNESCO 1978} This report examines conceptual approaches to evaluation of schooling and assesses their relevance to lifelong learning. It comes to three conclusions: 
1. It is critical for lifelong learners to develop evaluation systems that demonstrate what people can do rather than comparing them with others

2. There should be a much greater emphasis on formative assessment than is found in the school sector

3. Evaluative systems must be capable of measuring open-ended learning goals, ie should have a future focus

Type C

82. Smith E and Gorard S 2005: 'They don't give us our marks': the role of formative feedback in student progress, Assessment in Education, Vol 12 No 1 pp. 21-38

This paper presents the results of an experimental evaluation of a change in assessment practice in one comprehensive secondary school. The school divided 104 Year 7 pupils into four mixed-ability teaching groups. One of these was given enhanced formative feedback on their work for one year, but no marks or grades. The other three groups were given marks and grades with minimal comments, which was the usual prior practice in this school (and many others). Using data derived from assessment prior attainment, pupil attitudes and background information, we conducted a contextualized analysis of progress in the four teaching groups for all subjects. This showed that progress in the treatment group (formative feedback only) was substantially inferior to that of the other three groups. This paper uses data from observation of the process and from group interviews with the students involved, to help explain these results. The findings are relevant to a consideration of the often lessened impact of research findings when 'rolled out' into wider practice, and what may be done about this.

Type A, sample size: 104

\section{Spiegel $M$ and Sunderland $H$ 2006: Teaching basic literacy to ESOL learners: a teachers' guide, London: LLU+, 2006, especially chapter 9, on Assessment}

Explicit that assessment is a key aspect of any teacher's work, this chapter provides a guide to terminology in assessment that defines formative assessment as: 'assessment that helps a teacher check a learner's progress against objectives and goals identified as a result of the diagnostic assessment. It informs progress reviews and helps determine further work.' FA is presented as being an intermediary stage between diagnostic and summative assessment. However, the description of diagnostic assessment makes it clear that it can be a formative process based on dialogue with the learner, even those with limited spoken English skills. Checklists of skills are provided, but they are not seen as exhaustive - 'as we know, learners do not come in neat packages'. References the Planning, Learning, and Recording Achievement in Adult Literacy (PLRA) self-assessment concepts of 'emerging', 'consolidating' and 'established' but stresses their limitations. The section in this chapter on FA stresses that continuous monitoring of learning allows formative judgements about progress to 
be made, enabling adjustments to planning as necessary. The necessity of feeding back these judgements to learners is stressed. Praise and encouragement is recommended but not problematised. Feedback is explored thoroughly in its various forms - formal, informal, marking, etc, but there is no discussion of open-ended questioning or of qualitative advice as an addition to pointing out mistakes sensitively. Finally, the chapter recommends that assessment is done in partnership with learners. Type D

\section{Swain J 2005: Changes to Adult Learners' Identities through Learning Numeracy, Literacy and Numeracy Studies, Vol 14 No 1, pp 5-16}

This paper reports on findings from a small-scale qualitative research project $(n=35)$ exploring the ways in which numeracy has the potential to transform students' identities. The sample consisted of students from 3 colleges in England. Identity is assumed to be 'something we do, and are done by, rather than something we are', and is linked explicitly to the notion of 'learning careers'. Almost three quarters of the students in the study felt that they had changed as a person in some way through learning mathematics. The changes took different forms, mostly increases in confidence, but also perceptions of greater independence and autonomy, and the development of cultural capital. The study also finds that specific changes seem to occur when students learn mathematics they find meaningful, when the approach to teaching and learning is participatory, and when it is taught using real-world contexts. The study is unable to determine the degree to which the changes reported are attributable to the fact that the students are learning numeracy, or to the experience of learning in general.

Type A, sample size: 35

\section{Swain J, Baker E, Holder D, Newmarch B, Coben D 2005: 'Beyond the daily application': making numeracy teaching meaningful to adult learners, London: NRDC Research Report, October 2005}

This report describes research aiming to explore what makes numeracy teaching meaningful to adult learners. Its sample was 80 adult learners in 4 discrete numeracy classes who attended on a voluntary basis and were generally very well-motivated. Its findings are tentative, based as they are on a small-scale and qualitative approach, but raise important issues for the teaching and learning of adult numeracy. The main findings include:

- The meaningfulness of numeracy teaching for an individual is linked to that individual's motivation for learning

- Contexts for numeracy need to be defined in terms both of the situation in which numeracy practices are to be used, and of the individual learner' disposition for learning. Learning is inextricably linked to identities, and it is therefore vital for teachers to get to know their learners as well as possible

- The main motivational factors for numeracy learners were found to be proving that they have the ability to succeed in a subject seen as being a 
signifier of intelligence, helping children, and for understanding, engagement and enjoyment. Few learners were strongly motivated by their employment, or by feeling that they have a deficit in their everyday life

- Identities fashion learners' beliefs about themselves as learners and as potential mathematicians

- Numeracy is generally seen by learners as a subset of mathematics, but many different understandings of the terms exist in practice

- Most adult learners in the study reported that they used very little mathematics in their everyday lives, and few found that what they learnt in their classes had helped them in their lives outside the classroom

- Many learners have had a poor experience of schooling and are anxious about returning to formal learning: the nature of the first contact with the college and the teacher is therefore crucial.

Type A, sample size: 80 learners in four groups

\section{Swain J, Griffiths G, Stone $R$ 2006: Integrating formative/diagnostic assessment techniques into teachers' routine practice in adult numeracy, Research and Practice in Adult Literacy, Vol 59 Spring 2006}

Reports on a study of teachers' ability to assess the mathematical understanding of learners, and better integrate formative assessment into their routine practice. Data was collected by observations of questioning by 6 teachers, through peer observations, in depth interviews, reflective journals, and four group review sessions, with the teachers as participants. The study offers a typology for questioning, and found that teachers' practice and understanding of learning was improved by the focus on questioning. It also found improved levels of motivation in both teachers and learners. Type D

\section{Swan M 2005: Improving learning in mathematics: challenges and strategies, DfES Standards Unit 2005}

This publication is a collection of resources designed to support improved effectiveness in teaching and learning mathematics, and is aimed at the learning and skills sector in particular. It points out that teaching does not always lead to learning. It aims to promote the view that learning should be an active rather than a passive process, that teaching should aim to challenge learners and support collaborative enquiry and reflectiveness rather than the simple transmission of knowledge which is often decontextualised and fails to recognise what learners already know and any possible misperceptions they may have. It strongly promotes the use of 'non-linear dialogue' in teaching and learning, but also emphasises the pro-active role of the teacher, whose tasks include assessing learners and making constructive use of prior knowledge, choosing appropriate challenges for learners and making the purpose of activities clear, encouraging collaborative ways of working, aiming to remove the fear of failure by welcoming mistakes as opportunities for learning, challenging learners through effective, probing questioning, drawing out the important ideas in each session, and helping learners make connections between 
their ideas. Finally it identifies some fundamental principles for practice in mathematics teaching, including building on the knowledge that learners bring, exposing and discussing common misconceptions, developing effective questioning, using cooperative small group work, emphasising methods rather than answers, using rich collaborative tasks for learning, creating connections between mathematical topics, and using technology in appropriate ways. The resources in this publication exemplify and demonstrate this approach and these principles.

Type D

\section{Swan M 2006: Collaborative learning in mathematics - a challenge to our beliefs and practices, London and Leicester: NRDC and NIACE}

This book begins with an account of what we now know about learning situations in mathematics, drawing on research and development work conducted over 25 years. It considers research-based principles for effective teaching and learning, and reports on trials of these approaches in the classroom. It describes the impact of these approaches have had on the professional development of more than 40 teachers, in terms of changes to their beliefs and practices, and the resulting effects on their students' learning. Analysis of these trials produces new theoretical insights into both the design of learning activities and into approaches to the initial and continuing professional development of all teachers of mathematics. The major focus of the various research projects reported on is GCSE learning for low-achieving students ('retake' classes in particular) and their teachers. It concludes that a more student-centred, collaborative approach to learning, where discussion and reflection are central, will be more effective that the traditional transmission approach, with regard to the development of student understanding of, and attitudes towards learning, mathematics. It suggests that activities for learning should be designed so as to: focus on particular conceptual obstacles; focus on general, structural features rather than task-specific features; pose, or allow students to pose, significant and challenging questions; encourage a variety of interpretations; create tensions that require resolution, through careful juxtaposition of experiences; provide meaningful feedback to the student on his or her interpretations; be followed by some form of whole-class discussion in which new ideas and concepts are made explicit and institutionalised; allow 'consolidation' of what has been learned through the application of the students' constructed concepts. Swan concludes by saying that though this approach might appear to take more time than traditional transmission methods, 'it will result in student learning and, ultimately, a more enjoyable experience for all concerned.'

Type B

\section{Taylor M, Evans K, Abasi A 2006: Towards a Learning and Teaching Model in adult literacy: close-up look at experiences in Canada and the United Kingdom, Canadian Association for the Study of Adult Education (CASAE) 2006 National Conference On-Line Proceedings}

The purpose of this study was to investigate how adult students learn collaboratively 
with other peers in both formal and informal adult literacy programmes and what teaching styles best support this learning. A multi-site case study research design was used involving several different literacy organisations in Ontario, Canada and in London, United Kingdom. Findings suggest that collaborative learning is the cement that bonds the various building blocks in a community of practice across small, large and tutorial types of programme. Central in this framework is the component called the Instructor's Philosophy and Leadership Style which helps to explain the teaching and learning transaction.

Type A, sample size 12 groups, 9 in Canada and 3 in the UK

\section{Tout $D$ and Schmitt MJ 2002: The inclusion of Numeracy in Adult Basic Education, in J Comings, B Garner, and C Smith (eds), NCSALL annual review of adult learning and literacy, 3, pp152-202. San Francisco: Jossey Bass 2002} This chapter argues that numeracy should be differentiated from mathematics, as it connotes an approach to learning more in tune with the needs of adult learners. It describes adult numeracy education in the United States, numeracy in the US school system, and adult numeracy in several other countries, with an emphasis on trends, best practices and research. It concludes with a call for more attention to be paid to numeracy in adult basic education programmes, the provision of more resources for teaching and learning, and for more research.

'Very generally, when teachers teach math, students use a textbook or workbook and do lots of repetitive practice, they prepare for tests and exams, and they learn by formal rules, often by rote, with little consideration of why and how the skills they are expected to learn can be put to use in the real world. When teachers teach numeracy, they are more likely to teach math from a more authentic, contextual point of view, one in which math is derived from some actual or modeled activity, in which investigations and projects are used as vehicles for learning. Teachers of numeracy are also more likely to take into account the students' various informal ways of doing math, allowing the understandings and strategies amassed in and out of school to serve as valid resources'.

Type B

\section{Turner C and Watters K 2001: Proof Positive - learners' views on approaches to identifying achievement in non-accredited learning, NIACE 2001} This paper reports on an enquiry into learners' perspectives on a range of current systems for identifying, recording and validating achievement in non-accredited learning. Among the findings were: the value of non-accredited learning in terms of life-enhancement, health-giving and career-building. Many were surprised at becoming 'hooked' into learning. They demonstrated a wide range of purposes for learning, with both long and short-term goals, and often impossible to categorise as vocational or non-vocational. Most learners had general rather than specific aims. Learners used the term feedback rather than assessment, which was seen to connote 
judgemental and unsympathetic attitudes. Feedback was highly valued, and this distinction is a matter not just of language but approach. The learners were more interested in why they were learning than how successful they were being. Feedback was seen as enriching learning rather than judging. Three sources of knowledge about achievements in learning were identified: self-assessment, tutor assessment, and peer assessment. Learning outcomes were generally welcomed, but were more useful as a framework than rather than an exclusive goal. The paper ends with recommendations for improving systems for identifying achievement in order that they are more sensitive to the full range of learning that goes on: what is valuable is not necessarily measurable.

Type A, sample size: 169

\section{Tusting $K$ and Barton $D$ 2003: Models of adult learning - a literature review, London: NRDC, Institute of Education, 2003; republished Leicester: NIACE 2006}

This is a short survey of the development of different theoretical approaches to adult learning, categorised into psychological models (for example, behaviourism, constructivism, situated cognition, brain science, etc), models from adult education (for example humanistic psychology, andragogy, self-directed learning, informal learning, etc) and finally, models of learning in the context of rapid change, which mostly originate from work on organisational development. Different models are evaluated and compared, and the book concludes with seven key ideas about how adults learn: that adults have their own motivations for learning, based on their existing knowledge and experience, that adults have a drive towards self-direction and autonomy, that adults can learn about their own learning processes, that all real life activities contribute to adult learning, that adults reflect and build on their experience, that reflective learning is unique to each person, and that learning is often incidental and idiomatic, and that learning can be transformative, enabling people to reorganise their experience and see situations in new ways.

Type B

\section{Ward J and Edwards J 2002: Learning Journeys: learners' voices, LSDA 2002}

A report on a qualitative research project aiming to find out about learners' perceptions of progress in literacy and numeracy, to develop research instruments for involving literacy and numeracy learners, and develop and trial an approach to collaborative practitioner research into literacy and numeracy issues. The metaphor of a learning journey was used to facilitate discussion between learners and researchers, and this was found to work effectively. Learners' purposes were highly diverse. A minority had been involved in planning their learning. The metaphor was helpful in discussing the pace of learning and progress. Learners spoke of outcomes in terms both of tasks they could now perform and as technical skills acquisition. They related their progress to their ability to perform in real life contexts. The project reminded 
tutors of the importance of listening to learners and treating them as active participants. Learners' confidence and skills to participate in learning processes develop as learning progresses, and all learning programmes should develop these capacities. Many learners are deterred by or do not seek qualifications.

Type A, sample size: 70

\section{Whitty T 1993: Pieces of paper: A Survey of student attitudes to} accreditation in adult literacy and English classes in Southwark, RapAL Bulletin No 21, Summer 1993, reprinted in Insights from research and practice, ed M Herrington and A Kendall, NIACE 2005, pp330-337

Survey of attitudes to certification among adult literacy students. $80 \%$ wanted certification, $20 \%$ said certificates were not important to them. $100 \%$ said that certification was not the only reason for studying - gaining independence and confidence in communications skills was seen as more important than certification by $80 \%$ of the sample, though many saw the certificate as helping with confidence. Type A, sample size: 47

\section{Wilcox $S$ and Zielinski $R$ 1997: Using the assessment of students' learning to reshape teaching, The Mathematics Teacher, Vol 90, No 31997}

This paper looks in detail at how mathematics teachers can assess students' understanding and knowledge of geometry from evidence of their work on set tasks. Different types of task are contrasted for their usefulness in helping teachers assess students' understanding. In the first place, students carried out traditional construction tasks using a compass and ruler. Although the evidence used by experienced teachers includes all the marks made on the paper by students, this kind of task is not very informative about levels of understanding, as different elements of the evidence may be contradictory, and they give no clue as to students' ability to make connections, analyse relationships, or draw conclusions. In a different type of geometry problem, students applied a range of different strategies to a real-life situation involving lightning strikes heard by people in different locations. The strategies adopted in trying to structure the problem provided direct insight into the understandings of the different students, and therefore supported the teacher in future planning. The second type of assessment task, as well as supporting the teacher's planning, also supports the learning of the student. The paper concludes that having students complete imitative exercises that require them to duplicate a series of technical procedures may yield scant information about their mathematical understanding. It emphasises the importance for learning and for planning, of having students explain their reasoning, and to justify their procedures and persuade others of the reasonableness of their solutions. The paper also argues for the importance of teachers being part of a professional learning community, enabling the discussion of pedagogical issues such as this one, with the use of videos of students working on problems, recordings of whole class discussions, etc. in which teachers can work together to study and improve their practice

Type A, sample size: 1 group of students 


\section{Windsor V and Healey C 2006: Developing ESOL, supporting achievement, Leicester: NIACE, 2006}

A short handbook for practitioners and provider organisations on improving achievement in ESOL programmes. Points out the challenge to ESOL tutors of giving feedback in a way that can be understood formatively by language learners, who may not be familiar with the language of assessment, and may be unfamiliar or even resistant to the idea that they might be pro-active in their learning. It argues for clarity about the limits of the role of the tutor in tutorials: 'they are to support the learners' learning, not their personal needs'. The tutor's role is to help the student gain the skills needed to sort out their own problems, for example in relation to housing. However, it also points out that 'regular tutorials reveal a lot of learners' real motivations for learning and help teachers to encourage learners not just to 'get by' but to 'get on'. Type D

\section{Young 2000: 'I might as well give up': self-esteem and mature students' feelings about feedback on assignments, Journal of Further and Higher} Education, 24(3) 409-418

Lecturers working with adult students balance the need to provide feedback and assess students' work with a concern to protect vulnerable students. This article is based on a small-scale quantitative research project that looked at Access students' responses to feedback on assignments. All students found the first assignment problematic, but thereafter great variations were found, which related to varying levels of self-esteem. Students varied in their attitudes to receiving feedback, their perceptions of the messages they were receiving and whether it was important to them that they receive positive comments. They also differed in the extent of the impact of the feedback, for some students, it was 'only work'; for others, their whole self was at stake. Type A, sample size: 1 group of access students in FHE in the UK

\section{Zachry EM and Comings $J$ 2006: How do you teach content in adult education: an annotated bibliography, NCSALL Occasional Paper, 2006. Available at www.ncsall.net/fileadmin/resources/research/op_content_biblio.pdf , accessed 23-03-07}

This review follows an earlier NCSALL report on 'An Evidence-based adult education programme model suitable for research' and aims to complement it by providing a survey of sources that review research and professional wisdom on the effective teaching of content in adult education, with a particular focus on adult literacy, language and numeracy. The bibliography is annotated and divided into five subsections focussing on reading, writing, math and numeracy, English as a second language, GED (General Education Diploma), adult learning theory, and technology. Each section distinguishes between adult education sources and those based on work based in schools or in professional development.

Type B 


\section{Zuss M 1994: in Literacy across Languages and Cultures, ed Ferdman B, Weber R, and Ramirez R. Albany: State University of New York Press,}

\section{pp. 239-272}

This paper problematises simplistic approaches to 'student empowerment' in English as Second Language classrooms. It identifies a tendency among modern teachers to ignore the intentions and values students attach to the acquisition of literacy skills, which Zuss' research shows are primarily concerned with achieving mastery of language skills 'through which they can gain or regain positive self-definition, overcome shame, and utilize their experience and intelligence as full and equal participants in society.' Zuss argues that many educators aim to allow their students to develop 'voice' and negotiate the content and structure of curricula, and therefore are focussing more on form rather than content, on power in the classroom rather than power in the wider society. The paps is a reminder that the emphasis on dialogue in teaching and learning has complex and demanding implications for both teachers and students in terms of addressing issues of discourse, power, identity, and agency, as well as learning, both in the classroom setting and in the wider world. 


\section{Appendix 2: Analysis of review texts}

\begin{tabular}{|c|c|c|c|c|c|}
\hline Study No & Study & Country & Type & $\begin{array}{l}\text { Sample size (category A } \\
\text { only) }\end{array}$ & Focus \\
\hline 1 & Absolum 06 & New Zealand & $\mathrm{F}$ & & \\
\hline 2 & Alexander 04 & UK & $\mathrm{F}$ & & \\
\hline 3 & Barton et al. 04 & UK & A & 8 groups in 3 different cities & ABE \\
\hline 4 & Barton and Papen 05 & UK & $B$ & & $A B E$ \\
\hline 5 & Barton et al. 06 & UK & A & 282 (134 learners) & $A B E$ \\
\hline 6 & Baxter et al. 06 & UK & A & $76+$ students in 8 groups & $A B E$ \\
\hline 7 & Beder 05 & USA & A & 6 groups & $A B E$ \\
\hline 8 & Belfiore et al. 04 & Canada & A & 2 groups & Workplace learning \\
\hline 9 & Belzer 04 & USA & A & 5 students & $A B E$ \\
\hline 10 & Benn 97a & UK & $B$ & & $A B E$ \\
\hline 11 & Benn 97b & UK & B & & $A B E$ \\
\hline 12 & Beveridge 99 & UK (Scotland) & A & 1 group & \\
\hline 13 & Boud 00 & Australia/UK & $B$ & & \\
\hline 14 & Boud 02 & Australia/UK & $B$ & & \\
\hline 15 & Breen 01a & UK & $B$ & & $A B E$ \\
\hline 16 & Breen 01b & UK & $B$ & & $A B E$ \\
\hline 17 & Brookfield 90 & UK & $B$ & & \\
\hline 18 & Brown 94 & USA & D & & $A B E$ \\
\hline 19 & Clarke 91 & UK & A & 15 students & $A B E$ \\
\hline 20 & Claxton 95 & UK & $B$ & & \\
\hline 21 & Comings et al. 99 & USA & A & 150 learners & $A B E$ \\
\hline 22 & Condelli 02 & USA & A & 495 students in 38 groups & $A B E$ \\
\hline 23 & Degener 01 & USA & $B$ & & $A B E$ \\
\hline 24 & Derrick 04 & UK & C & & $A B E$ \\
\hline 25 & Donley and Napper 99 & UK & D & & \\
\hline 26 & Ecclestone 02 & UK & A & 2 groups & \\
\hline 27 & Ecclestone 04a & UK & $B$ & & \\
\hline 28 & Ecclestone 04b & UK & B & & \\
\hline 29 & Eldred 05 & UK & $D$ & & $A B E$ \\
\hline 30 & Eldred et al. 05 & UK & A & 350 students & \\
\hline 31 & Evans 02 & UK & $B$ & & Workplace learning \\
\hline 32 & Fordham et al. 95 & UK & $D$ & & ABE \\
\hline
\end{tabular}




\begin{tabular}{|c|c|c|c|c|c|}
\hline Study No & Study & Country & Type & $\begin{array}{l}\text { Sample size (category A } \\
\text { only) }\end{array}$ & Focus \\
\hline 33 & Fowler and Mace 05 & UK & $\mathrm{D}$ & & $A B E$ \\
\hline 34 & Freire 72 & Brazil & C & & $A B E$ \\
\hline 35 & Fuller and Unwin 02 & UK & $B$ & & Workplace learning \\
\hline 36 & Gardener 85 & UK & $D$ & & $A B E$ \\
\hline 37 & Gillespie 01 & USA & $B$ & & $A B E$ \\
\hline 38 & Ginsburg and Gal 1996 & USA & $B$ & & $A B E$ \\
\hline 39 & Good and Holmes 82 & UK & $E$ & & $A B E$ \\
\hline 40 & Greenwood and Wilson 04 & UK & A & 237 students & \\
\hline 41 & Grief 03 & UK & $\mathrm{D}$ & & $A B E$ \\
\hline 42 & Groves 02 & UK & A & 12 students & \\
\hline 43 & Hillier 02 & UK & $D$ & & \\
\hline 44 & Hodgen and Wiliam 06 & UK & $\mathrm{F}$ & & Mathematics \\
\hline 45 & Hostler 86 & UK & $B$ & & \\
\hline 46 & Ivanic and Simpson 88 & UK & $\mathrm{D}$ & & $A B E$ \\
\hline 47 & Ivanic 96 & UK & A & 10 students & $A B E$ \\
\hline 48 & Ivanic and Tseng 05 & UK & $B$ & & $A B E$ \\
\hline 49 & Ivanic et al. 06 & UK & A & 37 students & $A B E$ \\
\hline 50 & James 97 & Australia & A & 3 groups & Teacher training \\
\hline 51 & Jansen and Van der Veen 96 & Holland & B & & \\
\hline 52 & Kelly Soundranaygram Grief 04 & UK & $B$ & & $A B E$ \\
\hline 53 & Klenowski 95 & Australia & A & 2 groups: 1 school, 1 college & \\
\hline 54 & Klenowski 96 & Australia & A & 2 groups & $\begin{array}{l}\text { Vocational, teacher } \\
\text { training }\end{array}$ \\
\hline 55 & Knowles 83 & USA & C & & \\
\hline 56 & Kruidenier 02 & USA & $B$ & & $A B E$ \\
\hline 57 & Lindsay and Gawn 05 & UK & $\mathrm{D}$ & & $A B E$ \\
\hline 58 & Mace 79 & UK & C & & $A B E$ \\
\hline 59 & Marr 00 & Australia & A & 1 group & $A B E$ \\
\hline 60 & Marshall and Wiliam 06 & UK & $\mathrm{F}$ & & English \\
\hline 61 & Mary Ward Centre 01 & UK & $\mathrm{D}$ & & \\
\hline 62 & McGivney 96 & UK & $B$ & & \\
\hline 63 & McNair 96 & UK & C & & \\
\hline 64 & Merrifield 98 & USA & C & & $A B E$ \\
\hline 65 & Merton 01 & UK & A & 47 students & $A B E$ \\
\hline 66 & Millar 03 & Canada & A & 6 teachers & \\
\hline 67 & Morton McGuire Baynham 06 & UK & $B$ & & $A B E$ \\
\hline
\end{tabular}




\begin{tabular}{|c|c|c|c|c|c|}
\hline Study No & Study & Country & Type & $\begin{array}{l}\text { Sample size (category A } \\
\text { only) }\end{array}$ & Focus \\
\hline 68 & Moss 95 & UK & A & 1 student & ABE \\
\hline 69 & Newmarch 05 & UK & D & & ABE \\
\hline 70 & Nonesuch 06 & Canada & $D$ & & ABE \\
\hline 71 & NRDC 05 & UK & $B$ & & ABE \\
\hline 72 & Purcell-Gates et al. & USA & $B$ & & ABE \\
\hline 73 & Reder 94 & USA & $B$ & & ABE \\
\hline 74 & Reder 05 & USA & $A$ & 940 students & ABE \\
\hline 75 & Roberts et al. 04 & UK & A & 8 groups in 5 different settings & ABE \\
\hline 76 & Roberts et al. 05 & UK & A & 102 students in 9 groups & ABE \\
\hline 77 & Rogers A 02 & UK & D & & \\
\hline 78 & Rogers C 93 & USA & $B$ & & \\
\hline 79 & Rogers J 01 & UK & $\mathrm{D}$ & & \\
\hline 80 & Russell 99 & USA & A & 22 (18 learners) & ABE \\
\hline 81 & Skager 78 & USA & C & & \\
\hline 82 & Smith and Gorard 05 & UK & A & 104 students & School students \\
\hline 83 & Spiegel and Sunderland 06 & UK & $\mathrm{D}$ & & ABE \\
\hline 84 & Swain 05 & UK & A & 35 students & ABE \\
\hline 85 & Swain et al. 05 & UK & A & 80 students in four classes & $A B E$ \\
\hline 86 & Swain et al. 06 & UK & A & 6 students & ABE \\
\hline 87 & Swan 05 & UK & $\mathrm{D}$ & & Maths \\
\hline 88 & Swan 06 & UK & $B$ & & Maths \\
\hline 89 & Taylor, Evans and Abasi 06 & Canada-UK & A & $\begin{array}{l}12 \text { groups, } 9 \text { in Canada and } 3 \\
\text { in UK }\end{array}$ & $A B E$ \\
\hline 90 & Tout and Schmitt & USA-Australia & $B$ & & ABE \\
\hline 91 & Turner and Watters 01 & UK & A & 169 students & \\
\hline 92 & Tusting and Barton 03 & UK & $B$ & & \\
\hline 93 & Ward and Edwards 02 & UK & A & 70 students & ABE \\
\hline 94 & Whitty 93 & UK & A & 47 students & ABE \\
\hline 95 & Wilcox and Zielinski & USA & A & 1 group & Mathematics \\
\hline 96 & Windsor and Healey 06 & UK & $D$ & & ABE \\
\hline 97 & Young 00 & UK & A & 1 group & Access students \\
\hline 98 & Zachry and Comings 06 & USA & $B$ & & ABE \\
\hline 99 & Zuss 94 & USA & $B$ & & ABE \\
\hline
\end{tabular}




\section{Categories of studies reviewed}

A. academic papers published in peer-reviewed journals or books reporting on mostly small-scale studies on topics connected with formative assessment (37 studies, $38 \%$ ). The sample size in each case is given with the abstract or summary.

B. high-level academic studies providing overviews of the research literature on topics associated with formative assessment and adult learning (32 studies, 32\%)

C. reports making 'arguments to policy', usually including references to academic literature and other policy documents, on topics related to formative assessment (7 studies, 7\%)

D. papers and handbooks written to support good practice and pedagogy in the teaching of adults, dealing explicitly or implicitly with formative assessment (18 studies, 18\%)

E. publications aimed at adult learners, dealing with self-assessment (1 study, $1 \%$ )

F. publications dealing with formative assessment where the primary focus is the education of children, but which reference lifelong or adult learning (4 studies, 4\%)

Country of origin of the studies reviewed

UK

USA

Australia

Canada

New Zealand

Other
65

21

6 4

$6 \%$

$\begin{array}{ll}1 & 1 \% \\ 2 & 2 \%\end{array}$

\section{Adult Literacy, Numeracy and Language}

$58(59 \%)$ of the studies have a primary focus on adult literacy, numeracy or language teaching and learning. 